\title{
The Quality of apprenticeship training : conflicting interests of firms and apprentices
}

Citation for published version (APA):

Smits, W. (2005). The Quality of apprenticeship training : conflicting interests of firms and apprentices.

[Doctoral Thesis, Maastricht University]. ROA. https://doi.org/10.26481/dis.20050429ws

Document status and date:

Published: 01/01/2005

DOI:

10.26481/dis.20050429ws

Document Version:

Publisher's PDF, also known as Version of record

\section{Please check the document version of this publication:}

- A submitted manuscript is the version of the article upon submission and before peer-review. There can be important differences between the submitted version and the official published version of record.

People interested in the research are advised to contact the author for the final version of the publication, or visit the DOI to the publisher's website.

- The final author version and the galley proof are versions of the publication after peer review.

- The final published version features the final layout of the paper including the volume, issue and page numbers.

Link to publication

\footnotetext{
General rights rights.

- You may freely distribute the URL identifying the publication in the public portal. please follow below link for the End User Agreement:

www.umlib.nl/taverne-license

Take down policy

If you believe that this document breaches copyright please contact us at:

repository@maastrichtuniversity.nl

providing details and we will investigate your claim.
}

Copyright and moral rights for the publications made accessible in the public portal are retained by the authors and/or other copyright owners and it is a condition of accessing publications that users recognise and abide by the legal requirements associated with these

- Users may download and print one copy of any publication from the public portal for the purpose of private study or research.

- You may not further distribute the material or use it for any profit-making activity or commercial gain

If the publication is distributed under the terms of Article $25 \mathrm{fa}$ of the Dutch Copyright Act, indicated by the "Taverne" license above, 
The Quality of Apprenticeship Training

Conflicting Interests of Firms and Apprentices 
(C)2005 Wendy Smits, Maastricht

All rights reserved. No part of this publication may be reproduced, stored in a retrieval system, or transmitted, in any form, or by any means, electronic, mechanical, photocopying, recording or otherwise, without the prior permission in writing, from the author.

Published by ROA

Postbus 616

6200 MD Maastricht

ISBN 90-5321-403-8

Printed in the Netherlands by Unigraphic 


\title{
The Quality of Apprenticeship Training
}

Conflicting Interests of Firms and Apprentices

\author{
Proefschrift \\ ter verkrijging van de graad van doctor aan \\ de Universiteit Maastricht, \\ op gezag van de Rector Magnificus, \\ Prof.mr. G.P.M.F. Mols, \\ volgens het besluit van het College van Decanen, \\ in het openbaar te verdedigen op \\ vrijdag 29 april 2005 om 14.00 uur \\ door
}

Wendy Smits 


\section{Promotor:}

Prof.dr. J.A.M. Heijke

\section{Co-promotor:}

Dr. A.H. Borghans

\section{Beoordelingscommissie:}

Prof.dr. G.A. Pfann (voorzitter)

Prof.dr. A. de Grip

Prof.dr. J. de Koning (Erasmus Universiteit)

Dit onderzoek is gefinancierd door de Nederlandse Organisatie voor Wetenschappelijk Onderzoek (NWO), project 411-21-310.

This research has been financed by the Netherlands Organization for Scientific Research (NWO), grant 411-21-310. 


\section{Acknowledgements}

First of all I like to thank my supervisors Hans Heijke and Lex Borghans for their enthusiastic and stimulating support throughout this project. This study benefitted a lot from their valuable comments and suggestions. Furthermore I would like to thank Andries de Grip, who as a member of the assessment commission, provided me with pertinent comments on this study.

I am much indebted to Inge Sieben for her useful comments on Chapter 6 and Chapter 8 and for her comments on the survey questions of Chapter 8 . Daron Acemoglu, Giorgio Brunello, Monojit Chatterji, Arnaud Dupuy, Bart Golsteyn, Mark Loewenstein, Jasper van Loo, Lisa Lynch, Jim Malcomson, Philip Marey, Christophe Meng, Cathérine Ris, Paul Ryan, Margaret Stevens, Thorsten Stromback and Bas ter Weel I would like to thank for many helpful discussions and comments on earlier drafts of different chapters of this study.

This study has also benefited from comments of participants of the following conferences and seminars: the 1997 EALE conference in Aarhus, the 1998 EALE conference in Blankenberge, the 2002 EEA conference in Venice, the 2003 ESPE conference in New York, the NAKE-day 2003 in Amsterdam, and seminars at the Centre on Skills, Knowledge and Organisational Performance (SKOPE), University of Oxford and the Zentrum für Europäische Wirtschafsforschung (ZEW) in Mannheim.

GOC, Bouwradius, Som and OVDB, supported this study by providing me with the addresses of training firms for the survey in Chapter 8 of this study. Jos Teunen (GOC), Henk Hanssen (Bouwradius), Dries Pruis (SOM) and Bea Naninck (OVDB) provided me with valuable information on the practice of apprenticeship training in their sector. Furthermore I received many useful comments on earlier versions of the survey from Remko van den Dool (Intomart), Dirk Bakker (drukkerij Giethoorn), Jan Fleer (GOC), Marcel Rensen (drukkerij Salsedo), and Niels Smits.

Pascal, I want to thank you, not only for your love and support, but also for the very useful discussions we often had on topics of this study which always provided me with new insights. I dedicate this book to our children: Emiel, Madelief and Rozemarijn. 


\section{Contents}

1 Introduction $\quad 1$

1.1 Motivation . . . . . . . . . . . . . . . . . . 1

1.2 Outline of the Study . . . . . . . . . . . . . . . 4

2 Why Do Firms Supply Apprenticeships? 9

2.1 Introduction . . . . . . . . . . . . . . . . . . 9 9

2.2 Current Benefits of Apprenticeship Training . . . . . . . . . . 11

2.3 Future Benefits of Apprenticeship Training . . . . . . . . . . 16

2.3.1 Apprenticeship Training and the Human Capital Theory 17

2.3.2 Theoretical Models on Firms' Return to Training . . . 18

2.3.3 Empirical Evidence on Future Benefits . . . . . . . . 28

2.4 Appendix to Chapter 2 . . . . . . . . . . . . . . . . 33

2.4.1 List of Symbols . . . . . . . . . . . . . 33

3 Specific or Generic Skills? 35

3.1 Introduction . . . . . . . . . . . . . . . . . 35

3.2 A Model for Specific and Generic Skills . . . . . . . . . . . . 37

3.2.1 The Training Programme . . . . . . . . . . 38

3.2 .2 The Social Optimum . . . . . . . . . . . . . . 39

3.3 Private Training Decisions . . . . . . . . . . . . . . . . 41

3.3.1 The Training Firm and the Worker Decide Jointly on Training . . . . . . . . . . . . . . 45

3.3.2 Training Levels are Decided on at the Industry Level . 46

3.4 Discussion . . . . . . . . . . . . . . . . . . . . . . . . . 49

3.5 Appendix to Chapter $3 \ldots \ldots \ldots$. . . . . . . . . 51

3.5.1 Maximum Expected Marginal Return for the Industry 51 


\section{CONTENTS}

3.5.2 List of Symbols . . . . . . . . . . . . . . . . 52

4 Imperfect information $\quad 53$

4.1 Introduction . . . . . . . . . . . . . . . . . . . . 53

4.2 A Model for Training . . . . . . . . . . . . . . . . . . . . 55

4.2.1 Returns to Training . . . . . . . . . . . . 56

4.2.2 Training Costs . . . . . . . . . . . . . . 57

4.2 .3 Information Structure . . . . . . . . . . . . . 57

4.2.4 Training Wages and the Participation Constraint . . . 59

4.3 Investment in Training . . . . . . . . . . . . . . . . . . 60

4.3.1 Perfect Information . . . . . . . . . . . . . . 60

4.3 .2 Imperfect Information . . . . . . . . . . . . . . . . 61

4.4 The Optimal Degree of Firm-Specificity . . . . . . . . . . . . . 64

4.5 Conclusions and Policy Implications . . . . . . . . . . . . . . 65

4.6 Appendix to Chapter $4 \ldots \ldots$. . . . . . . . . . . . . 68

4.6 .1 List of Symbols . . . . . . . . . . . . . . . 68

5 The Dutch Apprenticeship System 69

5.1 Introduction . . . . . . . . . . . . . . . . . . . 69

5.2 Organisation of the Apprenticeship System . . . . . . . . . 71

5.3 Responsibility for the Quality of Apprenticeships . . . . . . 73

$6 \quad$ Measuring Training Intensity $\quad 77$

6.1 Introduction . . . . . . . . . . . . . . . . . 77

6.2 The Empirical Model . . . . . . . . . . . . . . . . . . . . . . 78

6.3 Training Input and Output in the Literature . . . . . . . . . . 81

6.3.1 The Economic and Sociological literature . . . . . . . . 81

6.3.2 The Educational Literature . . . . . . . . . . . . . . 83

6.4 A Novel Measure for Training Input . . . . . . . . . . . . . . . 85

6.5 Appendix to Chapter 6 . . . . . . . . . . . . . . . 87

6.5.1 List of Symbols . . . . . . . . . . . . . . . . 87

7 Training Intensity and Training Motives I $\quad 89$

7.1 Introduction . . . . . . . . . . . . . . . . . . . 89

7.2 The Survey . . . . . . . . . . . . . . . . . . . . . 9 90 
7.3 Items on Training Input . . . . . . . . . . . . . . . . . 91

7.4 Measures for Training Motives . . . . . . . . . . . . . . 97

7.5 Determinants of Training Input . . . . . . . . . . . . . . . 98

7.6 Training Input and Training Output . . . . . . . . . . . . 103

7.7 Conclusions . . . . . . . . . . . . . . . . . . . . . 108

7.8 Appendix to Chapter $7 \ldots \ldots$. . . . . . . . . . . 110

8 Training Intensity and Training motives II 111

8.1 Introduction . . . . . . . . . . . . . . . . . . 111

8.2 The Survey . . . . . . . . . . . . . . . . . . . . . . . . . 112

8.3 Items on Training Input . . . . . . . . . . . . . . . 115

8.3.1 Observability of the Training . . . . . . . . . . 122

8.4 Measures for Training Motives . . . . . . . . . . . . 126

8.5 Determinants of Training Input . . . . . . . . . . . . . . 138

8.6 Training Input and Training Output . . . . . . . . . . . . 141

8.7 Conclusions . . . . . . . . . . . . . . . . . . 143

8.8 Appendix to Chapter 8 . . . . . . . . . . . . . . . 145

9 Conclusion $\quad 165$

9.1 Main Findings and Policy Implications . . . . . . . . . . . . . 165

9.2 Future Research . . . . . . . . . . . . . . . . . . . . 167

$\begin{array}{ll}\text { Bibliography } & 169\end{array}$

$\begin{array}{ll}\text { Summary } & 181\end{array}$

Summary in Dutch 185

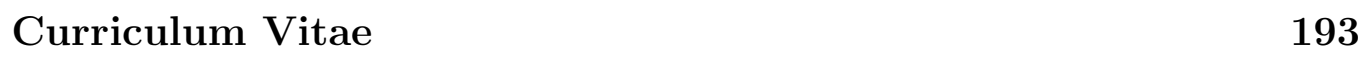

ROA Dissertation Series 195 


\section{CONTENTS}




\section{List of Figures}

3.1 Level of specific training: the social and private optimum compared . . . . . . . . . . . . . . . . . . . . . . . . 4 48

4.1 Training level under perfect information . . . . . . . . . 61

4.2 Training levels under perfect and imperfect information compared . . . . . . . . . . . . . . . . . 63

4.3 Social profits from training and the optimal degree of firmspecificity $\left(\delta^{*}\right)$ as a function of the degree of information incompleteness $(\lambda) \ldots \ldots \ldots 66$

5.1 The Dutch education system . . . . . . . . . . . 70

7.1 Cumulative distribution of the training input measure . . . . . 96

8.1 Densities of the training input measures . . . . . . . . 125 
LIST OF FIGURES 


\section{List of Tables}

2.1 Relative training cost and its main components: selected countries . . . . . . . . . . . . . . . . . . . 12

2.2 Percentage of training firms that report that apprentices constitute a net benefit during the training period. . . . . . . 15

3.1 Labour market outcomes . . . . . . . . . . . . . . . . 42

5.1 Intake at the labour market: education level of 24-34 year-old, $2000 \ldots \ldots \ldots \ldots \ldots 71$

5.2 Type of apprenticeship contract . . . . . . . . . . . 73

5.3 Minimum criteria for recognition . . . . . . . . . . . 76

7.1 The number of respondents by level and sector of training . . 91

7.2 Items on training input; distribution of respondents on response scale . . . . . . . . . . . . . . . . . . . . . . . . 93

7.3 Tests for reliability of the scale . . . . . . . . . . . . 95

7.4 Supervision from the school . . . . . . . . . . . 96

7.5 Type of apprenticeship place and type of appointment . . . . . 97

7.6 Determinants of training input (average score) . . . . . . . . . 99

7.7 Type of appointment during apprenticeship and average training input for apprentices who would choose the same training again retrospectively and apprentices who would not . . . . 102

7.8 Determinants of the chance to acquire a certificate of qualification (logit-estimation) . . . . . . . . . . . . 103

7.9 Wage determinants (OLS, dependent variable is the natural

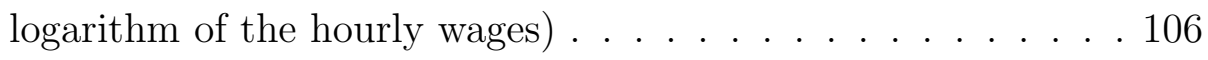




\section{LIST OF TABLES}

7.10 Descriptive statistics . . . . . . . . . . . . . 110

8.1 Method of interview and no apprentices at the moment of the survey by economic sector . . . . . . . . . . . . . . 113

8.2 Position of the respondent in relation to the apprenticeship system by economic sector . . . . . . . . . . . . . . . . . 114

8.3 Firm size by economic sector . . . . . . . . . . . . . . . . . . 114

8.4 Items on training input . . . . . . . . . . . . . . . . . . 116

8.5 Item-total correlation . . . . . . . . . . . . . . . . . . . . 119

8.6 New training input categories . . . . . . . . . . . . . . . . 121

8.7 Mean and standard deviation of training input measures . . . 123

8.8 Subjective chance to become the best training firm in the sector 124

8.9 Chance to be nominated for the best training firm award explained: The effects of training input and expected future benefits . . . . . . . . . . . . . . . . . . 124

8.10 The degree of firm-specificity of apprenticeship training . . . . 126

8.11 Most important type of firm-specific skills and knowledge learnt during the apprenticeship . . . . . . . . . . . . . . 127

8.12 Time needed for an externally trained worker to reach the same productivity as an internally trained worker (in weeks) . 128

8.13 Time needed for an externally trained worker to reach the same productivity as an internally trained worker (number of weeks) by level of firm-specificity of the training . . . . . . . . 128

8.14 Number of similar firms in the region (25 km radius) . . . . . 129

8.15 Urbanisation grade of place of business . . . . . . . . . . 130

8.16 Possibility to find a similar job in the region (25 km radius) . 131

8.17 Number of similar firms in the region by the ease to find a similar job in the region $(25 \mathrm{~km}$ radius $)$. . . . . . . . . . 131

8.18 Possibility to find a similar job by urbanisation grade of place of business . . . . . . . . . . . . . . . . . . . 132

8.19 Type of contract during the apprenticeship . . . . . . . . 133

8.20 Chance the apprentice wants to keep working in the firm (apprentices without a permanent contract) . . . . . . . . 134 


\section{LIST OF TABLES}

8.21 Average time an apprentice stays in the training firm after completing the training (conditional on staying) . . . . . . 134

8.22 How interesting are apprentices for the firm if costs are weight against the benefits in general and if the apprentice were to go after having completed the training . . . . . . . . 136

8.23 Chance the apprentice is offered an appointment at the firm (apprentices without a permanent contract) . . . . . . 137

8.24 Chance the apprentice is suitable to continue working in the firm (apprentices without a permanent contract) . . . . . 137

8.25 Measures for training motives . . . . . . . . . . . . . . . . . 139

8.26 Training input explained: tests on the effect of training motives141

8.27 Subjective chance that an apprentice obtains a diploma . . . . 142

8.28 Chance to obtain a diploma explained: The effects of training input and expected future benefits . . . . . . . . . . . 143

8.29 Probit analysis for the probability that the chance to be nominated as the best training firm in the sector is perceived as great . . . . . . . . . . . . . . . . . 145

8.30 Training input explained (OLS): Complexity of production tasks 147

8.31 Training input explained (OLS): Learning content of production tasks . . . . . . . . . . . . . . . . . . . . . 149

8.32 Training input explained (OLS): Time for learning and instruction . . . . . . . . . . . . . . . 151

8.33 Chance to obtain a diploma (interval regression) . . . . . . . 153

8.34 Selected qualifications (Crebo codes between brackets) . . . . 155 
LIST OF TABLES 


\section{Chapter 1}

\section{Introduction}

\subsection{Motivation}

In many industrialised countries, the apprenticeship system is an important route to prepare young people for the labour market. A well-known example is Germany, where about $60 \%$ of all young people enter an apprenticeship (Casey, 1986; Steedman, 1993; OECD, 1994; Den Broeder, 1995; Soskice, 1994; Lieshout, 1996; Neubäumer, 1999). In the smaller European countries, such as Austria, Switzerland, Denmark and, to a lesser extent, the Netherlands, as well as in Australia, the apprenticeship system is relatively strong (Smits and Stromback, 2001). In Britain the apprenticeship system has declined sharply from the late 1960s, but there has been a renewed interest in occupation- oriented workplace training for young people during the last decades, resulting in the launch of the 'Modern Apprenticeship' in 1993 (Gospel, 1994, 1998).

The key feature of the apprenticeship system is that an apprentice learns a trade while working in a firm. The organisation of the apprenticeship system differs between countries but there are also many similarities. Apprenticeship training usually combines workplace training in a training firm with school attendance one day a week. The typical entrance age of an apprenticeship is between 17 and 19 years, normally after completing (lower) secondary education. At the beginning of the apprenticeship the apprentice, the employer and sometimes other parties involved, such as schools or train- 


\section{CHAPTER 1. INTRODUCTION}

ing authorities, sign an apprenticeship contract which specifies the rights and duties of all parties and the conditions under which it may be terminated. The typical duration of an apprenticeship is three years. Apprentice pay is usually relatively low. ${ }^{1}$

Training in the firm differs greatly from one country to another but also between different sectors within countries. It may be more or less formalised, ranging from off-the-job training at special workshops to learning-by-doing during work. The curriculum of the training programme is usually specified by training authorities, often including representatives of employers, workers, schools and the government. In most countries an apprenticeship leads to a nationally recognised qualification.

The potential advantages of the apprenticeship system are multiple. First of all, workplace training in combination with school attendance is said to have many didactic advantages compared to school-based learning solely (Resnick, 1987; Jacobs and Jones, 1995; Rothwell and Kazanas, 1994; Nieuwenhuis and Onstenk, 1994). Secondly, the apprenticeship system also ensures a close match between the acquired and required skills. Firms know better than schools which skills are needed for a specific occupation. They will respond faster to technological developments in a trade that demand new skills. The apprentice thus acquires skills that are actually demanded by firms.

However, whether these theoretical advantages of apprenticeship training materialise depends on the way in which firms utilise the apprenticeship system. For a firm, training is not a goal in itself but is subject to the primary activity of the firm, which is the production of goods or services. Therefore, the training needs of the apprentice may conflict with the production interest of the training firm.

If the main reason for a firm to employ apprentices is their contribution to the production process, the firm may be more interested in their direct productivity than in their training. The training interest of the apprentice will then conflict with the production interest of the firm. Indeed, many economists have expressed the fear that firms only employ apprentices as

\footnotetext{
${ }^{1} \mathrm{~A}$ more detailed description of the apprenticeship system in different countries can be found in Smits and Stromback (2001).
} 


\subsection{MOTIVATION}

substitutes for unskilled or skilled labour (Ryan, 1994).

A firm that trains apprentices because of a future need for qualified labour wants to retain the apprentices after completion of their training. Therefore it has itself an interest in providing the training. However, conflicts of interests may still occur. The firm wants to teach the apprentice skills that are useful in the training firm, while the apprentice may want to leave the training firm after completing the training to work in another firm or industry. Therefore the apprentice has an interest in learning not only skills that are specific to the firm, the occupation or the industry he or she is trained in, but also some skills that have a wider applicability, so-called generic skills.

It depends on the specific institutional settings of an apprenticeship system how problematic conflicting interests will be in practice. For example, are there any institutional arrangements to guarantee the quality of training? Is there any monitoring of the training in the firm by a third party, such as a school or training authority? Is the training completed with an external examination? Who decides on the curriculum of the apprenticeship programme, the employers or the workers or both? Are there other parties involved, such as the schools for vocational education or training authorities?

In the absence of any regulation, the apprenticeship system could become very attractive for firms that search for cheap labour, but are not interested in training. Especially when apprentice pay is relatively low and apprentice productivity relatively high compared to the pay and productivity of unskilled workers. But even if firms train because of investment motives, regulation may be necessary to prevent training from becoming too firm- or industry-specific and the apprentice acquiring few skills that have a wider applicability.

Conflicting interests of firms and apprentices demand regulation of the apprenticeship system. However, it is unlikely that regulation can completely solve the conflicts of interests between firms and apprentices. Too much regulation may be even counterproductive. For example, if firms were not allowed to adapt part of the training programme to their own specific needs, the investment motive would be lost and the apprenticeship system would become attractive only for firms with current production motives. Moreover the training intensity will, in practice, be difficult to observe by a third 


\section{CHAPTER 1. INTRODUCTION}

party and therefore the training intensity cannot be regulated completely. If firms have mainly current production motives for employing apprentices, regulation of the training quality may not be sufficient to guarantee good training for all apprentices.

Training motives of firms also determine the margins for government policies aiming to stimulate the apprenticeship system, for example to increase the number of apprenticeship places. If such a policy were to stimulate mainly firms without investment motives to participate in the apprenticeship system, without any additional measures to guarantee training quality, average training quality may fall.

For a meaningful government policy regarding apprenticeship training, it is therefore important to gain insight in firms' training motives and the consequences of these motives for the quality of the training programme. This is the aim of the present study.

\subsection{Outline of the Study}

Most studies on apprenticeship training investigate why firms supply apprenticeship training (Acemoglu and Pischke, 1998; Clark, 2001; Elbaum and Singh, 1995; Franz and Soskice, 1995). The present study approaches this issue from a new perspective. Given that firms supply apprenticeship training, what are the consequences of their training motives for the quality of the training? I considered two aspects of training quality. Firstly, the curriculum of the training programme. A firm that trains an apprentice to fulfil a future need for qualified labour, has an interest in teaching firm-, occupation- and industry-specific skills and will be less inclined to teach skills with a wider applicability. Secondly, I considered the training intensity. Firms that only have current production motives to supply apprenticeships have no interest in the training itself and may therefore be tempted to save on training costs by giving less training. It is to be expected that both aspects of training quality are interrelated. The more specific the curriculum, the higher the firm's future marginal benefits from training will be and the higher the training intensity it will choose.

Chapter 2 gives an overview of the economic literature on firms' benefits 


\subsection{OUTLINE OF THE STUDY}

of apprenticeship training. It discusses theoretical en empirical evidence on current and future benefits of apprenticeship training for firms. I will introduce a simple theoretical model to illustrate the different features of the training models that can be found in the literature. Three main factors determining the firms' expected future benefits from training can be identified; the degree of firm-specificity, the degree of monopsony power and the quit rate.

In Chapter $3 \mathrm{I}$ will develop a theoretical model for the investment in specific and generic skills. Specific skills are defined as skills that are specific to an industry or occupation. Both generic and specific skills are transferable, in the sense that they can be used in other firms as well, but the market for specific skills is smaller than the market for generic skills. Firms can appropriate some of the returns to specific training but the returns to generic training fully accrue to the apprentice. In fact, the level of generic skills acts as an outside option for the apprentice and puts a minimum bound on posttraining wages. Firms want the generic component to be as small as possible, because their share in the returns to specific training decreases with the level of generic training. For the same reason, apprentices want the level of generic training to be as high as possible. If the firm and the apprentice decide jointly on the level of training, there will be overinvestment in generic skills and underinvestment in specific skills. If the apprentice does not participate in the training decision, there will be no generic training at all.

Chapters 4 to 8 deal with the second aspect of training quality, namely the training intensity. First, Chapter 4 presents a theoretical model for the training intensity if the training is not perfectly observable by the apprentice. Under imperfect information, the training level is lower than socially optimal, because apprentices anticipate that the training firm will cheat and are not prepared to accept a lower training wage in turn for more training. The underinvestment problem is less severe the higher the degree of firmspecificity of the training. If the training is partly firm-specific, the training firm can appropriate part of the returns to training and is therefore less likely to cheat. Therefore, the training level will be higher if part of the training is firm-specific.

The relation between training motives and training intensity will be tested 


\section{CHAPTER 1. INTRODUCTION}

empirically for the Dutch apprenticeship system. Apprenticeship training in the Netherlands is highly regulated and leads to nationally recognised qualifications. Concentrating on the Netherlands enables me to test whether regulation is sufficient to solve the moral hazard problem with respect to training intensity. Chapter 5 gives a sketch of the Dutch apprenticeship. It discusses the position of the apprenticeship system within the Dutch educational system and the institutional arrangements of the apprenticeship system. Special attention is paid to the way in which training quality is monitored.

Chapter 6 derives an empirical model to test the relation between training motives and training intensity to be used in chapters 7 and 8. It discusses how training intensity will be defined and measured. A distinction is made between training input and training output. Input is the variable of interest since it shows what the firm really does in terms of training, but for the apprentice the only inputs that matter are those that have a real impact on output. Therefore the empirical strategy to test the relation between training intensity and training motives is first to test whether there is a relation between the indicators for training motives and training input. Secondly it will be tested whether there is a relation between training input and output. Input is measured as the effort of the training firm to give priority to training relative to production. Output is measured by considering examination results and labour market performance after completing the training.

Chapter 7 is based on a survey among former apprentices. Chapter 8 draws upon a survey among Dutch training firms in four sectors, the construction industry, the printing industry the metal industry and the care sector. Both surveys included questions about the way in which training and work were organised in the firm. These questions tried to capture the extent in which the training firm gave priority to training relative to production. On the basis of these questions, I have constructed training input measures, in Chapter 7 a single input measure and in Chapter 8 separate input measures for different aspects of the training. Furthermore, the training input measures used in Chapter 8 all differ in the degree of observability, which makes it possible to test whether the relation between training motives and training intensity will be stronger if the training intensity is less well observ- 


\subsection{OUTLINE OF THE STUDY}

able, as is predicted in Chapter 4. The training input measures are regressed on measures of training motives. In Chapter 7 the type of contract during the apprenticeship is used as a measure for training motives. In Chapter $8 \mathrm{I}$ have used several measures for the degree of firm-specificity of the training, the degree of monopsony power and the quit rate.

Chapters 7 and 8 show that there is indeed a relation between training intensity and training motives. Firms with investment motives provide better training than firms with current production motives. Especially those aspects of the training input that are not easily observable by a third party will be neglected if the firm has no investment motives. Unfortunately these are also the aspects that are most effective in terms of output. It follows that regulation is not sufficient to guarantee good training to all apprentices if there are firms participating in the apprenticeship system that have no investment motives. 
CHAPTER 1. INTRODUCTION 


\section{Chapter 2}

\section{Why Do Firms Supply Apprenticeships? Theoretical and Empirical Evidence}

\subsection{Introduction}

The economic benefits of apprenticeship training for firms can relate to both the training period (current benefits) and the post-training period (future benefits). In the first case the apprentice's contribution to output and any training subsidies outweigh his wage and training costs. In the second case the firm has a benefit from the apprentice staying upon completion of the training. The question why firms supply apprenticeships is important for the quality of the training. If a firm supplies apprenticeships because of current benefits (current production motive) there is a potential conflict of interest with respect to training intensity. If, on the other hand, a firm trains apprentices because of future benefits (investment motive) there may be a conflict of interest with respect to the curriculum of the training programme.

This chapter gives an overview of the economic literature on firm's benefits from apprenticeship training. The earliest empirical work on this subject modelled the demand for apprentices as a function of current output and relative costs, to capture the current production motive, and the expected future output, to capture the investment motive (Lindley, 1975; Merrilees, 


\section{CHAPTER 2. WHY DO FIRMS SUPPLY APPRENTICESHIPS?}

1983). Lindley (1975) found that both the (apprentice) wage elasticity and output elasticity were close to unit which is clearly supporting the notion of a current production motive. Merrilees (1983) found that unfilled-orders and investment as proxies for future labour need have the expected effect on apprentice recruitment suggesting that the investment motive is important as well. Stevens (1994a) has estimated a model for apprentice demand in which the investment motive is made more explicit. In this model firms train apprentices to save on recruitment costs for skilled workers later on. The coefficient of the training cost variable is negative and the coefficient of the recruitment cost variable is positive indicating again that firms have an investment motive to take on apprentices. ${ }^{1}$

A weakness of these approaches is that they do not provide insight in the size of current and future benefits. Other training costs than wage cost are, for example, not taken into account. Also, it does not allow for differences in costs and benefits between firms. Which firms do have current benefits and which firms do have future benefits? This question is important for the study of conflicting interests of firms and apprentices.

The last decade many studies of the costs and benefits of apprenticeship training have been undertaken, especially for the German apprenticeship system. In this chapter I will first present the evidence for current benefits and I will show that although on average current benefits do not outweigh the costs of training apprentices, there are still a lot of firms for which the reverse is the case.

Secondly, I will concentrate on future benefits. An important question here is why firms would bother to train their own workforce. After all, by recruiting skilled workers who are trained externally instead, firms can save on training costs. As mentioned above, Stevens (1994a) argues that firms who train their own workforce can save on recruitment costs. During the last decade many other theoretical explanations for an investment motive have turned up in the literature. All these explanations focuss upon a wedge between productivity and pay of an internally trained worker. I will present a theoretical framework to classify these contributions and show that a wedge

\footnotetext{
${ }^{1}$ Training cost is measured by relative youth wages and the recruitment cost by a skills shortage index.
} 


\subsection{CURRENT BENEFITS OF APPRENTICESHIP TRAINING}

between productivity an pay can be decomposed into three components, the firm-specific returns, a wedge between the worker's value in external firms and the market wage and a wedge between the market wage and the wage paid by the training firm. Finally I will present the empirical evidence for future benefits for firms.

\subsection{Current Benefits of Apprenticeship Training}

If the value of an apprentice's output outweighs the costs of employing and training him, a firm may take on apprentices as substitutes for unskilled or skilled workers. Apprentice's costs include wage cost, and direct training costs such as wage cost of trainers and material and capital costs. As some skills are more easily learnt than other skills, training costs will vary between trades. Some skills can be learned without much supervising while performing the work, while other more complicated skills demand intensive additional training off-the-job. Clearly in the latter case direct training costs are much higher than in the former. Moreover an apprentice who is trained on-the-job also makes a contribution to output. Therefore apprentice output will be much higher if training takes place mostly on-the-job than if part of the training takes place off-the-job in training workshops. It is expected that current production motives, if they exists, will prevail in trades where apprentice pay is relative low and training takes place on-the-job, so that direct training costs are low and the apprentice output is high.

A lot of studies in different countries have taken place to measure the costs and benefits of employing apprentices. Smits and Stromback (2001) give an overview of the estimated costs and benefits relative to the cost of employing a skilled worker in a few countries, namely Australia, Great Britain, Germany and the Netherlands (see Table 2.1). Gross cost is the sum of wage and training costs (corrected for eventual subsidies). The most important component of the training costs are the costs of trainers. These are determined as the wage costs of trainers multiplied by the proportion of time they are engaged in training. Furthermore training costs include material 


\section{CHAPTER 2. WHY DO FIRMS SUPPLY APPRENTICESHIPS?}

and capital cost. Deducting apprentice output from gross cost gives the net apprentice training cost. Apprentice output is measured by the relative productivity of an apprentice times the wage cost of a skilled worker.

It appears that, although there are considerable differences between countries, on average the benefits from employing and training apprentices nowhere outweighs the costs. On the contrary, the average net costs of training apprentices are considerable. In all countries considered, the largest cost component is by far the apprentice's wage. Clearly there is a positive relation between apprentice output and apprentice pay. In countries where apprentices' contribution to production is high, like Australia and Britain, apprentices' wages are high as well. Surprisingly, however, is that in several countries, notably Germany, Britain and the Netherlands, wage costs exceed the value of the (average) apprentice output. So in these countries apprentices would be a net cost even if direct training costs were zero.

Table 2.1: Relative training cost and its main components: selected countries

\begin{tabular}{|c|c|c|c|c|c|c|}
\hline & $\begin{array}{l}\text { Wage } \\
\text { cost }\end{array}$ & $\begin{array}{c}\text { Training } \\
\text { cost }\end{array}$ & Subsidy & $\begin{array}{c}\text { Gross } \\
\text { cost }\end{array}$ & $\begin{array}{c}\text { Value of } \\
\text { apprentice } \\
\text { output }\end{array}$ & $\begin{array}{l}\text { Net } \\
\text { cost }\end{array}$ \\
\hline Australia & 0.57 & 0.21 & 0.02 & 0.76 & 0.59 & 0.17 \\
\hline Germany & 0.33 & 0.33 & - & 0.66 & 0.26 & 0.40 \\
\hline $\begin{array}{l}\text { Netherlands } \\
\text { (manufacturing) }\end{array}$ & 0.46 & 0.10 & 0.02 & 0.54 & 0.29 & 0.25 \\
\hline $\begin{array}{l}\text { Netherlands } \\
\text { (distribution) }\end{array}$ & 0.18 & 0.03 & 0.02 & 0.19 & 0.17 & 0.02 \\
\hline $\begin{array}{l}\text { Britain } \\
\text { (distribution) }\end{array}$ & 0.57 & 0.22 & - & 0.79 & 0.39 & 0.40 \\
\hline
\end{tabular}

Notes: Taken from Smits and Stromback (2001). Sources: Harhoff and Kane (1997); Bardenleben (1997); Dockery, Koshy, Stromback, and Ying (1997); de Vries and Heere (1993); Jones (1986). All figures are relative to the cost of employing a skilled worker: Australia AUD 32,500, Germany DM 44,500, Netherlands Nfl 50,000 , Britain $£ 8000$.

These average figures mask the enormous differences in training costs that exist between firms within countries. In Germany net costs differ significantly between the (mainly) small firms in the craft sector (handwerk) and the (mainly) large firms in industry and commerce. Firms in the industry 


\subsection{CURRENT BENEFITS OF APPRENTICESHIP TRAINING}

incur much higher training costs than firms in the craft sector. These differences in costs are due to the different organisation of the training. In the craft sector training takes place mainly on-the-job while large firms in the industry often train off-the-job in special training workshops. Several economists therefore argue that for many firms in the craft sector apprentices actually constitute a net benefit and that this is the main reason for those firms to take on apprentices (Soskice, 1994; Casey, 1986, 1991). However, although net training costs in the craft sector are on average much lower than in the industry and commerce they are still considerable. In 1991 the average net costs in the craft sector were 12,352 DM per year per apprentice and 20,509 DM in the industry and commerce (Von Bardeleben, 1994).

Soskice (1994) argues that net training costs in small firms in the craft sector are overestimated for two reasons. Firstly, the costs of trainers are determined as the total costs of the trainer multiplied by the proportion of time engaged in training. In small firms, however, supervising the training is a part-time activity. Generally the trainer will supervise the apprentice in slack periods when he is not busy with production himself. Therefore the actual marginal cost of the trainer may be much lower than suggested by the figures. Secondly, the apprentice's contribution to output is underestimated. The apprentice's output is measured by multiplying the wage costs of a skilled worker by the relative productivity of an apprentice. In small firms apprentices will often not only perform skilled work but unskilled work as well. A first year apprentice cannot perform many skilled tasks yet, but is fully capable to do unskilled work. Therefore it would be more appropriate to include the value of the apprentice contribution to unskilled work as well.

If wage costs of part-time trainers are not taken into account, the average net training costs in the craft sector would amount to 400 DM per year (against 9,193 in industry and commerce (Von Bardeleben, 1994)). On average training is still a net cost in the craft sector but Wagner (1998) states that for $30 \%$ of the apprentices in the craft sector training costs are actually negative. Surprisingly there are also many firms in the industry/commerce for which net training costs are negative, nearly $20 \%$ of the apprentices in these sectors is a net benefit to the training firm. This result suggests that the

contrast between the craft sector and the industry/commerce is not as sharp 


\section{CHAPTER 2. WHY DO FIRMS SUPPLY APPRENTICESHIPS?}

as could be concluded if only averages are compared between the sectors.

If, as suggested by Soskice (1994), in addition the apprentice output were valued at half of the labour costs of an unskilled worker, approximately DM 15,000 , the average net costs in the craft sector would be even negative.

So although on average German firms face positive net training costs, there is plenty of evidence that the variance between firms is high and that there is a considerable number of firms for which current benefits outweigh the training costs.

For the Netherlands there is less information available on the costs of apprentices. Kok, Groot, Hop, and Janssens (2002) investigated the costs and benefits of apprentices in the care sector and concluded that the net costs are considerable, in 2000 on average 11,100 guilders per year. De Vries and Heere (1993) provide estimates of costs and benefits of apprentices in a number of selected trades, namely chemical and process industry, metal industry, building trade and the distribution sector. The results are not entirely representative because only 31 firms were interviewed but still a number of important conclusions can be drawn. On average apprentices are a net cost to the training firm. Again, there are considerable differences between trades and even between firms within trades.

In the distribution sector average costs are very small. Some apprentices in this sector only have a learning and no employment contract, in which case they do not earn a wage although they may receive some compensation. ${ }^{2}$ Net costs are quite high in the building, metal and chemical industry. In these sectors apprentice pay is high compared to apprentice output. Although on average apprentices constitute a net cost, in $12 \%$ of the firms apprentices are a net benefit to the firm. Some of these firms admitted that these current benefits were the main reason to train apprentices. The share of firms for which apprenticeship training is a net benefit is lower than in Germany but De Vries and Heere (1993) suggest that firms with low training costs are underepresented in the sample because mainly firms with a long training tradition were included. This is confirmed by qualitative evidence on training costs. Borghans, Smits, Vlasblom, and Jacobs (2000) held a survey

\footnotetext{
${ }^{2}$ For a more detailed overview of the Dutch apprenticeship system and the types of apprenticeships places see Chapter 5 .
} 


\subsection{CURRENT BENEFITS OF APPRENTICESHIP TRAINING}

among Dutch training firms and asked about apprentices' cost during the training period. Two thirds of the training firms stated that the costs of employing apprentices are earned back during the training period, that is, the apprentice's output fully compensates for wage and training costs (see Table 2.2). This results suggests again that, as put forward by Soskice (1994), quantitative estimates sometimes overestimate net training costs.

Table 2.2: Percentage of training firms that report that apprentices constitute a net benefit during the training period.

\begin{tabular}{lc}
\hline \hline & $\%$ \\
\hline Industry & 73 \\
Garages & 87 \\
Building Trade & 65 \\
Hotel and Catering Industry & 76 \\
Business Services & 45 \\
Wholesale/retail trade & 59 \\
Non-profit & 71 \\
Total & 66 \\
\hline \hline
\end{tabular}

Source: Borghans, Smits, Vlasblom, and Jacobs (2000)

Information available on apprenticeship training in Britain suggests that English firms incur high training costs (Jones, 1986). Apprentice pay in Britain is high compared to the skilled wage rate. As apprentice output falls short of the apprentice wage costs, British training firms incur high net training costs. However, the information is based on a small sample of only 10 firms and more important only large firms are included. All firms have more than 100 employees but six of ten firms even have more than 2.500 employees. So there is no evidence on training costs in small English firms.

Like in Britain, apprentice pay in Australia is very high but so is the value of apprentice output. In fact apprentice output fully compensates apprentice wage costs. Training firms bear the direct costs of the training. As a consequence average net training costs in Australia are much smaller than in Britain. Still average costs are quite large. Qualitative evidence on training cost in Australia does not fit with quantitative measures, however. The majority of Australian training firms think that apprentices constitute 


\section{CHAPTER 2. WHY DO FIRMS SUPPLY APPRENTICESHIPS?}

a net benefit during the training period (Smits and Stromback, 2001). This finding suggests again that quantitative measures might overestimate net training costs.

From the quantitative evidence it can be conclude that for the majority of firms apprentices constitute a net cost, often quite large. There are, however, also firms for which apprentices constitute a net benefit. These are mainly small firms in which training takes place mainly on-the-job and as a consequence the apprentice contribution to output can be quite considerable. Also the cost of trainers is much lower in these firms because supervising apprentices is a part-time activity that takes mainly place during slack periods. It is not clear for how many firms this is actually the case. Quantitative evidence for Germany suggest between 20\% and 30\% of all firms. Qualitative evidence for the Netherlands and Australia suggests a larger share. Also, it is not sure that all these firms take on apprentices for current benefits only, future benefits may play a role as well. But, as the Dutch evidence shows, there certainly are firms that train mainly because of current benefits (de Vries and Heere, 1993).

\subsection{Future Benefits of Apprenticeship Train- ing}

The majority of firms that train apprentices seems to do so because of future benefits. Especially large firms, that have substantial training costs, retain most of their apprentices. But what are these future benefits? Why do these firms not simply try to recruit skilled workers that are trained elsewhere? The common approach in the literature is to seek these benefits in the wedge between productivity and pay of newly qualified apprentices that stay in the training firm (Acemoglu and Pischke, 1999a,c). A wedge between productivity and pay implies that the market for skilled labour is not perfectly competitive. The literature provides many explanations as to why this would be the case. 


\subsection{FUTURE BENEFITS OF APPRENTICESHIP TRAINING}

\subsubsection{Apprenticeship Training and the Human Capital Theory}

The human capital theory has played an important role in explaining training investments of firms and workers. Human capital can be defined as the entire set of skills and knowledge, emotional and physical conditions that determines someone's productivity. Investments in human capital raise future productivity. These include investments in training and education, but also in medical care. The returns to investments in human capital may either accrue to the worker or to the firm that employs him. With respect to onthe-job training Becker (1964) makes a distinction between general and firmspecific training. General training raises productivity equally in many firms while firm-specific training raises productivity only in the training firm. In a perfectly competitive labour market workers are paid their marginal product. Therefore an increase in general human capital will be fully reflected in an increase in the market wage. The worker, thus, receives the full benefit of general training. Since the firm cannot appropriate the returns to general training it will not be prepared to pay for it either. Following this theory, firms will only supply general training if workers bear all the costs. Training levels will be optimal as long as workers can finance the training investment themselves.

Firm-specific training, on the other hand, will not raise the worker's market wage. Still, the firm will not be prepared to bear the full costs of an investment in firm-specific skills. If the employment relation is not continued after the training the investment is lost. The same is true for the worker. Both the worker and the firm risk to lose the investment if the other party unilaterally breaks the employment relation. Hashimoto (1981) shows that if both parties share the costs and benefits of firm-specific training they both have an interest in continuing the employment relation after the training.

Applying the human capital theory to apprenticeship training, it follows that firms will only have a share in the future benefits of training if some of this training is firm-specific. However, apprenticeship training aims to provide occupation-specific skills that can be used in external firms. In practice it is inevitable that the apprentice will learn some firm-specific skills as well 


\section{CHAPTER 2. WHY DO FIRMS SUPPLY APPRENTICESHIPS?}

but the question is whether this component is large enough for firms to be willing to invest in apprenticeship training.

\subsubsection{Theoretical Models on Firms' Return to Training}

In recent years the literature has come up with several explanation as to why firms are willing to invest in technological general training. These explanations have in common that they deviate from the assumption that the market for general skills is perfectly competitive.

To illustrate this issue consider a two period training model. Training takes place in the first period. In the second period the worker might either stay in the training firm or quit to work in some other firm. Training increases productivity, the increase in productivity may be higher in the training firm than in external firms depending on the firm-specificity of the training. The productivity of an internally trained worker is given by $H\left(h_{g}, h_{s}\right)$, where $h_{g}$ is the level of general training and $h_{s}$ the level of firm-specific training. The firm's expected return to training is determined by the wedge between productivity and pay of an internally trained worker and the quit rate.

$$
(1-Q)\left(H\left(h_{g}, h_{s}\right)-w_{2}\right)
$$

where $Q$ is the quit rate and $w_{2}$ is the second-period wage paid by the training firm.

Productivity of an externally trained worker is equal to $H\left(h_{g}, 0\right)$. The difference between internal and external productivity is given by

$$
\mathcal{U}\left(h_{g}, h_{s}\right)=H\left(h_{g}, h_{s}\right)-H\left(h_{g}, 0\right)
$$

If external markets are imperfectly competitive we may have a wedge between external productivity and the market wage, $\omega$, in the second period.

$$
\mathcal{W}\left(h_{g}\right)=H\left(h_{g}, 0\right)-\omega\left(h_{g}\right)
$$

Furthermore the second-period wage paid by the training firm, $w_{2}$, may deviate from the market wage.

$$
\mathcal{V}\left(h_{g}, h_{s}\right)=\omega\left(h_{g}\right)-w_{2}\left(h_{g}, h_{s}\right)
$$




\subsection{FUTURE BENEFITS OF APPRENTICESHIP TRAINING}

Note that $\mathcal{V}$ may be negative. In that case the firm shares some of the training surplus with the worker.

The quit rate depends both on the wage offered by the training firm and the attachment of the worker to the training firm. The worker will quit if the gap between market wages and pay in the training firm exceeds some threshold $\mu+m$. Where $\mu$ is a random variable with $E(\mu)=0$, twice differentiable distribution function $F(\mu), f(\mu)$ and $-\bar{\mu}<\mu<\bar{\mu}$. The fixed component of the threshold, $m$, may depend on $h_{g}$ and $h_{s}$. If $\mu<\mathcal{V}-m$ the worker quits otherwise he will stay, The probability of quitting is given by

$$
Q=\int_{-\bar{\mu}}^{\mathcal{V}-m} f(\mu) \mathrm{d} \mu=F(\mathcal{V}-m)
$$

The expected quit rate if the firm offers a wage equal to the market wage $F(-m)$ can be interpreted as the exogenous quit rate.

By substituting for $\mathcal{U}, \mathcal{V}, \mathcal{W}$ and $Q$ in equation (2.1), the firm's expected return can be rewritten as:

$$
(1-F(\mathcal{V}-m))(\mathcal{U}+\mathcal{W}+\mathcal{V})
$$

The firm's expected return to training consists of three components. The first is the firm-specific returns to training $\mathcal{U}$, the second is the wedge between external productivity and pay, $\mathcal{W}$, and the third component is the wedge between the wage paid by the training firm and the market wage, $\mathcal{V}$. The wedge between external productivity and pay, $\mathcal{W}$, can also be appropriated by external firms if the worker quits the training firm.

Suppose training costs $C\left(h_{g}, h_{s}\right)$, including training-wage cost and foregone productivity, are increasing and convex in $h_{g}$ and $h_{s}, \frac{\partial C}{\partial h_{i}} \geq 0, \frac{\partial^{2} C}{\partial h_{i}^{2}} \geq 0$, $i=g, s$. Also suppose that the firm chooses the training intensity. ${ }^{3}$ The firm maximises profit with respect to $h_{g}, h_{s}$ and $w_{2}$ and then chooses to train if

\footnotetext{
${ }^{3}$ This does not imply that the apprentice does not share in the training costs, for example by accepting a lower wage than the unskilled wage rate. The training wage is incorporated in the cost function. If the apprentice shares in the training costs, training costs will increase less with training intensity than if the apprentice does not. Whether the apprentice shares in the training costs or not, does not affect the outcomes of the model, however.
} 


\section{CHAPTER 2. WHY DO FIRMS SUPPLY APPRENTICESHIPS?}

profits are positive. The first-order conditions are given by:

$$
\begin{aligned}
& \frac{\partial C}{\partial h_{g}}=(1-F(\mathcal{V}-m))\left(\frac{\partial \mathcal{U}}{\partial h_{g}}+\frac{\partial \mathcal{W}}{\partial h_{g}}+\frac{\partial \mathcal{V}}{\partial h_{g}}\right) \\
&-(\mathcal{U}+\mathcal{W}+\mathcal{V}) f(\mathcal{V})\left(\frac{\partial \mathcal{V}}{\partial h_{g}}-\frac{\partial m}{\partial h_{g}}\right) \\
& \frac{\partial C}{\partial h_{s}}=(1-F(\mathcal{V}-m))\left(\frac{\partial \mathcal{U}}{\partial h_{s}}+\frac{\partial \mathcal{V}}{\partial h_{s}}\right) \\
&-(\mathcal{U}+\mathcal{W}+\mathcal{V}) f(\mathcal{V})\left(\frac{\partial \mathcal{V}}{\partial h_{s}}-\frac{\partial m}{\partial h_{s}}\right) \\
&(\mathcal{U}+\mathcal{W}+\mathcal{V}) f(\mathcal{V})+F(\mathcal{V}-m)-1=0
\end{aligned}
$$

Substituting for (2.9) in equations (2.7) and (2.8) gives:

$$
\begin{gathered}
\frac{\partial C}{\partial h_{g}}=(1-F(\mathcal{V}-m))\left(\frac{\partial \mathcal{U}}{\partial h_{g}}+\frac{\partial \mathcal{W}}{\partial h_{g}}+\frac{\partial m}{\partial h_{g}}\right) \\
\frac{\partial C}{\partial h_{s}}=(1-F(\mathcal{V}-m))\left(\frac{\partial \mathcal{U}}{\partial h_{s}}+\frac{\partial m}{\partial h_{s}}\right)
\end{gathered}
$$

It is straightforward to see from equation (2.10) that if $\frac{\partial \mathcal{U}}{\partial h_{g}}>0, \frac{\partial \mathcal{W}}{\partial h_{g}}>0$ or $\frac{\partial m}{\partial h_{g}}>0$ the firm will supply general training. ${ }^{4}$ It will supply firm-specific training if $\frac{\partial \mathcal{U}}{\partial h_{s}}>0$ or $\frac{\partial m}{\partial h_{s}}>0$. In a competitive labour market $\frac{\partial \mathcal{U}}{\partial h_{g}}=0$, $\frac{\partial \mathcal{W}}{\partial h_{g}}=0$ and $\frac{\partial m}{\partial h_{g}}=0$. The firm will only supply firm-specific training. In the following section I will discuss a number of models from the literature that give explanations for $\frac{\partial \mathcal{U}}{\partial h_{g}}>0, \frac{\partial \mathcal{W}}{\partial h_{g}}>0$ or $\frac{\partial m}{\partial h_{g}}>0$.

From (2.10) it follows that firms will not provide training if the wedge between productivity and pay is a constant, that is if $\frac{\partial \mathcal{U}}{\partial h_{g}}=0, \frac{\partial \mathcal{W}}{\partial h_{g}}=0$ and $\frac{\partial m}{\partial h_{g}}=0$. There are, however, a number of models in the literature that only consider the size of the wedge and assume that firms will invest in general training if this size is large enough to offset the training costs. Usually this

\footnotetext{
${ }^{4}$ Compare Acemoglu and Pischke (1999a,c). They introduced a general framework to explain firms' investments in general training. In this framework firms will provide general training if the wedge between productivity and pay is increasing in training intensity. However, post-training wages in the training firm equal the outside option ( $\omega$ in the model presented here) so the wedge between productivity and pay can only stem from $\mathcal{U}$ or $\mathcal{W}$ and there is no role for $m$ in explaining training investments.
} 


\subsection{FUTURE BENEFITS OF APPRENTICESHIP TRAINING}

concerns models that investigate the firm's decision on the number of workers to be trained (for example, see Stevens (1994b); Booth and Chatterji (1998)). The training firm will supply training places up to the point that the marginal costs of an extra trainee equals the marginal costs. However, a constant wedge assumes that the training level is also a constant and exogenously given to the training firm, otherwise the training firm could lower the training level without affecting the return to training. In the limit the training level would then approach zero.

\section{Firm-Specificity of Apprenticeship Training $(\mathcal{U})$}

Models on firm-specificity of apprenticeship training seek to explain why $\frac{\partial \mathcal{U}}{\partial h_{g}}>0$. The main argument is that firm-specific skills are essential to function well within a company. Each firm has it's own equipment and machinery, procedures, culture etcetera. Franz and Soskice (1995) argue that a minimum of firm-specific skills is in fact necessary for using general skills. Firm-specific and general skills are thus technological complements. Both Franz and Soskice (1995) and Acemoglu and Pischke (1999a,c) have shown that the complementary of general and firm-specific skills provides an incentive for firms to invest in general apprenticeship training.

Although apprenticeship training primary aims to provide occupational skills which can be used outside the training firm, firm-specific skills can be taught at very low costs. Simply by being in the training firm the apprentice will learn about the firm's organisational structure. While learning occupational skills the apprentice will also learn to work with the firm's own machinery. So firm-specific skills are to some extent a by product of general training (Smits and Stromback, 2001). A firm that hires skilled workers on the external market will have to teach these workers firm-specific skills before the general skills can be made fully productive. As the value of general skills increases with the level of firm-specific skills, (technological) general skills are worth more in the training firm than at the external market. As a consequence there is a wedge between productivity in the training firm and the market wage that increases with the level of general training.

Lazear (2003) suggests an alternative way to define firm-specific skills. 


\section{CHAPTER 2. WHY DO FIRMS SUPPLY APPRENTICESHIPS?}

Skills may in itself be general but firms use them in different combinations and attach different weights to them. A worker who leaves the training firm after the training is not very likely to find a firm in which the set of general skills he has acquired is valued the same as in the training firm and therefore suffers a wage loss.

Kessler and Lülfesmann (2000) give an additional explanation. In their model general and firm-specific training are technologically separable (that is $\left.H\left(h_{g}, h_{s}\right)=H\left(h_{g}, 0\right)+H\left(0, h_{s}\right)\right)$ but the value of both components is uncertain ex ante. Using the 'outside option principle' they show that as long as the realised value of firm-specific training exceeds the realised value of general training, the returns to both firm-specific and general training are shared between the worker and the firm. Otherwise the returns to firmspecific training accrue to the firm and the return to general training to the worker. ${ }^{5}$ Therefore firms are willing to pay for general training.

There is little empirical evidence on the importance of firm-specific skills for the apprenticeship system. The curriculum of the apprenticeship program is often regulated but these regulations mostly set a minimum standard and firms are free to provide more training than that. Franz and Soskice (1995) state that in Germany large companies train apprentices 'well beyond minimum standards'. Furthermore firm-specific skills are more important in large complex organisations. Whether the firm-specific component is indeed the reason for these firms to invest in apprenticeship training remains a question that needs to be answered.

\section{Wedge between External Productivity and Pay $(\mathcal{W})$}

Imperfect Information on Training Quality In contrast to the training firm, external firms do not observe what training is taking place. Therefore, external firms might find it difficult to assess the value of a training program. It follows that if an increase in the level of training is not observed by external firms, then it will not lead to an equivalent increase in the market wage, so $\frac{\partial \mathcal{W}}{\partial h_{g}}>0$. The asymmetry of information gives firms an incentive to invest in training. The consequence of informational asymmetries with respect to

\footnotetext{
${ }^{5}$ More precisely $\mathcal{U}=H\left(0, h_{s}\right)+\frac{1}{2} P\left[H\left(0, h_{s}\right)>H\left(h_{g}, 0\right)\right]\left(H\left(h_{g}, 0\right)-H\left(0, h_{s}\right)\right)$.
} 


\subsection{FUTURE BENEFITS OF APPRENTICESHIP TRAINING}

the content of training programs was first mentioned by Katz and Ziderman (1990) and later modelled by Chang and Wang (1996). Katz and Ziderman (1990) argue that the value of an externally trained worker is an increasing function of the recruiting firm's information about a worker's training. If the recruiting firm has no information about the training, it has to incur costs to discover the worker's skill level. The value of an untrained worker in a job that requires training might be very low if not negative. Additionally, it will probably take some time for a firm to discover the productivity of an externally trained worker. Therefore, firms might not be willing to hire externally trained workers for skilled jobs.

Nowadays, in most countries apprenticeship training is regulated to a high degree. Amongst others, these regulations include monitoring and certification of the training. External firms can thus be sure that an externally trained worker has attained some minimum standard. Beyond this minimum standard, however, the quality of the training may differ considerably between firms. So certification does not completely solve the private information problem but it is not expected that this is an important reason for firms to provide apprenticeship training. On the contrary, the apprenticeship system is especially flourishing in countries where it is highly regulated.

Imperfect Information on Apprentice Quality Another type of private information is the ability of workers. The training firm, by having the opportunity to observe workers during the training period, has an informational advantage compared to external firms. Although external firms might observe the training intensity, the outcome might depend on both the training intensity and the ability of the worker. Several authors have addressed this issue, for example Elbaum and Singh (1995), Franz and Soskice (1995), Acemoglu and Pischke (1998, 1999a,c), Autor (2001), Boom (2001) and Clark (2002). The common feature of most models it the assumption that training raises productivity more for high ability workers than for low ability workers. That is, training and ability are complements. After the training period, the high ability workers are offered the market wage and the low ability workers dismissed or offered such a low wage that they will quit. However, some of the high ability workers will also leave for exogenous reasons. Acemoglu 


\section{CHAPTER 2. WHY DO FIRMS SUPPLY APPRENTICESHIPS?}

and Pischke (1999a,c) show that in a competitive labour market the equilibrium market wage will equal the expected productivity of an externally hired worker. The expected profits on externally hired workers are therefore zero. Furthermore, since the market wage is lower than the productivity of high ability workers, the firm earns a surplus on internally trained high ability workers. It follows directly that the surplus on trained high ability workers increases with the level of training $\left(\frac{\partial \mathcal{W}}{\partial h_{g}}>0\right)$ and therefore firms will invest in training.

Franz and Soskice (1995) provide some arguments why unobserved ability differences between workers is an important reason for German employers to train apprentices. In Germany, it is very costly to fire skilled workers. Thus, externally hired workers that turn out to be of low ability cannot easily be dismissed. Apprentices, on the other hand, can be dismissed after the training period at no cost. This explanation suggests that the apprenticeship system should be more common in countries in which the labour market is highly regulated. In general, this seems to be the case, but with some notable exceptions. However, using apprenticeships as a means to select the best workers is a costly method if the training period is relatively long or if the proportion of low ability workers is high.

Small Market for Skills Becker (1964) admitted that the dichotomy general-firm-specific is not applicable for all types of training. He states that 'some training may be useful not in most firms nor in a single firm, but in a set of firms defined by product, type of work, or geographical location'. Stevens (1994b, 1996) defines training that can be used in more than one firm as transferable. She argues that general training is only a special case of transferable training, that is characterised by a perfectly competitive labour market. If the labour market is not perfectly competitive Becker's results do not apply. Stevens (1994b) shows that in case of imperfect competition post-training wages will not necessarily equal marginal product. The mechanism of the model is as follows. Ex ante there is uncertainty on the value of training in the training firm and on the external market. Ex post it may turn out that the training is worth more in some firm outside the training firm than in the training firm. The worker will be employed in the firm in 


\subsection{FUTURE BENEFITS OF APPRENTICESHIP TRAINING}

which he can attain the highest productivity at a wage equal to his second highest value. This wedge between productivity and pay accrues to the firm that employs him. In the limiting case, when the number of firms where the training is of possible value approaches infinity, the difference between the highest and second highest and thus the wedge between productivity and pay approaches zero. In this model the wedge between wages and productivity does not depend on the level of transferable training, however.

Booth, Francesconi, and Zoega (2002) present a similar model as in Stevens (1996) in which there are only two firms competing for workers. In this model there is again a wedge between productivity and pay increasing in the level of training, due to the fact that there is uncertainty with respect to the preferences of workers to work for either firm. ${ }^{6}$

Acemoglu and Pischke (1999a,c) present a different model for a small market for skills. If the number of possible firms where the training has some value is limited, there is a positive probability that a worker who leaves the training firm will not find a skilled job. He would therefore be prepared to accept a job in his own trade at a wage below his productivity. In this model the wedge is again increasing in the level of training.

This explanation for a wedge between productivity and wages may have some validity for trades that have a relatively small market, such as printing trades, but less for apprenticeships in occupations that have a large market, mostly occupations that are not linked to any specific sector of industry, for example administrative occupations.

Imperfect competition can also stem from firm heterogeneity. Booth and Zoega (2000) present a model in which firms are characterised by the average quality of their workforce. Firms with a high quality workforce are able to perform more complex tasks. As a result the more complex tasks can be undertaken by a smaller number of firms than the less complex tasks. For that reason high quality firms face less competitors in the labour market than low quality firms. Due to this monopsony power high quality firms are

\footnotetext{
${ }^{6}$ In this model the retention rate depends on the wedge between wage paid in the training firm and the other firm operating on the same market. In equilibrium both wage rates are equal, so there is only a difference between productivity and market wage $(\mathcal{W}>0)$ and not between the market wage and the wage paid by the firm $(\mathcal{V}=0)$.
} 


\section{CHAPTER 2. WHY DO FIRMS SUPPLY APPRENTICESHIPS?}

prepared to invest in general training.

This explanation is more convincing for professional training (lawyers, auditors or doctors) than for apprenticeship training which usually aims at vocational training at the intermediate level.

The Role of Institutions Specific institution in a country may enable firms to appropriate part of the returns to general training. Examples are minimum wage legislation and the influence of trade unions. A minimum wage is commonly thought of as leading to less training than is socially desirable. A minimum wage applicable to the training period can prevent a firm from shifting the cost of training onto apprentices. However, a minimum wage for the post training period may be an incentive for firms to provide general training (Acemoglu and Pischke, 1999b). This would be the case if, due to other labour market distortions, the wage the firm would otherwise pay is strictly lower than the marginal productivity of the worker. Firms then have an incentive to raise productivity exactly to that level for which the wage they would otherwise pay equals this minimum wage. This is the minimum level of training for which the firm can appropriate the surplus from training.

Most apprenticeship training is specific to a trade or a sector of industry. In several countries, like Germany or the Netherlands, wages in these sectors are set by collective bargaining. Collective bargaining usually decreases wage differentials between workers of different skill levels. Acemoglu and Pischke (1999c) model the extreme case where the union sets an unique wage for all skill levels. The post-training wage is then unaffected by the level of training and the increase in the wedge between productivity and pay equals the increase in productivity.

\section{Wedge between Market Wage and Wage Paid by the Training Firm $(\mathcal{V})$}

Mobility Costs Apprentices may have a preference for staying in the training firm after the training, in which case we may have $\mathcal{V}>0$. This preference may be a result of residential inertia, workers are unwilling to move too far away from their home town (Harhoff and Kane, 1997). If the number of possi- 


\subsection{FUTURE BENEFITS OF APPRENTICESHIP TRAINING}

ble employers within an geographical acceptable range is small an apprentice who wants to switch employers probably have to leave the region. Other reasons may play a role as well, for example the non-pecuniary attributes of the job in the training firm. Anticipating on these high mobility costs for ex-apprentices the firm can pay them a wage below their productivity. If the number of potential employers in the surrounding will be smaller for high skilled workers than for low skilled workers we may have $\frac{\partial m}{\partial h_{g}}>0$. Harhoff and Kane (1997) show that in Germany firms are more likely to train if there are fewer work opportunities for workers in the surroundings. ${ }^{7}$

Wage Guarantees Black and Loewenstein (1997) and Loewenstein and Spletzer (1998) show that a wage guarantee from the side of the firm can have the same positive effect on training as a minimum wage, if the value of the training (both in and outside the training firm) is uncertain ex ante. In their model the firm commits to pay at least a certain wage in the posttraining period. If the productivity of the worker turns out to be below this wage guarantee the firm may lay him off. If the productivity turns out to be above the wage guarantee the firm may choose to offer him a higher wage. The worker will quit if he receives a higher wage offer of an external firm. If the productivity of the worker in the training firm falls between the wage guarantee and his market wage there is a wedge between productivity and pay. A higher level of training increases this wedge given that the apprentice does not quit. ${ }^{8}$ A wage guarantee can be seen as a promise of the training firm to pay the apprentice the skilled wage rate upon completion of the training.

\footnotetext{
${ }^{7}$ Note the difference between the mobility cost model and the models for a small market of skills discussed in the last section. In the mobility cost model it is assumed that the worker would have difficulties to find another job in the region but would have no problem to find a job in another region, so there are enough employment opportunities but they are spread unevenly between regions. In the models for a small market for skills the worker would face difficulties to find a job everywhere.

${ }^{8}$ This model does not fit exactly in the theoretical framework presented at the begin of this section. The difference is that this model assumes that the market value of the worker $\omega$ is uncertain ex ante. For that reason a higher training level at a given wage in the training firm is not completely offset by a higher chance that the worker quits.
} 


\section{CHAPTER 2. WHY DO FIRMS SUPPLY APPRENTICESHIPS?}

\subsubsection{Empirical Evidence on Future Benefits}

For firms to have future benefits from apprenticeship training there must be a reasonable probability that the apprentice will stay in the training firm for some time after completing the training and there must be a wedge between the wage and productivity of a retained apprentice. I will first discuss some figures on average retention rates of apprentices in different countries and next I will go into the empirical evidence on a productivity-wage gap for ex-apprentices.

\section{Retention Rates}

The retention rate is an important factor in determining firms' expected profits from apprenticeship training. However, not all firms supply apprentices because of investment motives. As we saw before, some firms employ apprentices for their contribution to production. These firms will probably lay-off apprentices after the training period. Ideally, one would therefore make a distinction between quits and lay-offs. Unfortunately most data sets do not allow this distinction. However, by assuming that apprentices first accept the job offer of the training firm and subsequently search for a better job opportunity, the initial retention rate can give an indication of the lay-off rate and the subsequent mobility an indication of the quit rate.

In Germany roughly $70 \%$ of all apprentices stay for some time in the training firm after completing the training (Harhoff and Kane, 1997; Euwals and Winkelmann, 2001). The proportion of stayers varies markedly between sectors. In large firms in the industry the retention rate is much higher than in small firms that can be find mostly in the craft sector. Two third of the apprentices that initially stay leave within 3 years. After 3 years only $24 \%$ of the apprentices is still in the training firm. For firms with more than 1000 employees this is 45\% (Euwals and Winkelmann, 2001). In recent years the retention rate has decreased somewhat (Euwals and Winkelmann, 2001). In Australia the initial retention rate is quite high as well, about 85\% (Centre for Labour Market Research, 1997). But like in Germany subsequent mobility is also high (Smits and Stromback, 2001). In Britain the retention rate seems to be slightly higher. Only $16 \%$ of the apprentices is laid off at completion 


\subsection{FUTURE BENEFITS OF APPRENTICESHIP TRAINING}

of the training (Booth and Satchell, 1994). A few years later the retention rate has decreased till $45 \%$.

In other countries retention rates are lower. In the Netherlands, less than $50 \%$ of graduated apprentices is still with the training firm one and a half year after graduation (Smits, 1999). There are considerable differences between training occupations. Apprentices trained in technical and care occupations stay more often with their training firm than apprentices trained in administrative occupations. Apprentices in large firms stay more often than apprentices in small firms. From a survey among Dutch training firms it appears that the average chance that an apprentice is offered a continuation in the training firm is more than $70 \%$. It can, therefore, be concluded that far less apprentices stay than firms would like. In Denmark retention rates are not very high either, $40 \%$ to $50 \%$, depending on stage of the business cycle (Westergard-Nielsen and Rasmussen, 1997).

In France, the proportion of stayers is quite small. Less than $30 \%$ of all apprentices remain for some time with the training firms after completing the training (Vialla (1997) cited in Schwerdt (2001)). Schwerdt (2001) shows that in 1998 only $12 \%$ of the ex-apprentices was still in the training firm one year after the training. This low rate is partly due to the fact that apprentices who continue the training on a higher level in the training firm are not included in the figures. In $199829 \%$ of the apprentices continued the training and $40 \%$ of them did so in the training firm. Surprisingly the retention rate is lowest for large training firms with more than 500 employees (only 7\%). As nearly $40 \%$ of apprentices trained in large firms gets unemployed after the apprenticeship, it is clear that the majority of apprentices does not leave voluntary.

All in all it can be concluded that, with the exception of France, in most countries the lay-off rate after the apprenticeship is low but that the quit rate in subsequent years is considerable. This suggests that the training investment must be recouped shortly after completing the training. 


\section{CHAPTER 2. WHY DO FIRMS SUPPLY APPRENTICESHIPS?}

\section{Wedge between Productivity and Pay}

Empirical evidence on future benefits from training for firms is limited. A major problem is that a wedge between wages and productivity is difficult to measure as productivity is usually not observable. For that reason empirical work on the wedge between productivity and pay concentrates mainly on wage differences between workers who stay in the training firm after completing the training and workers who move to another firm. The idea is that by moving to another firm workers can ascertain the market wage $(\omega)$. If wages of stayers are higher than wages of movers, there must be a surplus on training that is shared between the worker and the training firm. Note that this approach assumes that the wedge between the market wage and the wage paid in the training firm is negative $(\mathcal{V}<0) .{ }^{9}$ If $\mathcal{V}>0$ movers would earn more than stayers so this approach neglects the mobility costs explanations for a wedge between productivity and pay. The surplus can be either due to firm-specificity of training $(\mathcal{U})$ or a wedge between external productivity and the market wage $(\mathcal{W})$ stemming from imperfect competition. A complication of this approach is that apprentices that have had an offer to stay in the training firm will only leave if the outside offer exceeds their wages in the training firm. Therefore, without correcting for this selection effect, the mover-stayers wage gap will be upwardly biased.

Having said this, we will take a closer look at the empirical results. Nearly all empirical work on this issue concerns Germany. Werwatz (1996) aimed to analyse the degree of firm-specificity of apprenticeship training by comparing wages of stayers and movers using the data set Qualifikation und Berufsverlauf 1985/86. Including only those who move voluntary and correcting for self-selection, he found that on average movers earn more than stayers. However, there is a difference between those who quit immediately or shortly after the apprenticeship and those who quit later. Early movers face a wage loss while late movers who quit after a year gain. Including lay offs the wage loss is even bigger. There are also differences between sectors. Ex-apprentices in the industry who move, on average face a wage loss while ex-apprentices in the craft sector gain by moving.

\footnotetext{
${ }^{9}$ If the firm shares the surplus with the worker then by definition $\mathcal{V}<0$.
} 


\subsection{FUTURE BENEFITS OF APPRENTICESHIP TRAINING}

Using the same data set, but without correcting for self-selection, Harhoff and Kane (1997) also found that movers earn higher wages than those who stay. However, contrary to the results of Werwatz (1996) early movers do not face a wage loss. The wage differential decreases if the time of moving is later. They also found that in the craft sector the wage differences between stayers and movers are smaller than in the industry.

Acemoglu and Pischke (1998) used the same data set to test the relevance of private information with respect to ability for the German apprenticeship system. They compared wages of stayers and movers but made a distinction between those who left the training firm to do their military's service and other quitters. The idea was that firms will retain the most able apprentices and therefor stayers are on average of higher ability than movers except for those who move for exogenous reasons, the military quitters. Therefore the proportion of low ability workers among military quitters will be equal to the proportion of low ability workers in the whole population while the proportion of low ability workers among other quitters will be much higher. It is therefore to be expected that military quitters on average earn more than other quitters but less than stayers. They found that stayers earn more than movers, and military quitters earn more than other movers although the latter difference was not statistically significant. This finding supports their hypothesis that firms train apprentices to select the most able workers later on.

Euwals and Winkelmann (2001) used the IAB employment sample and observed wages in the first job after the apprenticeship. When all graduated apprentices were included they found no difference between earnings of stayers and movers. When they considered only apprentices trained in large firms they found that stayers earn about $4 \%$ more than movers in the first job.

Clark (2001) used the Social Economic Panel to analyse the mover-stayer differential, thereby distinguishing different types of movers, those who quit and those who move for other reasons. Again it is found that movers earn more than stayers, but unlike Werwatz (1996) he found no difference between those who quit and those who move for other reasons. Similar to Harhoff and Kane (1997) he found also that early movers earn a higher wage premium 


\section{CHAPTER 2. WHY DO FIRMS SUPPLY APPRENTICESHIPS?}

than late movers. Bougheas and Georgellis (2001) used the same data set and found that movers initially earn more on average than stayers but that for stayers in large firms the situation is reversed after some years.

Concluding, it can be stated that the empirical evidence on a productivity wage gap is not unambiguous. Some studies show a positive mover-stayers differential other a negative. However, there seem to be important differences between sectors of industry and between small and large firms. There is some evidence that a productivity-wage gap for retained apprentices is more important in large firms in the industry than in small firms in the craft sector. This finding is in line with other empirical evidence suggesting that small firms in the crafts sector train apprentices because of current production motives and large firms in the industry train because of investment motives. Small firms in the craft sector often face negative net training costs and low retention rates while the opposite is true for large firms in the industry. 


\subsection{Appendix to Chapter 2}

\subsubsection{List of Symbols}

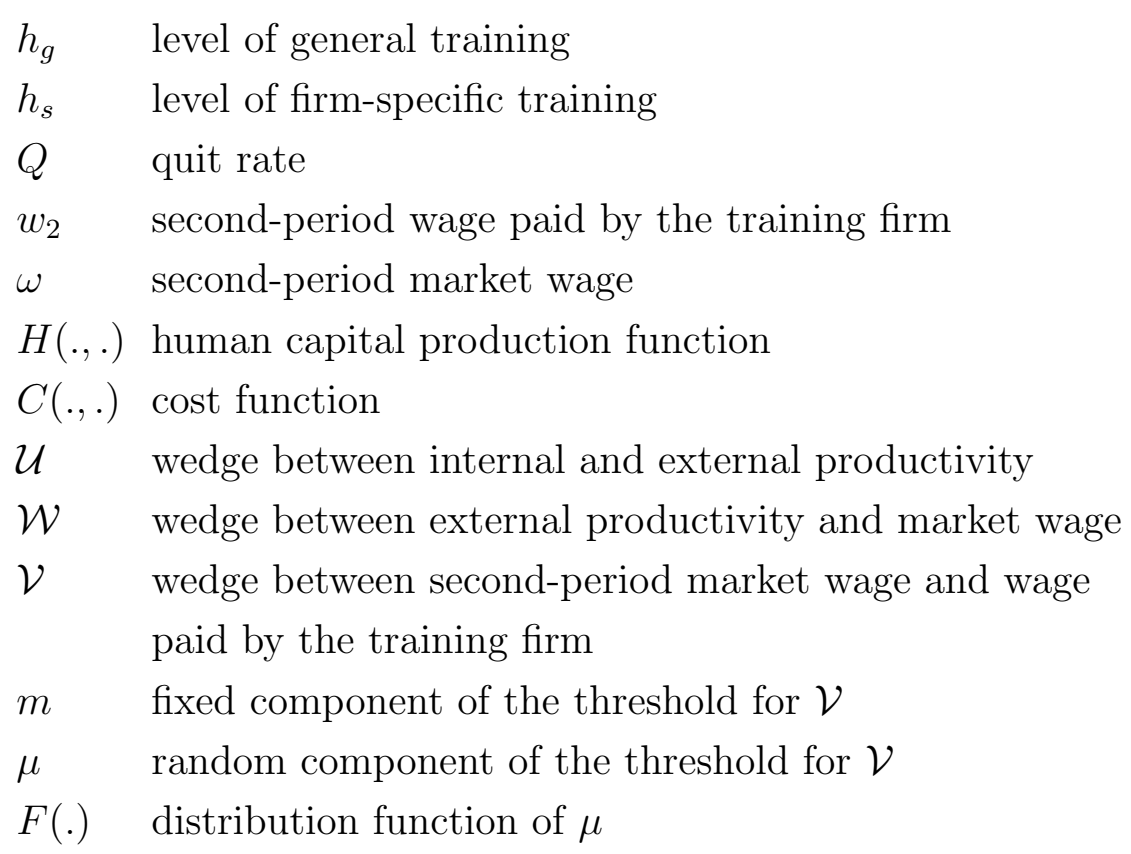


CHAPTER 2. WHY DO FIRMS SUPPLY APPRENTICESHIPS? 


\section{Chapter 3}

\section{Specific or Generic Skills?}

\subsection{Introduction}

The main part of apprenticeship training is specific to an occupation or industry. The apprentice learns to cut hair, do carpentry work or to print. The returns to specific training are to some extent uncertain. If a worker fails to find employment in the industry or occupation he is trained for, a substantial part of the training investment is lost. For that reason, workers who have to switch industries indeed suffer a significant wage loss as shown by Carrington (1993), Neal (1995) and Weinberg (2001). Apprentices therefore have an interest in acquiring not only skills that are specific to the industry or occupation, but also generic skills that have a wider applicability. ${ }^{1}$ For example academic skills such as reading, writing and mathematics, learning skills, but also basic technical skills (Bishop, 1995). If firms, on the other hand, train because of investment motives, they have little interest in providing apprentices with more training than is needed to function well in the firm. If it is up to the employer to decide, apprentices will learn few skills that are not specific to the industry or occupation they are trained for.

In this chapter I will model conflicting interests of firms and workers with respect to the training level for specific and generic skills. I will show

\footnotetext{
${ }^{1}$ See also Schimmel (1998), who presents a theoretical model for the decision to acquire universal or specific knowledge. Workers who choose universal education are able to work in more occupations and have a higher probability of obtaining and keeping a job.
} 


\section{CHAPTER 3. SPECIFIC OR GENERIC SKILLS?}

that, although it is socially optimal to have a generic training component, firms are not only unwilling to pay for generic training, they also want this component to be as small as possible, because it offers the worker better outside opportunities and forces firms in the industry to pay higher wages. At the same time, the existence of a generic component induces firms to invest in industry- or occupation-specific training. Given that firms in the industry, due to the generic component, have to pay higher wages, it pays off to increase the worker's productivity within the industry as well.

The results of my model are confirmed by the stylised facts. Oulton and Steedman (1994) argue that the content of the British Youth Training programmes is too industry-specific due to the fact that employers have a dominant influence on the curriculum. Heijke, Borghans, and Smits (2001) conclude that in the Netherlands industrial bodies for vocational education and training that develop training programmes tend to overestimate the importance of skills that are needed in the sector but do not sufficiently take into account the interindustrial mobility after the apprenticeship that demands more generic skills.

In the economic literature on training, conflicting interests of workers and firms with respect to the curriculum of the training programme receive little attention. It is acknowledged that firms tend to pay too much attention to firm-specific skills (Askildsen and Ireland, 1993), but the distinction between generic and industry- or occupation-specific skills is never made. ${ }^{2}$ Using a Beckerian framework, the distinction between specific and generic skills would be superfluous. Both types of skills can be used in external firms and can therefore be classified as general in the definition of Becker (1962), as opposed to (completely) firm-specific skills that are only useful in the training firm. Training for general skills raises the market wages of workers as much as their (marginal) productivity. The training firm cannot appropriate any of the returns to general training and as a consequence will not be prepared to bear any of the training costs either. Since it is the worker who receives the benefits from training it is also the worker who has to make the training investment. If we extend this argument to specific and generic training, the

\footnotetext{
${ }^{2}$ In the remainder of this chapter I will use the term specific skills to denote industryor occupation-specific skills.
} 


\subsection{A MODEL FOR SPECIFIC AND GENERIC SKILLS}

conclusion will be that the firm will be indifferent between the two types of training, since both types of training only have benefits for the worker. As long as workers are not credit-constrained, they will choose the optimal level of both specific and generic skills. The underlying assumption is, however, that the market for both types of skills is perfectly competitive. As we will see, this assumption will not necessarily hold for specific skills.

Some skills may be of use outside the training firm, but only in a limited number of firms or jobs. The usual properties for general training will not hold in this case. Stevens (1994b) therefore introduces the term transferable training. She states that general training is only a special case of transferable training, which is characterised by perfect competition on the market for skills. In the case of imperfect competition between firms on the labour market, wages will not rise as much as the productivity of trained workers, which means that firms can appropriate some of the returns to training. Firms therefore have an incentive to invest in transferable training. However, not only the training firm, but also external firms will profit from the training. The training firm risks to lose its trained workers to other firms and will therefore invest less than the social optimum. If the market for specific skills is not perfectly competitive, industry- or occupation-specific skills are not general, although they are transferable, and a distinction between specific and generic skills will make sense.

The model presented in this chapter is related to Stevens' model for transferable training (Stevens, 1994b). The innovation of my model is that I consider two types of transferable training, instead of one, that is generic and specific training, each of which has a different market. I will show that imperfect competition for specific skills may lead to a distortion in the mix of specific and generic skills.

\subsection{A Model for Specific and Generic Skills}

Consider a sector of industry in which $n$ firms are operating. The number of firms outside the industry is very large. Training may take place in any firm in the industry. Initially, there are many identical untrained workers in the economy. Assuming constant returns to labour, I will consider the training 


\section{CHAPTER 3. SPECIFIC OR GENERIC SKILLS?}

decision for a single worker. The world lasts two periods. The sequence of events is as follows: At the beginning of period one, it is decided how much training the worker will receive. Training takes place during the first period. During the second period, the worker will work for the firm that offers the highest wages. This may be a firm in the industry or, alternatively, a firm outside the industry.

\subsubsection{The Training Programme}

The training may consist of a specific part $h$ and a generic part $a$. It is assumed that $h$ has only value within the industry while $a$ has less value within the industry than outside the industry. The rationale behind this assumption is that a worker who moves to another sector needs generic skills, for example learning skills, to acquire the skills and knowledge required in that sector.

The value of specific training is uncertain ex ante, because firms in the industry are subject to productivity or demand shocks. There are two types of shocks namely industry- and firm-specific shocks. An industry-specific shock affects all firms in the industry in the same way, for example a demand shock. Firm-specific shocks reflect ex ante uncertainty in the match between the skills needed in the firm and the skills the worker actually possesses. Not all specific skills are equally important in all firms in the industry. At the same time, some workers will turn out to be better in one skill and others in other skills. It depends on the relative importance of the various techniques in a firm and the talent of the worker, how productive a trained worker will eventually be in a certain firm.

The firm-specific shocks $\varepsilon_{i}$ are independent and identically distributed with zero mean, finite support $[-\bar{\varepsilon}, \bar{\varepsilon}]$ and continuous distribution and density functions $F($.$) and f($.$) . The industry-specific shock \eta$ has support $\langle-\infty, \infty\rangle$ and continuous distribution and density functions $G($.$) and g($.$) , with g($. symmetric and $g^{\prime \prime}(0)<0$. The assumptions on the support of the industryspecific and firm-specific shocks ensure that there is always a positive chance that the worker will leave the industry. 


\subsection{A MODEL FOR SPECIFIC AND GENERIC SKILLS}

The productivity of a trained worker in a firm $i$ in the industry is given by:

$$
\tilde{v}_{i}=h+(1-\delta) a+\varepsilon_{i}+\eta=v_{i}+(1-\delta) a
$$

where $\delta$ is a measure for the usefulness of generic skills in the industry, $0 \leq \delta \leq 1$. For $\delta=1$ generic skills are of no use in the industry and for $\delta=0$ generic skills are fully usable in the industry. It is supposed that generic skills can always be fully used outside the industry. ${ }^{3}$ The productivity of the worker in any firm outside the industry is thus given by $a$.

Training costs depend on the level of both specific and generic training. The cost function is defined by $C(h, a)$. This function is increasing and convex in $h$ and $a$, so $\frac{\partial C}{\partial h}>0, \frac{\partial^{2} C}{\partial h^{2}}>0, \frac{\partial C}{\partial a}>0, \frac{\partial^{2} C}{\partial a^{2}}>0$. For simplicity, and without affecting the key results of the model I will assume that there is no interaction between $h$ and $a$ on the cost side, that is $\frac{\partial^{2} C}{\partial a \partial h}=0$.

\subsubsection{The Social Optimum}

The expected social return to training is determined by the probability that the worker will leave the industry after the first period. Define $v^{1} \leq v^{2} \leq$ $\cdots \leq v^{n}$ as the order statistics corresponding to $v_{1}, v_{2}, \ldots, v_{n}$.

Proposition 1 Perfect competition outside the industry ensures that industry mobility is efficient, that is if $v^{n}<\delta$ a the worker leaves the industry.

Proof. The second period market wage outside the industry is given by $\omega=a$. The best wage offer in the industry $w_{2} \leq v^{n}+(1-\delta) a$. If $v^{n}<\delta a$, we have $w_{2}<a$. If $v^{n} \geq \delta a$, there is at least one firm in the industry that can make non-negative profits by offering a wage $w_{2} \geq a$.

\footnotetext{
${ }^{3}$ So, the value of generic skills may be greater outside the industry than inside the industry. One plausible reason for this is that generic skills that facilitate the acquisition of new skills, for example learning skills, once the trade has been learned, are more important outside the industry than inside the industry, since a worker who moves to another industry has to acquire some new skills and knowledge to function well, for example through learning by doing.
} 


\section{CHAPTER 3. SPECIFIC OR GENERIC SKILLS?}

The expected social return is given by:

$$
R=E\left[v^{n}+(1-\delta) a \mid v^{n} \geq \delta a\right] \operatorname{Pr}\left[v^{n} \geq \delta a\right]+a \operatorname{Pr}\left[v^{n}<\delta a\right]
$$

and the probability that a worker will leave the industry by:

$$
\begin{aligned}
\operatorname{Pr}\left[v^{n}<\delta a\right] & =\operatorname{Pr}\left[v^{n}<\delta a, \eta>\delta a-h-\bar{\varepsilon}\right]+\operatorname{Pr}[\eta<\delta a-h-\bar{\varepsilon}] \\
& =\int_{\delta a-h-\bar{\varepsilon}}^{\delta a-h+\bar{\varepsilon}} F^{n}(\delta a-h-\eta) g(\eta) \mathrm{d} \eta+G(\delta a-h-\bar{\varepsilon})
\end{aligned}
$$

since for $\eta<\delta a-h-\bar{\varepsilon}$ the maximum productivity in the industry is always below the productivity outside the industry $\left(\operatorname{Pr}\left[v^{n}<\delta a \mid \eta<\delta a-h-\bar{\varepsilon}\right]=1\right)$. If the industry-specific shock is sufficiently small, the firm-specific shock has no effect on the probability of moving.

Proposition 2 The probability of leaving the industry is strictly positive and decreasing in the level of specific training $(h)$ and the number of firms in the industry ( $n$ ) and increasing in the level of generic training (a).

\section{Proof.}

$$
\begin{aligned}
\lim _{n \rightarrow \infty} \operatorname{Pr}\left[v^{n}<\delta a\right] & =G(\delta a-h-\bar{\varepsilon})>0 \\
\frac{\partial \operatorname{Pr}\left[v^{n}<\delta a\right]}{\partial h} & =-\int_{\delta a-h-\bar{\varepsilon}}^{\delta a-h+\bar{\varepsilon}} f_{n}(\delta a-h-\eta) g(\eta) \mathrm{d} \eta<0 \\
\frac{\partial \operatorname{Pr}\left[v^{n}<\delta a\right]}{\partial a} & =\int_{\delta a-h-\bar{\varepsilon}}^{\delta a-h+\bar{\varepsilon}} f_{n}(\delta a-h-\eta) g(\eta) \mathrm{d} \eta>0 \\
\frac{\partial \operatorname{Pr}\left[v^{n}<\delta a\right]}{\partial n} & =-\int_{\delta a-h-\bar{\varepsilon}}^{\delta a-h+\bar{\varepsilon}} \log (F(\delta a-h-\eta)) F^{n}(\delta a-h-\eta) g(\eta) \mathrm{d} \eta<0
\end{aligned}
$$

where $f_{n}=n f(). F(.)^{n-1}$

Proposition 3 The expected social marginal return to specific training is equivalent to the probability that the worker stays in the industry and the expected social marginal return to generic training is equivalent to one minus the value loss of one unit of generic training if the worker stays in the industry ( $\delta$ ) times the probability that the worker stays in the industry. 


\subsection{PRIVATE TRAINING DECISIONS}

Proof.

$$
\begin{aligned}
\frac{\partial R}{\partial h} & =\int_{-\infty}^{\infty}\left(1-F^{n}(\delta a-h-\eta)\right) g(\eta) \mathrm{d} \eta=\operatorname{Pr}\left[v^{n} \geq \delta a\right] \\
\frac{\partial R}{\partial a} & =(1-\delta) \int_{-\infty}^{\infty}\left(1-F^{n}(\delta a-h-\eta)\right) g(\eta) \mathrm{d} \eta+\int_{-\infty}^{\infty} F^{n}(\delta a-h-\eta) g(\eta) \mathrm{d} \eta \\
& =1-\delta \operatorname{Pr}\left[v^{n} \geq \delta a\right]
\end{aligned}
$$

Equalising the expected marginal returns to specific and generic training with marginal costs we find that the socially optimal training levels $\left(h^{*}, a^{*}\right)$ are the ones that provide

$$
\begin{aligned}
& \frac{\partial C}{\partial h}=\operatorname{Pr}\left[v^{n} \geq \delta a\right] \\
& \frac{\partial C}{\partial a}=1-\delta \operatorname{Pr}\left[v^{n} \geq \delta a\right]
\end{aligned}
$$

It is clear that even if the number of firms in the industry were very large and generic training had no value in the industry (e.g. $\delta=1$ ), it would be socially optimal for workers to learn some generic skills.

\subsection{Private Training Decisions}

The social optimum will not be attained if the private profits of the agents who decide on training do not coincide with the social profits. To examine whether private training decisions deviate from the social optimum we need to know how the returns to training are shared between the worker and the firm that employs him. From Proposition 1 it follows that a worker who stays in the industry will earn a wage which lies somewhere between the outside option $a$ and the highest match in the industry $v^{n}+(1-\delta) a$. The final wage outcome does also depend on the second highest match in the industry.

Proposition 4 If the worker's value is highest in the industry then competition in the industry ensures that if $v^{n-1} \geq \delta a$ the best wage offer in the industry will be $w_{2}=v^{n-1}+(1-\delta) a$ and if $v^{n-1}<\delta a \leq v^{n}$ it will be $w_{2}=a$. 


\section{CHAPTER 3. SPECIFIC OR GENERIC SKILLS?}

Proof. Stevens (1994b) shows that the following strategy for firm $i$ ( $i=$ $1, \ldots n)$ is a Nash equilibrium: if $v_{i}=v^{n}$ offer a wage $w_{2}=\kappa+\epsilon$; otherwise $w_{2}=v_{i}$. Where $\kappa$ is the second highest value of the worker in the economy, that is if $v^{n-1} \geq \delta a$ then $\kappa=v^{n-1}$ and if $v^{n-1}<\delta a \leq v^{n}$ it will be $\kappa=a$.

Table 3.1: Labour market outcomes

\begin{tabular}{llll}
\hline \hline & value specific skills & & returns \\
$v^{n}$ & $v^{n-1}$ & worker & firm \\
\hline$v^{n}<\delta a$ & & $a$ & 0 \\
$v^{n} \geq \delta a$ & $v^{n-1}<\delta a$ & $a$ & $v^{n}-\delta a$ \\
$v^{n} \geq \delta a$ & $v^{n-1} \geq \delta a$ & $v^{n-1}+(1-\delta) a$ & $v^{n}-v^{n-1}$ \\
\hline \hline
\end{tabular}

Table 3.1 summarises the different labour market outcomes. The expected return to the worker $R_{w}$ is given by:

$$
\begin{aligned}
R_{w}= & E\left[v^{n-1}+(1-\delta) a \mid v^{n-1} \geq \delta a\right] \operatorname{Pr}\left[v^{n-1} \geq \delta a\right] \\
& +a \operatorname{Pr}\left[v^{n-1}<\delta a\right]
\end{aligned}
$$

The total expected return to firms in the industry:

$$
\begin{aligned}
R_{f}= & E\left[v^{n}-v^{n-1} \mid v^{n-1} \geq \delta a\right] \operatorname{Pr}\left[v^{n-1} \geq \delta a\right] \\
& +E\left[v^{n}-\delta a \mid v^{n-1}<\delta a \leq v^{n}\right] \operatorname{Pr}\left[v^{n-1}<\delta a \leq v^{n}\right]
\end{aligned}
$$

Since there is no firm-specific training component, ex ante all firms in the industry have equal probability to employ the worker in the second period and the expected return to an individual firm $i$ is given by $R_{f} / n$. Note that the expected return to the training firm does not exceed the expected return to any other firm in the industry. The return to firms outside the industry is zero, because these firms pay the worker his full productivity.

Proposition 5 Part of the marginal expected return to specific training accrues to firms in the industry 


\subsection{PRIVATE TRAINING DECISIONS}

Proof. The expected private marginal returns with respect to $h$ are equal to:

$$
\begin{aligned}
& \frac{\partial R_{w}}{\partial h}=\operatorname{Pr}\left[v^{n-1} \geq \delta a\right] \\
& \frac{\partial R_{f}}{\partial h}=\operatorname{Pr}\left[v^{n-1}<\delta a \leq v^{n}\right]
\end{aligned}
$$

Note that this result is in contrast to Stevens (1994b), where the marginal benefit of transferable training fully accrues to the worker. The reason for this difference is that in my model, due to the option to work outside the industry, an increase in the level of specific training will not always lead to an increase in the worker's second-period wages. Black and Loewenstein (1997) and Loewenstein and Spletzer (1998) obtain a similar result for a minimum-wage guarantee for the post-training period given by the training firm. They show that if the firm has to pay a certain minimum wage in the post-training period, it can increase its profits by increasing the productivity of the worker by just as much as is possible without increasing the chance that the worker will leave the training firm. Acemoglu and Pischke (1999c) also show that the existence of minimum wages provides an incentive for firms to provide transferable training in order to increase the worker's productivity level to the minimum wage level. In this respect, the outside option for the worker in my model, $\omega=a$, acts as a minimum wage, but while in Acemoglu and Pischke (1999c) this minimum wage is exogenously given, here it is endogenous to the model as it depends on the level of generic training. As long as $v^{n-1}<\delta a \leq v^{n}$, the worker stays in the industry and the firm that employs him has to pay wages equal to $a$, in which case the conditional return increases in $h$.

Proposition $\left.6 \frac{\partial R_{f}}{\partial h}\right|_{h=0}$ attains a maximum for $a>0$.

Proof. It is proved in the appendix that $\left.\frac{\partial^{2} R_{f}}{\partial h \partial a}\right|_{\substack{a=0 \\ h=0}}>0$ and $\frac{\partial^{3} R_{f}}{\partial h \partial a^{2}}<0$.

As the level of generic training increases, the chance that the worker will be paid the minimum-wage guarantee increases, but the chance that the 


\section{CHAPTER 3. SPECIFIC OR GENERIC SKILLS?}

worker will stay in the industry decreases. If the chance that the worker will stay in the industry approaches zero, for example if $a$ becomes very large, the effect of the minimum-wage guarantee on $h$ diminishes. Note that for $\delta=0$, the effect of the outside option is independent of $a$. Generic training is worth just as much in the industry as outside the industry, but the option to leave the industry still acts as a minimum-wage guarantee.

Proposition 7 For $\delta>0$, the expected marginal return to generic training for the worker is greater than the expected social marginal return and the expected marginal return to firms in the industry is negative.

Proof. The expected private marginal returns with respect to $a$ are equal to:

$$
\begin{aligned}
& \frac{\partial R_{w}}{\partial a}=1-\delta+\delta \operatorname{Pr}\left[v^{n-1}<\delta a\right] \\
& \frac{\partial R_{f}}{\partial a}=-\delta \operatorname{Pr}\left[v^{n-1}<\delta a \leq v^{n}\right]
\end{aligned}
$$

Given the level of specific training, an increase in the level of generic training increases the outside option for workers more than their productivity in the industry and thus decreases the expected returns to firms.

Proposition 8 If $n$ becomes very large, the marginal benefits of specific and generic training of the worker approach the social marginal benefits and the marginal benefit of the firms in the industry approaches zero.

Proof. We have

$$
\lim _{n \rightarrow \infty} \operatorname{Pr}\left[v^{n-1}<\delta a \leq v^{n}\right]=0
$$

Since

$$
\operatorname{Pr}\left[v^{n-1}<\delta a\right]=\operatorname{Pr}\left[v^{n}<\delta a\right]+\operatorname{Pr}\left[v^{n-1}<\delta a \leq v^{n}\right]
$$

it follows that

$$
\lim _{n \rightarrow \infty} \operatorname{Pr}\left[v^{n-1}<\delta a\right]=\lim _{n \rightarrow \infty} \operatorname{Pr}\left[v^{n}<\delta a\right]
$$

In the following subsections, I will consider the training outcomes if (1) the training firm and the worker decide jointly on training and (2) the training levels are decided at the industry level. 


\subsection{PRIVATE TRAINING DECISIONS}

\subsubsection{The Training Firm and the Worker Decide Joint- ly on Training}

Suppose that the training firm and the worker decide jointly on the levels of specific and generic training, that is training levels are chosen such that they maximise the joint profits of the firm and worker. ${ }^{4}$ Their joint private optimum is given by:

$$
\begin{aligned}
& \frac{\partial C}{\partial h}=\frac{1}{n} \operatorname{Pr}\left[v^{n} \geq \delta a\right]+\frac{n-1}{n} \operatorname{Pr}\left[v^{n-1} \geq \delta a\right] \\
& \frac{\partial C}{\partial a}=1-\delta+\delta\left(\frac{1}{n} \operatorname{Pr}\left[v^{n}<\delta a\right]+\frac{n-1}{n} \operatorname{Pr}\left[v^{n-1}<\delta a\right]\right)
\end{aligned}
$$

Proposition 9 In a labour market in which the worker and the firm decide jointly on the training program we have that, for $\delta>0$, the level of generic training will be too high and the level of specific training will be too low compared to the social optimum

Proof. The social optimum $\left(h^{*}, a^{*}\right)$ is given by (3.4) and (3.5) and the private optimum $(\hat{h}, \hat{a})$ by $(3.8)$ and (3.9). Since $C(h, a)$ is convex in $h$ and $a, \frac{1}{n} \operatorname{Pr}\left[v^{n} \geq \delta a\right]+\frac{n-1}{n} \operatorname{Pr}\left[v^{n-1} \geq \delta a\right]<\operatorname{Pr}\left[v^{n} \geq \delta a\right]$ and $\frac{1}{n} \operatorname{Pr}\left[v^{n}<\delta a\right]$ $+\frac{n-1}{n} \operatorname{Pr}\left[v^{n-1}<\delta a\right]>\operatorname{Pr}\left[v^{n}<\delta a\right]$ it follows immediately that $\hat{a}>a^{*}$ and $\hat{h}<h^{*}$

The private marginal return to specific training is below the social marginal return while the private marginal return to generic training is above the social marginal return. The reason for this is that the return to the other firms in the industry is not incorporated in the training decision. The worker always wants more generic training than is socially optimal because the level of generic training puts a lower bound on the wage he will be paid during the second period, irrespective of whether he stays in the industry or moves. For the same reason, the training firm wants to offer less generic training

\footnotetext{
${ }^{4}$ For the outcomes of the model it is not important how this is done. One scenario one could think of is that the expected benefits of the worker enter the profit function of the firm through the training wage. Assuming that the firm has all bargain power, the training wage of the worker would then be equal to the unskilled wage rate minus the expected value of the training benefits for the worker in the post-training period.
} 


\section{CHAPTER 3. SPECIFIC OR GENERIC SKILLS?}

but since the firm only accounts for its own loss and not for the loss of other firms in the industry, its weight in the training decision is low compared to that of the worker.

Furthermore, the worker wants less specific training than is socially optimal because it will only increase his expected future wage if not only his maximum productivity $\left(v^{n}\right)$ exceeds his outside productivity but also the second-best match $\left(v^{n-1}\right)$. If the second-best match does not exceed his outside value, the extra returns accrue to the firm that will employ him. This latter result is in contrast with Stevens's model where, as mentioned before, the marginal benefits of transferable training fully accrue to the worker and, as a consequence, the choice of the level of transferable training is not directly affected by the externality. ${ }^{5}$ This externality disappears if the number of firms becomes very large since $\lim _{n \rightarrow \infty} \operatorname{Pr}\left[v^{n-1} \geq \delta a\right]=\lim _{n \rightarrow \infty} \operatorname{Pr}\left[v^{n} \geq \delta a\right]$.

Note that for $\delta=0$, the expected wage increase is equal to the expected increase in productivity, both within and outside the industry. In that case, the private optimal level of generic training will be equal to the social optimum.

\subsubsection{Training Levels are Decided on at the Industry Level}

Since all firms in the industry may profit from the training, the expected profits for the industry may increase if training decisions take place on the industry level. Suppose that workers do not pay for their training and as a result do not participate in the training decision. ${ }^{6}$ For example because they are credit-constrained or because they have insufficient information on the quality of the training. Also suppose that there is a co-ordinating body that first decides on the level of training and then levies a training contribution of $\frac{1}{n} C(h, a)$ to all firms in the industry. Firms that train are refunded the training costs. So, all firms pay an equal amount of the costs of training workers, irrespective of where this training takes place. The co-ordinating body decides on the training levels by maximising profits at the industry

\footnotetext{
${ }^{5}$ Although it might be indirectly affected through the costs function.

${ }^{6}$ That is, the benefits of the worker are not allowed for in the training decision.
} 


\subsection{PRIVATE TRAINING DECISIONS}

level. The first order conditions for the private optimum in this case are given by:

$$
\begin{aligned}
& \frac{\partial C}{\partial h}=\operatorname{Pr}\left[v^{n-1}<\delta a \leq v^{n}\right] \\
& \frac{\partial C}{\partial a}=-\delta \operatorname{Pr}\left[v^{n-1}<\delta a \leq v^{n}\right]
\end{aligned}
$$

Proposition 10 If training decisions take place at the industry level than (i) there will be no generic training $(\hat{a}=0)$ and (ii) the level of specific training might be above or below the social optimum, that is $\hat{h}$ may be greater than or less than $h^{*}$.

Proof. (i) Since the right-hand side of (3.11) is negative or zero and $\frac{\partial C}{\partial a}>0$, there is no internal solution for $a$. A corner solution is given by $\hat{a}=0$. (ii) $\hat{h}$ is given by:

$$
\frac{\partial C}{\partial h}=\operatorname{Pr}\left[v^{n-1}<0 \leq v^{n}\right]
$$

and the social optimum $h^{*}$ by (3.4). In the appendix it is shown that $\operatorname{Pr}\left[v^{n-1}<0 \leq v^{n}\right]$ attains a maximum for $h<0$ and is decreasing on $[0, \infty\rangle$. Proposition 2 shows that $\operatorname{Pr}\left[v^{n} \geq \delta a^{*}\right]$ is continuous in both $h$ and $a$, increasing in $h$ and decreasing in $a$.

Furthermore $\left.\lim _{a \rightarrow \infty} \operatorname{Pr}\left[v^{n} \geq \delta a\right]\right|_{h=0}=0$. Therefore $\exists \bar{a}>0$ for which $\left.\operatorname{Pr}\left[v^{n} \geq \delta \bar{a}\right]\right|_{h=0}=\left.\operatorname{Pr}\left[v^{n-1}<0 \leq v^{n}\right]\right|_{h=0}$. If $a^{*}>\bar{a}$ then there is an interval $[0, \bar{h}]$ for which $\operatorname{Pr}\left[v^{n} \geq \delta a^{*}\right]<\operatorname{Pr}\left[v^{n-1}<0 \leq v^{n}\right]$. In that case $\hat{h}$ may be greater or less than $h^{*}$ depending on $\frac{\partial C}{\partial h}$. If $a^{*}<\bar{a}$ then $\hat{h}<h^{*}$

The industry provides no generic training since generic training lowers the expected future profits of the firms in the industry. Compared to the social optimum, the level of specific training is affected in two ways, as is illustrated by Figure 3.1. Firstly, the training firm does not allow for the expected parts of the returns to specific training that accrue to the worker $\left(\operatorname{Pr}\left[v^{n-1} \geq \delta a\right]\right)$. This direct effect, $\left(\tilde{h}-h^{*}\right)$ is negative.

Secondly, the level of generic training indirectly affects the level of specific training. The level of generic training acts as a minimum-wage guarantee and given that firms in the industry have to pay this minimum wage, profits can be increased by increasing the level of specific training. A decrease in $a$ may either increase or decrease the marginal return to specific training since 


\section{CHAPTER 3. SPECIFIC OR GENERIC SKILLS?}

it lowers the minimum-wage guarantee but also leads to less interindustrial mobility. Therefore this second effect, $(\hat{h}-\tilde{h})$, may be either positive or negative. Note that for $\delta=0$ this second effect does not occur. In that case, the lower bound on the second-period wages does not depend on the actual level of generic training. If the second effect is positive and outweighs the first effect, the private optimum for $h$ will be above the social optimum.

From (3.10) it follows that if the number of firms in the industry becomes very large, it will be optimal not to provide any specific training at all. It is only profitable for the industry to provide specific training if competition is less than perfect.

Note that the level of specific training that is chosen if training decisions take place at the industry level, exceeds the level of specific training that would be chosen by an individual training firm as an individual firm would not take into account the expected returns to other firms in the industry.

Figure 3.1: Level of specific training: the social and private optimum compared $\mathrm{MR}, \mathrm{MC}$

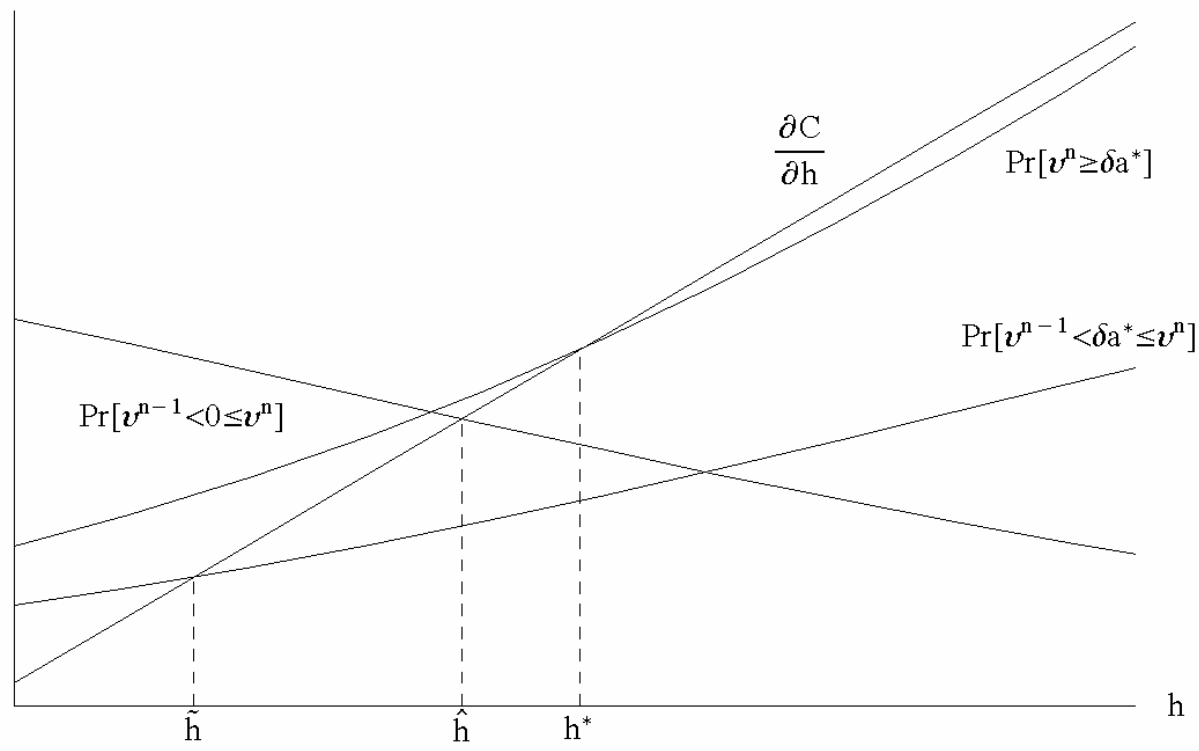

Note: The social optimal level of specific training $\left(h^{*}\right)$ is given by the intersection of the social marginal returns given $a=a^{*},\left(\operatorname{Pr}\left[v^{n}>\delta a^{*}\right]\right)$, and the marginal costs $\left(\frac{\partial C}{\partial h}\right) . \hat{h}$ and $\tilde{h}$ are the private optimal training levels for firms in the industry given $a=a^{*}$ and $a=0$. 


\subsection{DISCUSSION}

\subsection{Discussion}

In this chapter, it is shown that firms and workers have conflicting interests with respect to the curriculum of training programmes. I considered two types of skills, specific skills, which only have a value in one particular sector of industry or occupation, and generic skills, which have a value in a number of industries or occupations. Imperfect competition for specific skills allows firms in the industry to obtain a positive share of the returns to specific training. However, the expected returns to specific training for firms decrease with the level of generic training. This is because the expected future wages that firms in the industry have to pay increase more with the level of generic training than the expected productivity of workers. More generic training thus directly lowers the expected profits of firms in the industry. Therefore firms are not only unwilling to pay for generic training, they also want this training component to be as small as possible. Workers, on the other hand, want more generic training than is socially optimal at a given level of specific training.

The model also shows that the industry can increase it's profits by coordinating training activities as not only the training firm profits from the training but also the other firms in the industry. However, if workers do not have a voice in the training decision the industry will not supply any generic training at all.

The results of the model have important policy consequences for worked based systems of vocational education like the apprenticeship system. In most countries the apprenticeship system is part of the national system of secondary education and not only aims to provide young people with industryor occupation-specific skills but also with generic skills. It is clear that this aim is only attained if apprentices join in the training decision. The model thus provides a rationale for the German apprenticeship system where worker representatives have considerable influence on the content of the training programme (Lynch, 1993; Soskice, 1994). As a result, the generic training component in German apprenticeship training programs is relatively large 
CHAPTER 3. SPECIFIC OR GENERIC SKILLS?

compared to other countries (Oulton and Steedman, 1994; Finegold, Wagner, and Mason, 2000) and the training is highly transferable across a wide range of occupations (Clark and Fahr, 2001). 


\subsection{Appendix to Chapter 3}

\subsubsection{Maximum Expected Marginal Return for the In- dustry}

The expected marginal return for the industry can be rewritten as follows

$$
\begin{aligned}
\frac{\partial R_{f}}{\partial h} & =\operatorname{Pr}\left[v^{n-1}<\delta a \leq v^{n}\right] \\
& =\int_{\delta a-h-\bar{\varepsilon}}^{\delta a-h+\bar{\varepsilon}} n F^{n-1}(\delta a-h-\eta)(1-F(\delta a-h-\eta)) g(\eta) \mathrm{d} \eta \\
& =\int_{-\bar{\varepsilon}}^{\bar{\varepsilon}} n F^{n-1}(-\eta)(1-F(-\eta)) g(\delta a-h+\eta) \mathrm{d} \eta \\
& \equiv \int_{-\bar{\varepsilon}}^{\bar{\varepsilon}} F_{n, n-1}(-\eta) g(k+\eta) \mathrm{d} \eta
\end{aligned}
$$

where $k \equiv \delta a-h$. If $g($.$) has zero skewness then it follows from F_{n, n-1}(\eta)>$ $F_{n, n-1}(-\eta)$ for $0<\eta<\bar{\varepsilon}$ and $n>2$ that

$$
\begin{aligned}
& \left.\frac{\partial \int_{-\bar{\varepsilon}}^{\bar{\varepsilon}} F_{n, n-1}(-\eta) g(\eta+k) \mathrm{d} \eta}{\partial k}\right|_{k=0}=\int_{-\bar{\varepsilon}}^{\bar{\varepsilon}} F_{n, n-1}(-\eta) g^{\prime}(\eta) \mathrm{d} \eta \\
= & \delta \int_{0}^{\bar{\varepsilon}} F_{n, n-1}(-\eta) g^{\prime}(\eta) \mathrm{d} \eta+\delta \int_{-\bar{\varepsilon}}^{0} F_{n, n-1}(-\eta) g^{\prime}(\eta) \mathrm{d} \eta \\
= & -\delta \int_{-\bar{\varepsilon}}^{0} F_{n, n-1}(\eta) g^{\prime}(\eta) \mathrm{d} \eta+\delta \int_{-\bar{\varepsilon}}^{0} F_{n, n-1}(-\eta) g^{\prime}(\eta) \mathrm{d} \eta \\
> & -\delta \int_{-\bar{\varepsilon}}^{0} F_{n, n-1}(-\eta) g^{\prime}(\eta) \mathrm{d} \eta+\delta \int_{-\bar{\varepsilon}}^{0} F_{n, n-1}(-\eta) g^{\prime}(\eta) \mathrm{d} \eta=0
\end{aligned}
$$

Furthermore if $g^{\prime \prime}(0)<0$ we have

$$
\frac{\partial^{2} \int_{-\bar{\varepsilon}}^{\bar{\varepsilon}} F_{n, n-1}(-\eta) g(\eta+k) \mathrm{d} \eta}{\partial^{2} k}=\int_{-\bar{\varepsilon}}^{\bar{\varepsilon}} F_{n, n-1}(-\eta) g^{\prime \prime}(\eta) \mathrm{d} \eta<0
$$

So $\operatorname{Pr}\left[v^{n-1}<\delta a \leq v^{n}\right]$ reaches a maximum for some $k>0$. It follows immediately that $\left.\operatorname{Pr}\left[v^{n-1}<\delta a \leq v^{n}\right]\right|_{h=0}$ reaches a maximum for some $a>0$ (Proposition 6) while $\operatorname{Pr}\left[v^{n-1}<0 \leq v^{n}\right]$ reaches a maximum for some $h<0$ (Proposition 10). 


\section{CHAPTER 3. SPECIFIC OR GENERIC SKILLS?}

\subsubsection{List of Symbols}

$h \quad$ level of industry- or occupation-specific training

a level of generic training

$\varepsilon_{i} \quad$ firm-specific shock for firm $i$

$\eta \quad$ industry-specific shock

$F($.$) distribution function of firm-specific shocks$

$G($.$) distribution function of industry-specific shocks$

$\tilde{v}_{i} \quad$ productivity of a trained worker in firm $i$

$v_{i} \quad$ specific part of productivity of a trained worker in firm $i$

$\delta \quad$ measure for the usefulness of generic skills within the industry

$C(.,$.$) cost function$

$\omega \quad$ second-period market wage

$w_{2} \quad$ second-period wage in the industry

$n$ number of firms in the industry

$R \quad$ expected social return to training

$R_{w} \quad$ expected return to the worker

$R_{f} \quad$ expected return to firms in the industry 


\section{Chapter 4}

\section{Imperfect Information and Training Intensity}

\subsection{Introduction}

In Chapter 1 it was explained that firms may supply apprenticeships either because of a current production motive or because of an investment motive. In the first case, the main reason to employ apprentices is their contribution to the firm's current production. The firm then uses apprentices as a substitute for unskilled or skilled labour. In the second case, the firm trains apprentices to fulfill a future need for qualified workers.

The incentives for firms to train apprentices may impact on the quality of training places. Firms that train apprentices because of a future need for qualified workers have an interest in providing good training. Firms that have no future benefits from training are probably more interested in apprentices' current productivity than in their training (Ryan, 1994; Borghans and Smits, 1997).

Absence of future training benefits may result in apprentice exploitation if the training intensity is not perfectly observed by apprentices or not verifiable by a third party. Apprenticeship training usually comprises various components, such as courses at a training institute, training-on-the-job and learning-by-doing. Not all components are equally well observed by the apprentice. Training off-the-job in training institutes is better observed than 


\section{CHAPTER 4. IMPERFECT INFORMATION}

the 'learning-by-doing' component of the training. It will be difficult for an apprentice to judge whether certain tasks he has to fulfil are useful for his training or not. This is confirmed by research from Barron, Berger, and Black (1997a,b). A survey on training incidence and intensity among both firms and workers reveals that firms more often mention informal training such as 'informal co-worker training', workers mention more often trainingoff-the-job. Another finding is that firms report much more training than workers actually observe.

In this chapter, I will develop a theoretical model in which the training intensity or training level is not perfectly observed by the worker. The mechanism of the model is as follows. Training wages depend on the worker's observation of the training level. Since this observation is imperfect, a decrease in the training level will not be fully reflected in the training wages. The training firm can thus increase its profits by saving on training costs. As a result the training level will be below the social optimum. Both the firm and the worker would be better off if the training firm could commit to the socially optimal training level in turn for low training wages. However, as such a commitment is not credible, the worker will not be prepared to accept sufficiently low training wages. If the training is partly or entirely firm-specific, the firm will be able to share in the benefits from training and will harm itself if it decreases the training level. Thus, the underinvestment problem will be more severe to the extent that the training is more general. I will show that for this reason it may be socially optimal to ensure that part of the apprenticeship training is firm-specific even in the presence of turnover.

Several authors have considered the issue of the training level as private information of the training firm. Both Chang and Wang (1996) and Katz and Ziderman (1990) have addressed informational asymmetries not between training firms and workers, as in this chapter, but between the training firm and other firms. As an increase in the training level is not observed by other firms, it will not lead to an equivalent wage increase after the training period. Again, workers will not be prepared to share in the costs of general training but, in contrast to my model, underinvestment will be less severe as firms can now appropriate some of the future returns to general training and will 


\subsection{A MODEL FOR TRAINING}

thus invest in general training, although in the case of labour turnover the investment will still be less than the social optimum.

My model is also related to the work of Schlicht (1996) and Malcomson, Maw, and McCormick (1997), who looked at informational asymmetries with respect to the training level between firms and workers. In Schlicht (1996), the training level is private information of the training firm and trainability of the worker is unknown ex ante. In my model, all workers are similar but firms differ in training efficiency, represented by differences in training cost functions. In some firms, it may be possible to embed training activities in the production process (training on-the-job and/or learning-by-doing), while in other firms most training has to be off-the-job. This explains the considerable differences in the level of apprenticeship training provided which appear to exist between firms in, for example, Germany (Lieshout, 1996). Not only between firms in different trades, but also between large and small firms and between traditional and technologically advanced firms (Damm-Rüger, Degen, and Grünewald, 1988). I will show that if there is perfect information on training intensity, efficient training firms can provide general training and make profits, whereas in the case of imperfect information, the training level will be very low for all firms.

Malcomson, Maw, and McCormick (1997) considered the regulation of contract length to solve the underinvestment problem. If contract length exceeds the period needed to learn the trade, then the firm will have an interest in providing good quality training, since near the end of the contract the apprentice will be as productive as a skilled worker but still be receiving relatively low apprentice wages. In my model, I will consider a different solution. I will show that by making part of the training firm-specific, firms also profit from the training and as apprentices know that the firm now has less incentive to cheat, they will be prepared to accept low training wages.

\subsection{A Model for Training}

I will consider a model for training in an economy with many unskilled workers and (training) firms. Firms live infinitely and workers live two periods. Workers can either undertake an apprenticeship during their first period or 


\section{CHAPTER 4. IMPERFECT INFORMATION}

remain unskilled. Assuming constant returns to labour, I consider the training decision of a single firm and a single worker. Before the start of an apprenticeship, the worker and the firm negotiate about the worker's training wage. If they reach an agreement, the apprenticeship will start. If not, the worker will find unskilled employment in both periods.

At the beginning of the second period, the firm offers the worker a secondperiod wage. At that moment, both the training firm, the worker, and all other potential employers have complete knowledge of the worker's increase in human capital. If the worker accepts the wage offer, the employment relation continues. It is assumed that a fraction of the workers, denoted by $\gamma$, leaves for exogenous reasons. Other workers stay as long as the wage offer of the firm is not below their market wage. Assuming that the training firm possesses all bargaining power, the wage offer will equal the market wage. Since the returns to training in the training firm are always at least equal to the returns in any other firm, there is no risk of turnover due to wage differences in this model. ${ }^{1}$ Furthermore, without loss of generality, it is assumed that there is no discounting between periods.

\subsubsection{Returns to Training}

The training level, $h$, is expressed as the worker's increase in productivity. The potential productivity of the worker in the first period is given by:

$$
y_{1}=h^{0}
$$

where $h^{0}$ is the initial amount of human capital of the worker. This is the productivity that could be achieved without training. In the second period, the worker's productivity in his training firm becomes:

$$
y_{2}=h^{0}+h
$$

The human capital acquired is partly firm-specific. $\delta$ is a measure of the degree of firm-specificity of the training and is exogenous to the model,

\footnotetext{
${ }^{1}$ Unlike in many other training models (e.g. Hashimoto, 1981), there is no random component involved in the returns to training inside or outside the training firm. In models with such a random component, there is a positive probability that the returns to training are higher outside the training firm, which leads to extra turnover.
} 


\subsection{A MODEL FOR TRAINING}

$0 \leq \delta \leq 1$. For $\delta=1$ the training is wholly firm-specific and for $\delta=0$ the training is wholly general. $\delta$ is known by both the firm and the worker.

The value of the training to other firms is $(1-\delta) h$. Since the post-training wage in the training firm, $w_{2}$, will be equal to the market wage, we have

$$
w_{2}=h^{0}+(1-\delta) h
$$

It follows that the returns to training for the firm are given by $\delta h$. The worker will capture the general part of the returns, while the firm will capture the specific part of the returns to training.

\subsubsection{Training Costs}

During the first period, the firm incurs training costs. Training costs include both lost productivity as a result of the training and the costs of supervision, materials, et cetera. Even if firms all operate on the same market (produce the same goods), they may differ as to their organisational and production structure, which will be reflected in different training cost functions. Some firms may be more efficient in providing training than others, and hence training costs at a given level of training may differ between firms. These differences in costs are explained entirely by differences between firms and are not the result of differences between workers. The cost of training for a firm $i$ as a function of the training level is given by $C_{i}(h) . C_{i}(h)$ is characterised by: $C_{i}^{\prime}(0)=0, C_{i}^{\prime}(h)>0$ if $h>0$ and $C_{i}^{\prime \prime}(h)>0$. This difference in cost functions between firms implies that the optimal level of training to provide differs between firms. Workers do not know the training cost function of a particular firm.

\subsubsection{Information Structure}

Workers do not have full knowledge of the level of training provided during their apprenticeship. I have assumed that workers observe the level of training with an error. So, instead of the real training level, workers observe (see also Lang, 1994):

$$
h^{*}=h+u, E(u)=0, \operatorname{VAR}(u)=\sigma_{u}^{2}, 0 \leq \sigma_{u}^{2}<\infty
$$




\section{CHAPTER 4. IMPERFECT INFORMATION}

This observation error has zero expectation and a variance $\sigma_{u}^{2}$. If $\sigma_{u}^{2} \rightarrow$ 0 , workers can observe the training level quite well, and for $\sigma_{u}^{2}=0$ their observation is perfect. If, on the other hand, $\sigma_{u}^{2} \rightarrow \infty$, the observation $h^{*}$ gives hardly any information on the real training level. Note that it is assumed that all workers observe the same training level, which means that the observation error, $u$, in a specific firm, is equal for all workers. ${ }^{2}$ Firms do not know the observation error in advance, but they do know its variance.

Furthermore, workers know the distribution of the training output in the economy. Let $\bar{h}$ be the expected output from training. It then follows that:

$$
h=\bar{h}+e
$$

where $e$ is defined as the deviation from the expected level of training, which is $e=h-\bar{h}$. By definition $E(e)=0$. The variance in training output, given by $\sigma_{e}^{2}, 0<\sigma_{e}^{2}<\infty$, is known by both workers and firms.

Workers combine their observations of the training level in their firms with this additional information on the average output from training to obtain an optimal estimate of the training level. This optimal estimate for the level of training is given by:

$$
\widehat{h}=\lambda \bar{h}+(1-\lambda) h^{*}
$$

The optimal weight, $\lambda$, depends on the variance of the two error terms. Minimising the mean square error of the estimate $\widehat{h}$ :

$$
E(\widehat{h}-h)^{2}=\lambda^{2} \sigma_{e}^{2}+(1-\lambda)^{2} \sigma_{u}^{2}
$$

gives $\lambda=\frac{\sigma_{u}^{2}}{\sigma_{u}^{2}+\sigma_{e}^{2}}$

The more accurate the observation by workers of the training level, the more weight will be given to this observation. If information is perfect, that is $\sigma_{u}^{2}=0$, the conjectured training level is equal to the real training level. If, on the other hand, the observation is very inaccurate, workers will place more weight on the average training level in the economy and less on their observation in the firm.

\footnotetext{
${ }^{2}$ If the observation error were not firm-specific, the training firm would search for the worker with the most favourable observation of the training level.
} 


\subsection{A MODEL FOR TRAINING}

\subsubsection{Training Wages and the Participation Constraint}

It is assumed that workers participate in the costs of training by accepting lower wages than their market wages in the absence of training. If the worker does not participate in the training programme, his wage will be equal to his initial productivity in both periods. A worker will therefore be willing to participate in the training programme as long as his life-time earnings will be at least equal to $2 h^{0}$.

If information is imperfect, however, a worker will not perfectly observe the level of training and will therefore not have full knowledge of his returns to training before the start of the second period. In that case, it is not possible to have training wages completely contingent on the level of training.

Workers will use their estimation on the training level to estimate their future market wage, which I have denoted by $\widehat{w}_{2}$. Substituting $\widehat{h}$ for $h$ in (3) gives $\widehat{w}_{2}=h^{0}+(1-\delta) \widehat{h}$. As long as the estimated life-time earnings in the case of apprenticeship training are at least equal to the earnings in the case of no training, workers will participate. The participation constraint for workers is thus given by:

$$
w_{1}+\widehat{w}_{2} \geq 2 h^{0}
$$

To determine the eventual training wage outcome, it is necessary to make some additional assumptions on the wage bargaining process at the start of the first period. It is assumed that at the time of bargaining the firm has already made the training investment. The firm therefore decides on the level of training before knowing the workers' estimation of the training level. As mentioned before, the observation error is equal for all workers. Since the firm has all bargaining power, the participation constraint (4.7) is binding and the eventual training wage will be given by $w_{1}=h^{0}-(1-\delta) \widehat{h}$. The eventual wages may be very unfavourable for the training firm, but since the firm has already made the training investment, it will not withdraw its training offer if workers accept the lowest wages that satisfy their participation constraint.

Note that if the training is completely firm-specific, workers do not share in the costs of training. The firm is willing to pay the full costs of firm-specific training because there is only exogenous turnover. 


\subsection{Investment in Training}

\subsubsection{Perfect Information}

In the case of perfect information, workers know the level of training perfectly. This means that $h^{*}=h$ and $\sigma_{u}^{2}=0$. In that case, the training wage is completely contingent on the level of training and given by: $w_{1}=h^{0}-$ $(1-\delta) h$. Total profits of a firm $i$ are given by:

$$
\pi_{i}=y_{1}-w_{1}-C_{i}(h)+(1-\gamma)\left(y_{2}-w_{2}\right)
$$

If a firm is very efficient in providing training, there may exist a training level, $h>0$, for which the first-period net productivity of workers $\left(y_{1}-C_{i}(h)\right)$, exceeds the first-period wage costs. In that case, the firm will offer training even if this training is completely general and as a consequence the future benefits of training to the firm are zero.

Substituting first-period and second-period productivity and wages in (4.8) gives:

$$
\pi_{i}=(1-\gamma \delta) h-C_{i}(h)
$$

From (4.9) it follows that the profits of training for a firm are equal to the social profits of training. This is because, having all bargaining power, the training firm can appropriate the full returns from training by charging the worker a training fee equal to his returns from training. The optimal training level for the firm is found by maximising (4.9) with respect to the training level. The optimal training level is given by $h^{p}$ satisfying:

$$
C_{i}^{\prime}\left(h^{p}\right)=1-\gamma \delta
$$

Since $C_{i}^{\prime \prime}(h)>0$, it follows that $\pi_{i}^{\prime \prime}(h)<0$, for all $h$, and therefore by assumption the second order condition holds.

If the market for training were competitive, that is, if firms had equal cost functions, total benefits would equal total costs. Then, the costs of training would be shared according to the share in the benefits for both parties. So the training firm paid the firm-specific part and workers paid the general part of training, and both parties had zero profits. This is not true, however, 


\subsection{INVESTMENT IN TRAINING}

Figure 4.1: Training level under perfect information

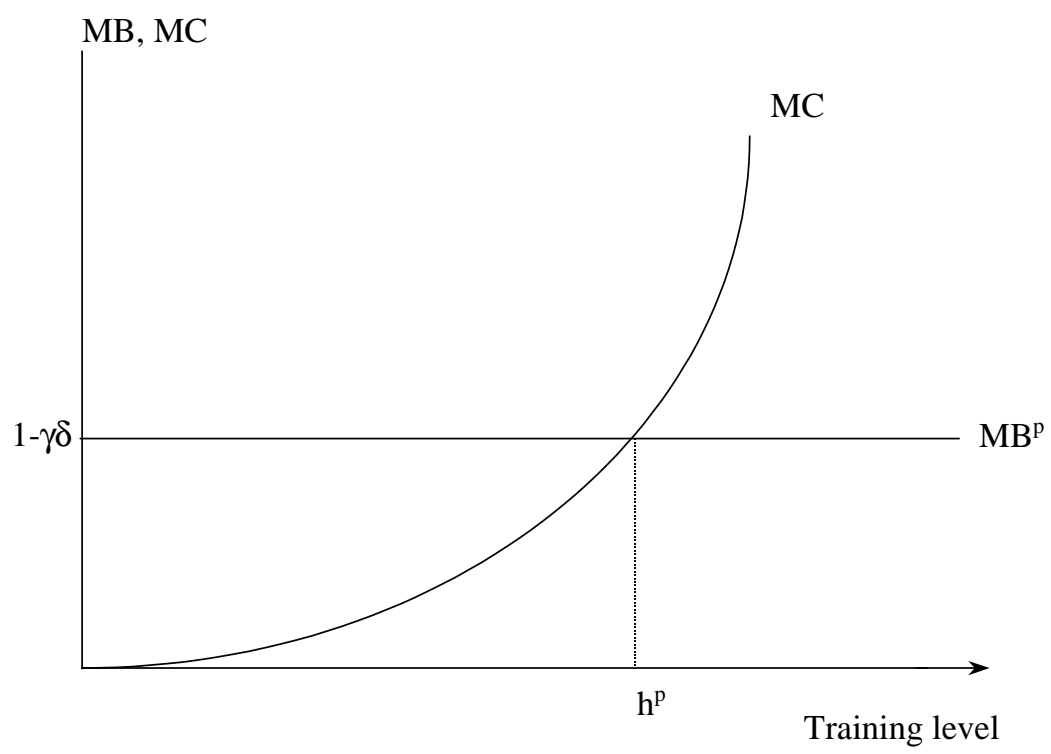

Note: The private optimal training level under perfect information $\left(h^{p}\right)$ is given by the intersection of the marginal benefits under perfect information $\left(\mathrm{MB}^{p}\right)$ and the marginal costs (MC).

if costs for a given training level differ between firms. Firms that have low training costs at a given level of training make more profits than firms that have high training costs. As mentioned above, firms can even make a profit if the training is completely general. Workers will not share in these profits as they have no bargaining power.

\subsubsection{Imperfect Information}

Under perfect information, workers have perfect knowledge of their future returns to training and are therefore prepared to pay for their training by accepting lower wages during the training period than their market wages in the case of no training. If workers do not have full knowledge of the returns, however, an increase in the level of training will not be fully reflected in the expected training wages that the firm has to pay. Maximising profits 


\section{CHAPTER 4. IMPERFECT INFORMATION}

with respect to training, the firm has to allow for the expected training wage it has to pay at a given amount of training, which is given by: $E w_{1}=$ $h^{0}-(1-\delta)(\lambda \bar{h}+(1-\lambda) h)$.

Expected profits for firm $i$ are then given by:

$$
E \pi_{i}=(1-\delta) \lambda \bar{h}+(1-\lambda+\lambda \delta-\gamma \delta) h-C_{i}(h)
$$

The first order condition of the profit maximisation problem of the firm is now given by:

$$
C_{i}^{\prime}(h)=1-\lambda+\lambda \delta-\gamma \delta
$$

Since $0 \leq \delta \leq 1$ and $0 \leq \lambda \leq 1$, it follows that the optimal training level for the firm under imperfect information is less than the optimal training level under perfect information. This can also be seen from Figure 4.2. The optimal amount of training under perfect information $(\lambda=0)$ is given by $h^{p}$. Imperfect information decreases the expected marginal returns from training for all $h$. This is because an increase in the training level does not lead to an equivalent expected decrease of the training wages. An increase in the level of training by 1 increases general human capital of the worker by $1-\delta$ and as a consequence, training wages need to fall by the same amount. Under imperfect information, however, the firm expects workers only to incorporate an increase in the training level of $1-\lambda$ in their estimation, and the expected wage decrease in the first period then equals $(1-\lambda)(1-\delta)$. Because the firm does not expect the worker to pay fully for his increase in general human capital, the marginal returns line shifts down. The optimal training level for the firm under imperfect information $(\lambda>0)$ is given by $h^{n p}$.

As $\lambda$ increases, the optimal training level for the firm decreases. Since workers only pay for an increase in their general human capital, the underinvestment problem will be more severe to the extent that the training is more general. If the training is completely firm-specific, $\delta=1$, profits depend solely on the real level of training, while if the training is completely general, the firm's profits depend solely on the conjectured training level. For $\delta=0$ and $\sigma_{u} \rightarrow \infty$ we have $h \rightarrow 0$ and $C_{i}^{\prime} \rightarrow 0$. So, imperfect information with 


\subsection{INVESTMENT IN TRAINING}

respect to the training level will lead to less training than is socially optimal and the underinvestment problem becomes more serious as the training is more general. ${ }^{3}$

Note that if the variance in training levels between firms is low, for example because the training cost functions do not differ much, we also have $\lambda \rightarrow 1$. In that case, the average training level in the industry can be much lower than the social optimum, even if the variance of the observation error is low.

Figure 4.2: Training levels under perfect and imperfect information compared

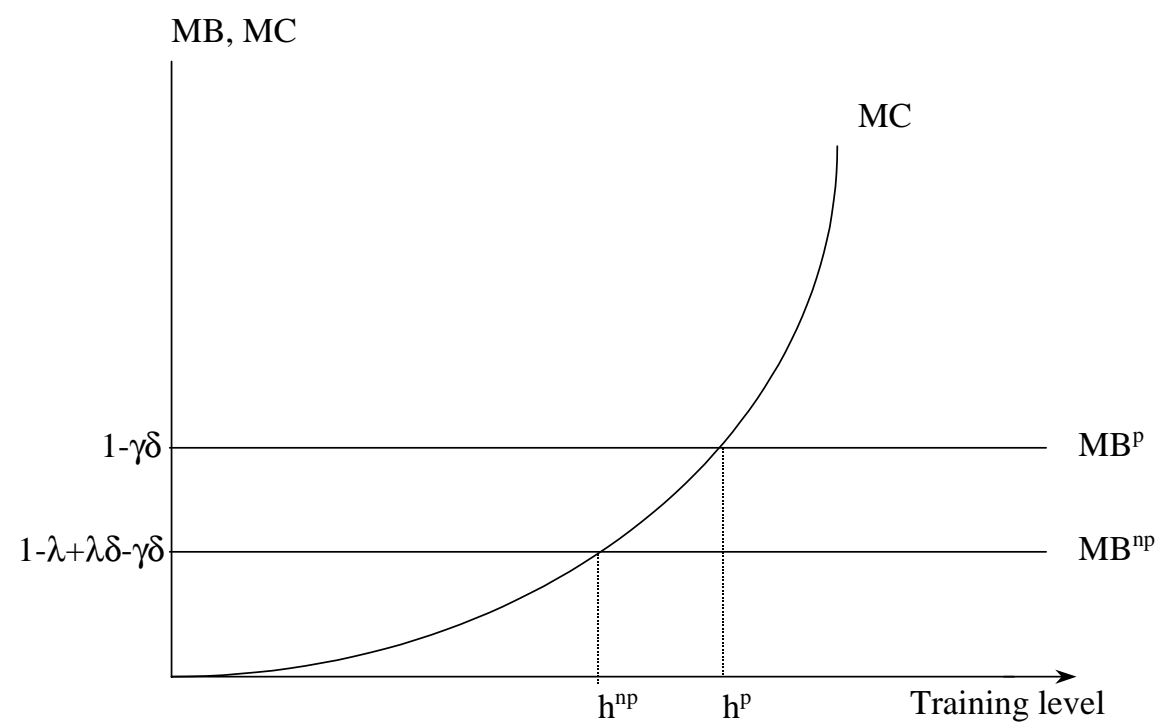

Note: The private optimal training levels under perfect and imperfect information $\left(h^{p}\right.$ and $h^{n p}$ ) are given by the intersections of the marginal benefits under perfect and imperfect information $\left(\mathrm{MB}^{p}\right.$ and $\left.\mathrm{MB}^{n p}\right)$ and the marginal costs (MC), respectively.

\footnotetext{
${ }^{3}$ Note that the assumption that the firm-specificity of the training is exogenous is of crucial importance for this conclusion. If firms could decide freely on the extent of firmspecificity of the training, they would, in this setting, choose $\delta=1$ and no underinvestment would occur.
} 


\section{CHAPTER 4. IMPERFECT INFORMATION}

The underinvestment problem cannot be solved by having the firm reveal the level of training. This is because the level of training that would be socially optimal is not credible to workers. The firm has an incentive to announce a higher level of training than it will actually provide.

\subsection{The Optimal Degree of Firm-Specificity}

The problem of underinvestment due to imperfect information is more severe when the training is more general. On the other hand, a higher degree of firm-specificity leads to a higher loss if the worker leaves after the training. The question is what degree of firm-specificity maximises social profits? Let $h(\delta)$ be the firm's optimal choice of the level of training as a function of the degree of firm-specificity following from (4.12). The social profits from training as a function of $\delta$ are then given by:

$$
\pi_{s}=(1-\delta \gamma) h(\delta)-C(h(\delta))
$$

which can be rewritten as the sum of the expected profits for the worker and the expected profits for the firm:

$$
\pi_{s}=(1-\delta) \lambda h(\delta)+(1-\lambda+\delta \lambda-\delta \gamma) h(\delta)-C(h(\delta))
$$

The first term on the right-hand side of equation (4.14) represents the part of the social profits that is appropriated by the worker. The training firm does not allow for this part when deciding on the training level. Maximisation of (4.14) with respect to $\delta$ gives the first order condition (provided that the restriction $0 \leq \delta \leq 1$ is not binding):

$$
(1-\delta) \lambda h^{\prime}(\delta)-\gamma h(\delta)=0
$$

The first term of equation (4.15) gives that part of a marginal increase in the level of training that is not paid for by the worker. A marginal increase in the degree of firm-specificity at a given training level will, however, lead to a larger loss when the worker leaves the training firm. This loss is given by the second term.

If $\lambda<\gamma$, the negative effect of the quit rate dominates the effect of incomplete information and $h^{\prime}(\delta)<0 \forall \delta$. In that case, it is never socially optimal 


\subsection{CONCLUSIONS AND POLICY IMPLICATIONS}

for training to be partly firm-specific and the solution of the optimisation problem is given by $\delta=0$. If, on the other hand, $\lambda \geq \gamma$, it will be optimal for part of the training to be firm-specific. Lastly, if all workers stay in their training firms, that is if $\gamma=0$, the solution of the optimisation problem is given by $\delta=1$.

Figure 4.3 illustrates the optimisation problem. The figure presents the social profits as a function of $\lambda$ in the case that the training is completely general, completely firm-specific or chosen as the solution of equation (4.15). The cost function is chosen to be quadratic and the quit rate is set at 10 percent. The figure shows that if the training is completely firm-specific, social profits do not depend on the degree of information incompleteness. If, on the other hand, the training is completely general, social profits decrease as information becomes more incomplete. This decrease can be partly offset by making the training partly firm-specific.

\subsection{Conclusions and Policy Implications}

This chapter investigates the impact of informational asymmetries during the training period. Workers have incomplete information on the level of training in firms. It is therefore not possible to have training wages that are contingent on the amount of training provided. As a result, training wages are too low, which, in turn, prevents firms from recouping the full benefits from training and leads to underinvestment in training.

This finding has important consequences for government policies aimed at increasing the number of apprenticeships. If such policies mainly stimulate firms without investment motives to hire apprentices, average training intensity will fall. This will be the case with, for example, wage cost subsidies for firms that employ apprentices. Wage cost subsidies make it profitable to hire apprentices but give no incentive to provide these apprentices with good training. Therefore, there is a risk that most of the additional apprenticeship places generated by these subsidies are in firms that provide little training.

To prevent underinvestment in training, informational asymmetries should be removed. Or, in other words, the variance of the observation error, $\sigma_{u}^{2}$, must be reduced. This problem could be solved with a system of 


\section{CHAPTER 4. IMPERFECT INFORMATION}

Figure 4.3: Social profits from training and the optimal degree of firm-specificity $\left(\delta^{*}\right)$ as a function of the degree of information incompleteness $(\lambda)$
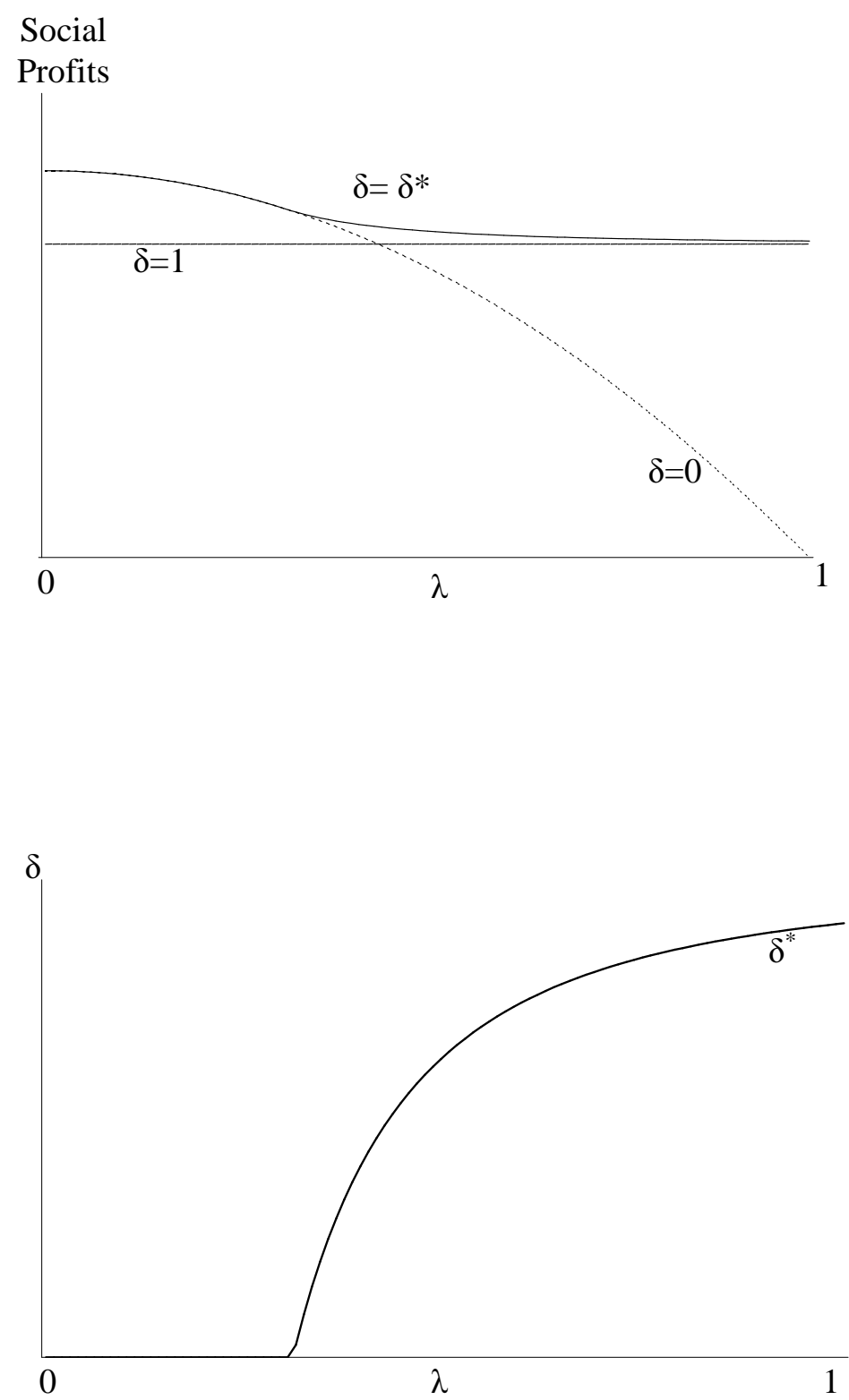

Note: Social profits are drawn for different degrees of firm-specificity of the training, namely completely firm-specific $(\delta=1)$, completely general $(\delta=0)$, and the optimal degree of firm-specificity $\left(\delta=\delta^{*}\right) . \delta^{*}$ is the degree of firm-specificity that maximises social profits at a given level of $\lambda$. 


\subsection{CONCLUSIONS AND POLICY IMPLICATIONS}

training certification, in which training standards are fixed and controlled by external bodies. If training in firms is regulated, workers are guaranteed a certain value of their training and will therefore be more prepared to accept low training wages. The case of Germany clearly supports this view. Apprenticeship training in Germany is regulated to a high degree and apprentices' wages are low (Casey, 1986; Steedman, 1993) resulting in a high level of training.

This is precisely the opposite of what Katz and Ziderman (1990) suggest. They argued that 'certification may lead to less rather than more general training' because firms would then be less prepared to finance general training, since they risk losing their investment. The problem with this argument is, of course, that it is not firms but workers who should invest in general training. Under perfect information and in the absence of any other restrictions, such as credit constraints or minimum wages, there is no reason why firms should make the investment instead of workers. If credit constraints do prevent workers from investing in their human capital, other imperfections may indeed induce firms to invest. Still, it may be more efficient to remove these credit constraints and reduce informational asymmetries.

It is, however, probably not feasible to remove informational asymmetries completely. Even if training standards were fixed, external bodies would have problems in controlling these standards. For example, if certain standards were not reached, it would not always be clear whether this was due to the firm not providing enough training or the apprentice not putting in enough effort or not being able enough. Therefore firms should be given enough freedom to adapt part of their training to their own specific needs and circumstances. That is, training standards should not aim at training that is completely general. If part of the training is firm-specific, firms will have an incentive to provide good training. 


\section{CHAPTER 4. IMPERFECT INFORMATION}

\subsection{Appendix to Chapter 4}

\subsubsection{List of Symbols}

$h \quad$ level of training

$y_{1} \quad$ first-period productivity of the worker

$h^{0} \quad$ initial amount of human capital of the worker

$y_{2} \quad$ second-period productivity of the worker

$\delta \quad$ degree of firm-specificty

$w_{2} \quad$ second-period wage

$C$ (.) training cost function of firm $i$

$\gamma \quad$ quit rate

$h^{*} \quad$ observed level of training

$u \quad$ workers' observation error

$\bar{h} \quad$ average training level

$e \quad$ deviation from average training level

$\hat{h} \quad$ estimated level of training

$\lambda$ optimal weight

$w_{1} \quad$ first-period wage

$\pi_{i} \quad$ profits of firm $i$

$\pi_{s} \quad$ social profits

$h^{p} \quad$ firm's private optimal training level under perfect information

$h^{n p} \quad$ firm's private optimal training level under imperfect information 


\section{Chapter 5}

\section{The Dutch Apprenticeship System}

\subsection{Introduction}

In the Netherlands apprenticeship training is a formal part of the national educational system. ${ }^{1}$ Figure 5.1 gives an overview of the Dutch system. After finishing primary education (BAO), at the age of twelve, pupils move on to secondary education (VO). They can either choose vocational training (VMBO) or general secondary education (HAVO or VWO). ${ }^{2}$ The latter prepares for higher professional education (HBO) and University (WO). Pupils who choose the vocational track start with pre-vocational education (VMBO) and can continue in senior secondary vocational education (MBO). In 2002 about one third of all Dutch school-leavers had a vocational qualification at the MBO-level (see Table 5.1). Most qualifications at this level can both be acquired by doing an apprenticeship (BBL) and by attending school-based education (BOL). Since 1996 both routes lead to formally equivalent diplomas (OCenW, 1996). Both routes have a practical component, for the apprenticeship route this component must be at least $60 \%$ of the study-duration, for

\footnotetext{
${ }^{1}$ This section draws mainly on a publication of the Dutch Ministry of Education (Ministry of Education, Culture and Science, 2003).

${ }^{2}$ The first two or three years of secondary education is called 'basic education' and is equal for all school types.
} 


\section{CHAPTER 5. THE DUTCH APPRENTICESHIP SYSTEM}

school-based education it must be minimal $20 \%$ and maximal $60 \%$. The theoretical part of the training is attended at a school for vocational education. About one third of the pupils at the MBO-level serves an apprenticeship. Apprenticeship training is most prominent in agriculture, technical and care occupations.

Figure 5.1: The Dutch education system

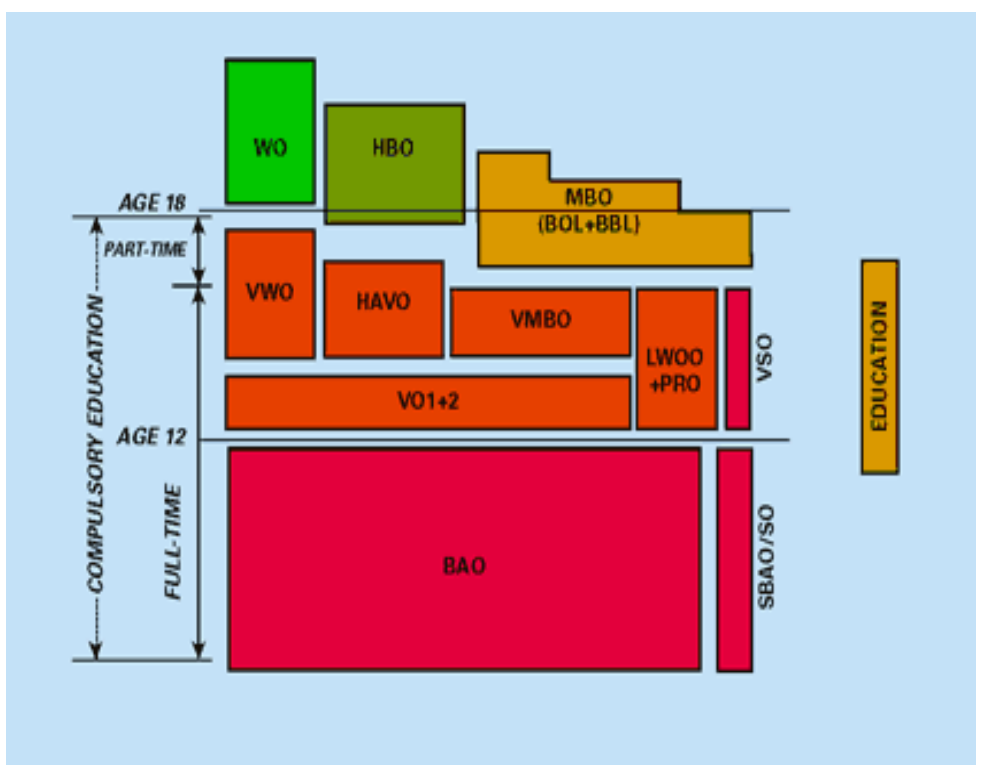

Source: OCenW

Although most people enter into an apprenticeship immediately after finishing pre-vocational education, there are also many people that choose first to work a few years before starting an apprenticeship. Very often they start the training on initiative of the firm they work for, for example because they lack the necessary skills to move up. In that case, the training has to be seen in the light of their career path. 


\subsection{ORGANISATION OF THE APPRENTICESHIP SYSTEM}

Table 5.1: Intake at the labour market: education level of 24-34 year-old, 2000

\begin{tabular}{lr}
\hline \hline Unqualified & $\%$ \\
VMBO & 10 \\
HAVO/VWO & 24 \\
MBO & 6 \\
Higher Education & 35 \\
Total & 24 \\
\hline \hline
\end{tabular}

Source: OCenW

\subsection{Organisation of the Apprenticeship Sys- tem}

On average an apprenticeship takes two till four years. Normally, the apprentice attends theoretical off-the-job training at a school for vocational education one day per week. Four levels of qualifications can be distinguished: assistant (level 1), novice tradesman (level 2), journeyman (level 3) and specialist or master tradesman (level 4).

The training is organised by industry or occupational category. For each industry there is a body for vocational education. ${ }^{3}$ The bodies are responsible for the qualification structure, the quantity and quality of apprenticeship places and the control on the examinations. The bodies are independent organisations managed by representatives of employers and employee organisations in the industry and sometimes representatives of schools for vocational education.

Apprenticeship places in the Netherlands can be subdivided into two groups; traditional apprenticeship places and new style apprenticeship places. At a traditional apprenticeship place, apprentices not only have an learning contract with their training firm, but also an employment contract. In this case, the apprentice receives a wage. These wages are usually set by sectoral agreements. This type of apprenticeship places is most prevalent in economic sectors that traditionally looked to the apprenticeship system as a means to train workers, for example the printing industry (Borghans and Smits, 1996).

\footnotetext{
${ }^{3}$ In Dutch: Kenniscentra Beroepsonderwijs Bedrijfsleven.
} 


\section{CHAPTER 5. THE DUTCH APPRENTICESHIP SYSTEM}

In the eighties the offer of apprenticeship places fell short of the demand, as a result of the economic decline in those years (Frietman, 1990). Youth unemployment was high but at the same time there was a concern that the low training incidence would lead to skill shortages in the future, when labour demand would rise again. For that reason new types of apprenticeship places were introduced in several sectors of industry. These new style apprenticeship places are less tied to the labour organisation and the production process. Usually apprentices only have a learning contract but no employment contract which means that they do not earn a salary, although sometimes they obtain some allowances depending on the firm's individual policy. So, these contracts are much cheaper for the training firm.

Another development was the coming of training co-operations. In many sectors firms started to co-operate their training activities. In that case apprentices do not have a learning contract with a single firm but with a co-operation of firms. Apprentices then circulate between the co-operating firms. The advantage of such constructions is that firms that are too small to offer apprenticeship places, for example because they do not have all the required machinery the apprentice should practice with, can still participate in the apprenticeship system.

Nowadays the share of new style apprenticeship places is substantial. In Borghans, Smits, Vlasblom, and Jacobs (2000) we show that in $30 \%$ of the training firms, apprentices only have a learning contract and $9 \%$ of the firms employ apprentices through a co-operation. The differences between economic sectors are substantial, however. In administrative occupations in the service sector, new style apprenticeships are the rule, $65 \%$ of the firms do not give their apprentices an employment contract, while in the wholesale and retail trade this is only the case for $17 \%$ of the firms. Contracts through cooperations are very common in the building trade and the hotel and catering industry.

The organisation of training and working at the apprenticeship differs between sectors and within sectors also between firms. Of course, it will also depend on the type of apprenticeship place. In traditional apprenticeship places the apprentice is an employee of the firm who takes part in the production process and usually most of the training is informal on-the-job 


\subsection{RESPONSIBILITY FOR THE QUALITY OF APPRENTICESHIPS}

Table 5.2: Type of apprenticeship contract

\begin{tabular}{lccc}
\hline \hline & $\begin{array}{c}\text { Learning } \\
\text { contract }\end{array}$ & $\begin{array}{c}\text { Learning\& } \\
\text { employment } \\
\text { contract } \\
\text { Sector of Industry }\end{array}$ & $\begin{array}{c}\text { Contract with } \\
\text { co-operation }\end{array}$ \\
\hline Industry & $\%$ & $\%$ & $\%$ \\
Garages & 36 & 51 & 12 \\
Building Trade & 21 & 64 & 10 \\
Hotel and Catering & 27 & 52 & 20 \\
Business Services & 35 & 50 & 14 \\
Wholesale/retail trade & 65 & 34 & 1 \\
Non-profit & 17 & 82 & 1 \\
Total & 50 & 41 & 9 \\
\hline \hline
\end{tabular}

Source: Borghans, Smits, Vlasblom, and Jacobs (2000)

(Frietman, 1990). In new style apprenticeship places often part of the training takes place off-the-job. Mostly the apprentice has a task book from the school that gives the practical assignments the apprentice has to fulfill in he firm.

The apprentice has a supervisor from the school and a supervisor from the training firm. The supervisor from the school visits the training firm a few times during the apprenticeship period to discuss the progress of the apprentice. The supervisor in the firm, the so-called practical trainer, is responsible for the daily supervision at the workplace. Large firms sometimes employ a full-time practical trainer. In smaller firms, on the other hand, the practical trainer is usually a craftsman who only spends part of his time on supervision.

\subsection{Responsibility for the Quality of Appren- ticeships}

Since 1996, apprenticeship training has been organised within the framework of the Adult \& Vocational Education Act (WEB) which aimed to improve the quality of education. Before the introduction of the WEB, the bodies for vocational education and training were responsible for the supervision of the 


\section{CHAPTER 5. THE DUTCH APPRENTICESHIP SYSTEM}

apprentice during the term of apprenticeship. A consultant of the concerning body visited the training firm on a regular basis to see how the apprentice was doing. Within the WEB responsibilities have shifted. The bodies are still responsible for the quantity and quality of apprenticeship places but they do not interfere with individual apprentices, this responsibility now rests with the school for vocational education. The school is also responsible for the examination of the practical component at the apprenticeship place.

Firms that want to train apprentices need to be approved by the concerning body for vocational education. Although there are some minimum criteria set by the national body for vocational education and training, the umbrella organisation of the industry bodies (see Table 5.3), the criteria for approvement differ between bodies. Some bodies have strict criteria and, for example, require practical trainers in firms to undertake special training for supervisors. A potential problem is that the bodies are both responsible for the quantity and the quality of apprenticeship places. These responsibilities may conflict with each other (Kraayvanger, 1998). Indeed, the criteria for approvement seem to be less severe in industries where less firms are prepared to participate within the apprenticeship system. For that reason there exist considerable differences in quality both between and within sectors of industry.

Given these differences between sectors, it is not surprising that the quality of apprenticeship places demands some concern. There are still many firms with a low training consciousness as stated by Frietman (1999). Especially small firms often seem to consider apprentices as cheap labour. The schools for vocational education that are responsible for the supervision of apprentices do not have the means to supervise the training in the firm intensively (Den Boer, Frietman, and Hövels, 2001). Nieuwenhuis (2001) concludes, based on interviews with managers of schools for vocational education, that the schools for vocational education leave the responsibility for the quality of the learning at the apprenticeship place to the practical trainer in the training firm. From a survey among schools for vocational education, Leenknegt (2001) also concludes that very often the apprenticeship place is of insufficient quality. Blokhuis, Jellema, and Nijhof (2002) have studied the 


\subsection{RESPONSIBILITY FOR THE QUALITY OF APPRENTICESHIPS}

quality of the apprenticeship places and internships ${ }^{4}$ of pupils of one school (ROC Eindhoven) and state that there are several problems with the quality of the apprenticeship places. Problems mentioned are that firms give priority to production, apprentices are not always given the possibility to work on their practical assignments from their task book and production tasks are not always relevant for their training.

All in all, it can be concluded that although the apprenticeship system in the Netherlands is highly regulated, the quality of apprenticeship training varies between firms. These differences in training quality mainly concern the training intensity and no so much the curriculum of the training programme. In chapters 7 and $8 \mathrm{I}$ will investigate whether these variations in training intensity, are connected to differences in training motives between firms.

\footnotetext{
${ }^{4}$ The practical component of school-based vocational education (BOL).
} 


\title{
CHAPTER 5. THE DUTCH APPRENTICESHIP SYSTEM
}

Table 5.3: Minimum criteria for recognition

\begin{abstract}
Condition 1
A company offering apprenticeships provides the apprentice with a place to work which fits within its everyday operations. In addition, the apprentice is able to practise the occupation for which he or she is being educated. A company offering apprenticeships is able to allow the apprentice to carry out (a large part of the assignments that he or she needs to have fulfilled in order to comply with the final attainment requirements (through intermediate tests).
\end{abstract}

\section{Condition 2}

A company offering apprenticeships offers students the facilities that are necessary for proper practical training. The guarantees for an optimal learning place are contained in five specific quality statements.

Statement 1

A company offering apprenticeships shall appoint a practical trainer. A practical trainer is an individual who has at least the level of subject-specific knowledge and skills for which the apprentice is being trained. In addition, the practical trainer must be able to adequately transfer professional knowledge to the student. The practical trainer may give proof of such teaching skills by submitting relevant diplomas, certificates or verifiable experience.

Statement 2

A company offering apprenticeships shall contact the apprentice's school regularly, in order to stay informed of the progress of the practical training.

Statement 3

A company offering apprenticeships shall use a practical learning plan or supervision tools to ensure that the apprentice is trained in a structured way.

Statement 4

A company offering apprenticeships shall be prepared to make time, space and resources available for practical training.

Statement 5

A company offering apprenticeships shall avail of the support of a consultant from the body for vocational education and training for its practical training. Source: Colo 


\section{Chapter 6}

\section{Measuring Training Intensity}

\subsection{Introduction}

The theoretical relationship between training motives and training intensity deduced in Chapter 4 will be tested empirically in the following chapters. To this end a measure for training intensity is needed. As learning takes place within the head of the apprentice the learning process itself is not observable. What we can (partly) observe is the firm's input and/or the output of the learning process.

Training intensity can thus be measured both in terms of input and in terms of output. Training output will not only depend on the firm's training input but also on inputs the firm cannot control, like apprentice ability or motivation. So even if we had a perfect measure for training output, it would not be clear to what extent this output is due to the firm's training input or to other (unobservable) inputs. Therefore the firm's training input is better suited to test the relation between training motives and training intensity empirically, than the training output. However, the relevance of such a relation depends on the extent to which output from training is eventually affected. Therefore both the relation between training motives and training intensity and the relation between training input and training output needs to be considered.

The economic literature on school quality shows that it is not straightforward to measure inputs in the learning process. Most inputs considered 


\section{CHAPTER 6. MEASURING TRAINING INTENSITY}

in the literature, such as the pupil/teacher ratio and indicators for teacher quality (teacher education), are not found to have much impact on schooling output (Hanushek, 2003), suggesting that other not observable school inputs are more important. The input in training is even more difficult to measure than the input in schooling because training interacts with working. It will very often be difficult to state whether certain activities are aimed at working or at learning. Moreover, not only the formal part of the training which is regulated and therefore better observable should be measured but also the less formal parts of the training programme. Indeed, training firms have more possibilities to cheat on the latter than the first. In this chapter I will give an overview of input and output measures for training (and schooling) used in the literature and I will introduce a measure for training input which explicitly takes into account the interaction of working and learning. This measure will be used to test the relation between training motives and training input. The chapter will start by deriving the empirical model for the relation between training motives and training input and the relation between training input and output that will be tested in chapters 7 and 8 .

\subsection{The Empirical Model}

Suppose the firm's profit of training an apprentice is given by:

$$
\pi_{f}(h, X, Z)=l(Z) H(h, X)-C(h)
$$

where $=H(h, X)$ represents the human capital production function, with $h$ the training input of the training firm, and $X$ the input that is exogenous to the training firm, for example the ability or motivation of the apprentice. Assume that $\frac{\partial H}{\partial h} \geq 0, \frac{\partial^{2} H}{\partial h^{2}}<0, \frac{\partial H}{\partial X} \geq 0$ and $\frac{\partial^{2} H}{\partial h \partial X}>0 . C(h)$ is the cost function, including forgone productivity and apprentice wages, ${ }^{1} \frac{\partial C}{\partial h} \geq 0$, $\frac{\partial^{2} C}{\partial h^{2}} \geq 0 . l(Z), 0 \leq l(Z) \leq 1, \frac{d l}{d Z}>0$, is a function of a an exogenous variable $Z$ that determines the part of the returns to training that can be appropriated by training firms, for example the degree of firm-specificity (see Chapter 4).

\footnotetext{
${ }^{1}$ For simplicity I assume that $C$ does not depend on $X$. This assumption does not affect the outcomes of the model.
} 


\subsection{THE EMPIRICAL MODEL}

For ease of presentation, I will refer to $Z$ as the training motive of the firm. If $l(Z)>0$, the firm has future benefits from training. It is assumed that there are constant returns to scale, so we can concentrate on the training decision for a single apprentice. The aim of the empirical chapters that follow is to find the relation between training input $(h)$ and the training motive $(Z)$. The first order condition for the firm's optimal training input is given by:

$$
l(Z) \frac{\partial H}{\partial h}=\frac{\partial C}{\partial h}
$$

The firm's input will depend positively on $Z$ since

$$
\frac{d h}{d Z}=\frac{d l}{d Z} \frac{\partial H}{\partial h}\left(\frac{\partial^{2} C}{\partial h^{2}}-l(Z) \frac{\partial^{2} H}{\partial h^{2}}\right)^{-1}>0
$$

Furthermore, if it is possible for the firm to react on $X$, training input will increase in $X$ as well since

$$
\frac{d h}{d X}=l(Z) \frac{\partial^{2} H}{\partial h \partial X}\left(\frac{\partial^{2} C}{\partial h^{2}}-l(Z) \frac{\partial^{2} H}{\partial h^{2}}\right)^{-1}>0
$$

In Chapter 4 it was assumed that $H(h, X)=h$, training input was equal to output and there where no exogenous factors, like apprentice ability, affecting training output. Although this assumption has no impact on the results of the theoretical model, it is not valid empirically. Differences in output between firms need not to be due entirely to differences in training inputs of the firm, they may also depend on factors exogenous to the training firm. If there is no data on the exogenous factors affecting training output, a regression of $H$ instead of $h$ on $Z$ will lead to overestimating the effect of $Z$. On the other hand, the relation between $h$ and $Z$ is only relevant if $h$ has indeed impact on $H$. Therefore, I will consider both the relation between training motives and training input and the relation between training input and output.

To illustrate the issue of missing data on exogenous input $X$, suppose that $H(h, X)=\frac{1}{\gamma} X^{\delta} h^{\gamma}, C(h)=h$ and $l(Z)=Z^{\rho}$. Substituting in (6.2) gives

$$
h=Z^{\alpha} X^{\beta}
$$

where $\alpha=\frac{\rho}{1-\gamma}$ and $\beta=\frac{\delta}{1-\gamma}$ 


\section{CHAPTER 6. MEASURING TRAINING INTENSITY}

Taking logs, rewriting the model in deviation form and allowing for measurement errors in training input and output, we obtain the following statistical model to be estimated.

$$
\begin{gathered}
\tilde{h}_{i j}=\tilde{Z}_{i j} \alpha+\tilde{X}_{i} \beta+\varepsilon_{i j} \\
\tilde{H}_{i j}=\tilde{h}_{i j} \gamma+\tilde{X}_{i} \delta+\eta_{i j}
\end{gathered}
$$

Where $\varepsilon_{i j}$ and $\eta_{i j}$ are independent normal distributed measurement errors (zero mean). Equation (6.6) gives the relation between training input for apprentice $i$ in firm $j$ and the training motives firm $j$ has for this apprentice, thereby controlling for the indirect effect of exogenous input for apprentice $i$. Equation (6.7) gives the relation between training output and input for apprentice $i$ in firm $j$ while controlling for the direct effect of exogenous input.

Missing Data on Exogenous Input A problem that is often encountered is that data on exogenous input $(X)$ is missing. ${ }^{2}$ Regressing $\tilde{h}$ on $\tilde{Z}$ gives the OLS-estimator $\hat{\alpha}$ with mean

$$
E(\hat{\alpha})=\alpha+\left(\tilde{Z}^{\prime} \tilde{Z}\right)^{-1} \tilde{Z}^{\prime} \tilde{X} \beta
$$

If data on exogenous input $(X)$ is missing, the OLS-estimator is biased only in the case that the training motive $(Z)$ is correlated with exogenous input $X$.

Regressing $\tilde{H}$ on $\tilde{h}$ gives OLS-estimator $\hat{\gamma}$ with mean:

$$
E(\hat{\gamma})=\gamma+\left(\tilde{h}^{\prime} \tilde{h}\right)^{-1} \tilde{h}^{\prime} \tilde{X} \delta
$$

This bias consists of two components $\left(\tilde{h}^{\prime} \tilde{h}\right)^{-1} \alpha^{\prime} \tilde{Z}^{\prime} \tilde{X} \delta$ and $\left(\tilde{h}^{\prime} \tilde{h}\right)^{-1} \beta^{\prime} \tilde{X}^{\prime} \tilde{X} \delta$. The second component will be equal to zero if $\beta=0$, that is if the firm's training input $h$ is not affected by exogenous input $X$. That is the case if firms cannot react on exogenous input $X$, for example because $X$ is not observed by firms.

\footnotetext{
${ }^{2}$ Compare Todd and Wolpin (2003) who discuss missing data issues which play a role when estimating educational production functions.
} 
Missing Data on the Firm's Training Input If there is no data available on the firm's training input $h$, the relation between training motives and training output can be estimated directly. Substituting (6.6) in (6.7) gives the relation between output and training motives.

$$
\tilde{H}_{i j}=\tilde{Z}_{i j} \gamma \alpha+\tilde{X}_{i}(\gamma \beta+\delta)+\varepsilon_{i j} \eta_{i j} \delta
$$

The effect of training motives $(Z)$ on training output $(H)$ depends both on the effect of $(Z)$ on training input $(h)$, that is $\alpha$, and the effect of training input $(h)$ on training output $(H), \gamma^{3}$ In that case, regression of $\tilde{H}$ on $\tilde{Z}$ gives an estimator $\hat{\alpha} \gamma$ with

$$
E(\hat{\alpha} \gamma)=\alpha \gamma+\left(\tilde{Z}^{\prime} \tilde{Z}\right)^{-1} \tilde{Z}^{\prime} \tilde{X}(\beta \gamma+\delta)
$$

There are two sources of a bias. First, there is a direct effect $(\delta)$ of exogenous input $(X)$ on output $(H)$. The larger the impact of $X$ on output the larger the bias. Secondly there is an indirect effect due to the effect of exogenous input $(X)$ on training input $(h)$. So, if data on $X$ is missing and there is a correlation between $Z$ and $X$ the bias of $\hat{\alpha \gamma}$ is larger than the bias of $\hat{\gamma}$.

\subsection{Training Input and Output in the Liter- ature}

\subsubsection{The Economic and Sociological literature Training Input}

The literature on the effects of school inputs on educational performance considers various inputs. Roughly two types of inputs can be distinguished, teacher quality and resources per pupil. Measures for teacher quality include teacher education, teacher experience and teacher test scores (Hanushek, 2003). The pupil/teacher ratio and expenditure per pupil are examples of resources per pupil (Card and Krueger, 1992; Hanushek, 2003). A problem

\footnotetext{
${ }^{3}$ These effects cannot be identified separately.
} 


\section{CHAPTER 6. MEASURING TRAINING INTENSITY}

of these input measures is that they do not take into account the factors that, according to educational research, matter for educational performance, like teaching methods, contact between teachers and pupils, or time spent on certain subjects (Jonker, 2001). For example, Rivkin, Hanushek, and Kain (2002) show that teacher quality matters a lot for educational performance but that the usual measures for teacher quality, like teacher education, only explain a small part of variations in teacher quality.

The input in training is even more difficult to measure because training interacts with working. Equivalent to teacher quality as a school input, the quality of the practical trainer could be taken as a measure of training input. However, while in a school the teacher will dominate the learning process, this is not necessarily true for the practical trainer at the workplace. For example, other (qualified) colleagues may also instruct the apprentice during the work. Furthermore, it is important whether the practical trainer indeed takes the time necessary to teach the apprentice. Unlike a teacher in school whose primary activity is to teach, a practical trainer often combines training activities with production activities.

Training input measures equivalent to the resources per pupil are the expenditures per apprentice ${ }^{4}$ or the time spent on training. For example, Bailey, Hughes, and Barr (1998) and Bailey and Hughes (1999) tried to measure the quality of work-based learning placements for high-school students. One measure of training input they considered, is the percentage of the internship spent on learning. A problem with this measure is that it is often difficult to decide whether an activity should be classified as a learning or a production activity, since it will often be both. For the same reason the expenditure per apprentice is also difficult to measure since not only direct costs have to be incorporated but also the opportunity costs, as emphasis on learning may be at the cost of productivity (see also the discussion of training costs in Chapter 2).

Another measure for input considered by Bailey, Hughes, and Barr (1998) is based on the characteristics of the internship. Is there a written training agreement and an individual training plan for each student? Is there any documentation of learning at the work site? Is there a supervisor in the training

\footnotetext{
${ }^{4}$ In this case, input is equal to training cost, that is $C(h)=h$.
} 


\subsection{TRAINING INPUT AND OUTPUT IN THE LITERATURE}

firm? Adding the positive responses, they obtain a measure of training intensity. An advantage of such a measure is that it takes into account more aspects of the training place. A disadvantage is that it only considers the formal aspects of the training programme, which are easily observable. Whether training actually takes place is not taken into account.

\section{Training Output}

The output from training is the apprentice's increase in human capital, that is the increase in (the level of) skills and knowledge he has. In the economic literature on educational performance, this output is either measured by standardised test scores or by labour market outcomes, like wages (Loeb and Bound, 1996). Test scores are usually not available for apprentices. If the training is completed with an examination, like in the Netherlands, the exam results can be used as a measure of training output. For example, Frietman (1990) studied the quality of different types of apprenticeship places in the Netherlands by looking at the completion rate, that is the percentage of apprentices that successfully completes an apprenticeship with a certificate of qualification.

Labour market outcomes, such as wages after the apprenticeship, can also be used as indicators of training output. However, as the training may be partly firm-specific, a distinction has to be made between ex-apprentices who move and ex-apprentices who stay because the former cannot use their firm-specific skills and knowledge anymore (Werwatz, 1996). Other labour market indicators for training output that are used in the literature are the chance to find a job after completing the training and the level of this job (Borghans and Smits, 1997; Frietman, 1990).

\subsubsection{The Educational Literature}

The educational literature emphasises the importance of the workplace as a learning environment (Resnick, 1987) but there is little empirical evidence about the optimal configuration of the workplace for learning. How should the apprenticeship place be organised to obtain the highest learning effect?

Effectiveness of the learning process will depend on characteristics of the 


\section{CHAPTER 6. MEASURING TRAINING INTENSITY}

apprenticeship place, characteristics of the apprentice and characteristics of the occupation the apprentice is trained for (Onstenk, 1997; Van der Klink, 1999; Blokhuis, 2003; Poortman, Nijhof, and Nieuwenhuis, 2003). Apprentice characteristics include qualification, experience, learning abilities and motivation (Onstenk, 1994, 1997) and intelligence, learning style, personal traits, age, gender, social economic and social cultural background and social competence (Poortman, Nijhof, and Nieuwenhuis, 2003). The occupation matters as well; a technical occupation may demand other didactics than an occupation in the care sector.

Onstenk (1997) argues that the complexity and content of the job determine the learning possibilities. The same is true for the possibility to make mistakes. Blokhuis (2003) gives an overview of factors at the workplace that may affect the effectiveness of the training. First of all, it is important that an apprentice participates at working activities and that there is an opportunity to perform and to use what is learned (interaction between theory at school and activities at the apprenticeship place). Furthermore there needs to be variation in work situations. A high work load is supposed to have a negative effect on learning because it negatively affects the time to learn. Finally interaction with others at the workplace (colleagues and supervisors) and support of colleagues ('approval of managers and employees that a student is participating in a work process as part of a learning process' which 'implies making mistakes and doing it in their own pace') are supposed to increase the effectiveness of the training. ${ }^{5}$

None of the above studies gives a definite answer to the question of how the apprenticeship place should be designed to generate optimal learning possibilities. It seems to be important that the job is complex and does not consist of routine tasks only, and there must be enough room to make mistakes. Apart from that, empirical research on this subject is still in its infancy and is far from conclusive yet.

\footnotetext{
${ }^{5}$ Blokhuis (2003) also mentions some factors that are less relevant for apprenticeship places but that will determine the learning possibilities of jobs that are not especially designed for learning. These factors include tasks obscurity (is it clear what is expected of the worker), task autonomy (level of control) and task information (with respect to results and performance).
} 


\subsection{A Novel Measure for Training Input}

Because of the interaction of work and training, training input involves more dimensions than time spent on training or the quality of a practical trainer. Training at the apprenticeship place can take different forms. It may take place on-the-job or off-the-job, it may be either formal or informal learningby-doing. For my aim, testing the relation between training input and training motives, it is important to consider all aspects of the apprenticeship place, including the informal aspects that are more difficult to observe. To measure the training input I will therefore consider the total training effort of a firm. This is the effort to organise training and work at the apprenticeship place in favour of learning. Do firms give priority to activities that are useful for the learning process or alternatively to activities that engender a high direct productivity?

I will consider various aspects of the apprenticeship place, both the productive work the apprentice is employed at and the formal parts of the training programme. From the educational literature it can be concluded that it is important that the production tasks the apprentice has to perform are sufficiently complex. So the first aspect I will consider is the complexity of production tasks. Is the apprentice introduced to all aspects of the trade or is he given simple supporting tasks in which he is directly productive?

The second aspect is the learning content of production tasks. Is the apprentice given tasks from which he can learn or tasks in which he reaches a high productivity? As the educational literature provides little evidence on the optimal configuration of the apprenticeship place I will not study the exact nature of production tasks but I will study whether they are aimed (in the view of the firm or the apprentice) at learning. I will also examine whether there is a relation between the production tasks and what is learnt at school.

The third and fourth aspect I will consider, the formal learning activities and the instruction and supervision of the apprentice in the training firm both refer to the formal part of the training programme. Is the apprentice given enough time to perform his practical assignments for school (which usually have no value for the firm). Is there enough time for instruction or 


\section{CHAPTER 6. MEASURING TRAINING INTENSITY}

supervision or is the practical trainer too busy with his own productive work.

Due to asymmetric information, the effort of the training firm is difficult to observe for the researcher. Ideally one would like to inspect the organisation of the apprenticeship place directly during a longer period. Such a method, however, is very costly to carry out on a large scale. Apart from that, there is a risk that in firms where such an inspection takes place training practices would be adjusted and training quality would be better than it had been otherwise.

To measure the training effort I therefore interviewed both ex-apprentices (Chapter 7) and training firms (Chapter 8). I formulated a number of statements concerning the organisation of training and work at the apprenticeship place and the respondents had to indicate to what extent these statements applied to their former apprenticeship place/firm. These statements try to capture the extent to which firms gives priority to learning relative to production. The exact formulation of the statements is discussed in the following chapters. 


\subsection{Appendix to Chapter 6}

\subsubsection{List of Symbols}

$\pi_{f} \quad$ firm's profit

$h \quad$ firm's training input

$X \quad$ other training input

$H(.,$.$) \quad human capital production function$

$C$ (.) training cost function

$l($.$) \quad part of the returns to training appropriated by the training firm$

$\gamma, \delta, \rho, \alpha, \beta \quad$ parameters

$i \quad$ indexes apprentices

j $\quad$ indexes firms

$\varepsilon, \eta \quad$ error terms 
CHAPTER 6. MEASURING TRAINING INTENSITY 


\section{Chapter 7}

\section{Training Intensity and Training Motives I: Evidence from Former Apprentices}

\subsection{Introduction}

In this chapter the relation between training motives and training intensity will be tested on data on former apprentices. The chapter draws upon a written survey among newly qualified apprentices in the Netherlands. Apprentices, being the recipients of the training, observe the training continuously. Ryan (1994) argues that apprentices have difficulties to assess the quality of the training at the start of the apprenticeship but that they will obtain more information during their training. Former apprentices are therefore in a good position to provide information on training input. They must be able to judge whether some tasks were useful for their training because they know what skills they learned when performing specific tasks.

To assess the training input at their former apprenticeship place, respondents received a number of items formulated as statements and were asked to indicate to what extent these statements applied to their apprenticeship place. The items tried to capture the effort of the training firm to give priority to the learning process relative to production.

Based on these items I will construct a training input measure. This 


\section{CHAPTER 7. TRAINING INTENSITY AND TRAINING MOTIVES I}

training input measure will be related to both the firm's training motives and the training output. The characteristics of the apprenticeship place will be used as an indicator for firms' training motives. I will consider two output indicators, namely the chance that the training is completed with a diploma, and the wages after the apprenticeship.

\subsection{The Survey}

The analyses in this chapter are based upon a written survey among individuals who had finished an apprenticeship in the Netherlands about a year and a half before. ${ }^{1}$ This survey, which was carried out in 1997, addressed both the situation during their apprenticeship and the current labour market position of former apprentices. About 6,000 individuals were approached, of whom 4,000 had done an apprenticeship at the lower level (level 1 or 2), and about 2,000 had done an apprenticeship at a higher level (level 3 or 4). The response was 19 percent for the first mentioned and 27 percent for the second. Eventually, this resulted in a data set with 975 respondents, of whom 747 had successfully completed the training with a certificate of qualification and 228 dropped out without a qualification. Table 7.1 shows the number of respondents by training level and training sector and presents some characteristics of the respondents. For more survey details see also Smits (1999) and Willems and Welters (1999).

A low response may affect the results if the non-response is selective. One might especially worry about a low response by those apprentices who were already with the training firm before the start of the training and had a permanent employment contract. The survey was designed for schoolleavers and is therefore less identifiable for former apprentices who entered the labour market much longer ago. However, it appears that nearly one third of the respondents already worked in the training firm before the start of the training. This number is reasonably in line with other research, so there is no evidence that this group is under-represented (Borghans, Smits, Vlasblom, and Jacobs, 2000). The sample is therefore not selective with

\footnotetext{
${ }^{1}$ This survey was part of the school-leaver survey RUBS.
} 


\subsection{ITEMS ON TRAINING INPUT}

respect to apprentices who start an apprenticeship immediately after leaving school relative to apprentices who work a few years before starting an apprenticeship. Another possible source of selectivity is the firm's training input. One could worry that apprentices who were disappointed with their apprenticeship place were less inclined to respond. Since the estimates of the relation between training motives and training input will be biased downwards in the presence of this type of selectivity they should be seen as a lower bound.

Dropouts included only those apprentices who had dropped out in their final year. It is to be expected that early dropouts will have more problems answering questions about their former apprenticeship place and have less information about the quality of the apprenticeship place. Therefore apprentices who dropped out before their final year were not included in the sample. Note that if there is a strong relation between the training input and the chances of dropping out, the average training input would be overestimated.

Table 7.1: The number of respondents by level and sector of training

\begin{tabular}{lcrr}
\hline \hline Training occupation & $\begin{array}{c}\text { Women } \\
\%\end{array}$ & Average age & $\mathrm{n}$ \\
& 40 & 25.2 & 566 \\
Apprenticeship level 1/2 & 11 & 24.7 & 305 \\
Technical & 67 & 25.0 & 198 \\
Administration & 97 & 28.2 & 63 \\
Social services & & & \\
& 37 & 26.5 & 439 \\
Apprenticeship level 3/4 & 11 & 25.3 & 246 \\
Technical & 46 & 25.3 & 97 \\
Administration & 96 & 30.8 & 96 \\
Social services & & & \\
\hline \hline
\end{tabular}

\subsection{Items on Training Input}

To investigate the effort of the firm to organise training and work in such a way that a high learning effect can be achieved, I formulated a number of 


\section{CHAPTER 7. TRAINING INTENSITY AND TRAINING MOTIVES I}

statements on items such as the training itself and the training firm. Respondents were asked to indicate for each item on a 4-point response scale to what extent it applied to their former apprenticeship place. Table 7.2 gives the distribution of each item on the response scale. Items 3 and 6 refer to the complexity of production tasks. To introduce apprentices to all aspects of the trade, they should perform the same tasks as qualified tradesmen (item 3 ). For most former apprentices, this was indeed the case. Priority to direct productivity, on the other hand, implies simple tasks in which apprentices are directly productive (item 6). Only a small proportion of the former apprentices agree that they were given the irksome tasks at the workplace.

Items 1, 2 and 4 refer to the learning content of production tasks. As can be seen from Table 7.2 , nearly $60 \%$ of the former apprentices fully agrees that their tasks in the training firm were useful for their training and $35 \%$ fully agrees that they were given special tasks to learn the job well. The relation between formal off-the-job training at school and on-the-job training in the firm appears to be less satisfying. Less than a quarter of the former apprentices fully agrees with the statement that there was a close link between the subjects dealt with at school and their tasks in the training firm.

Item 5 ('Sometimes I missed lessons at school because I was too busy with my work at the training firm') refers to time for formal learning activities. Only few former apprentices said that they missed school because it was too busy at work. Item 8 refers to instruction and supervision at the training firm. Most former apprentices seem to be quite satisfied with the supervision at the training place. Nearly half of them agreed that supervision in the training firm was good. Lastly, item 7 gives a direct measure of the quality of the training place. More than half of the former apprentices fully agree that their training firm was a good place to learn the occupation. An overall measure for the training input can be obtained by taking the average score of all the items. 


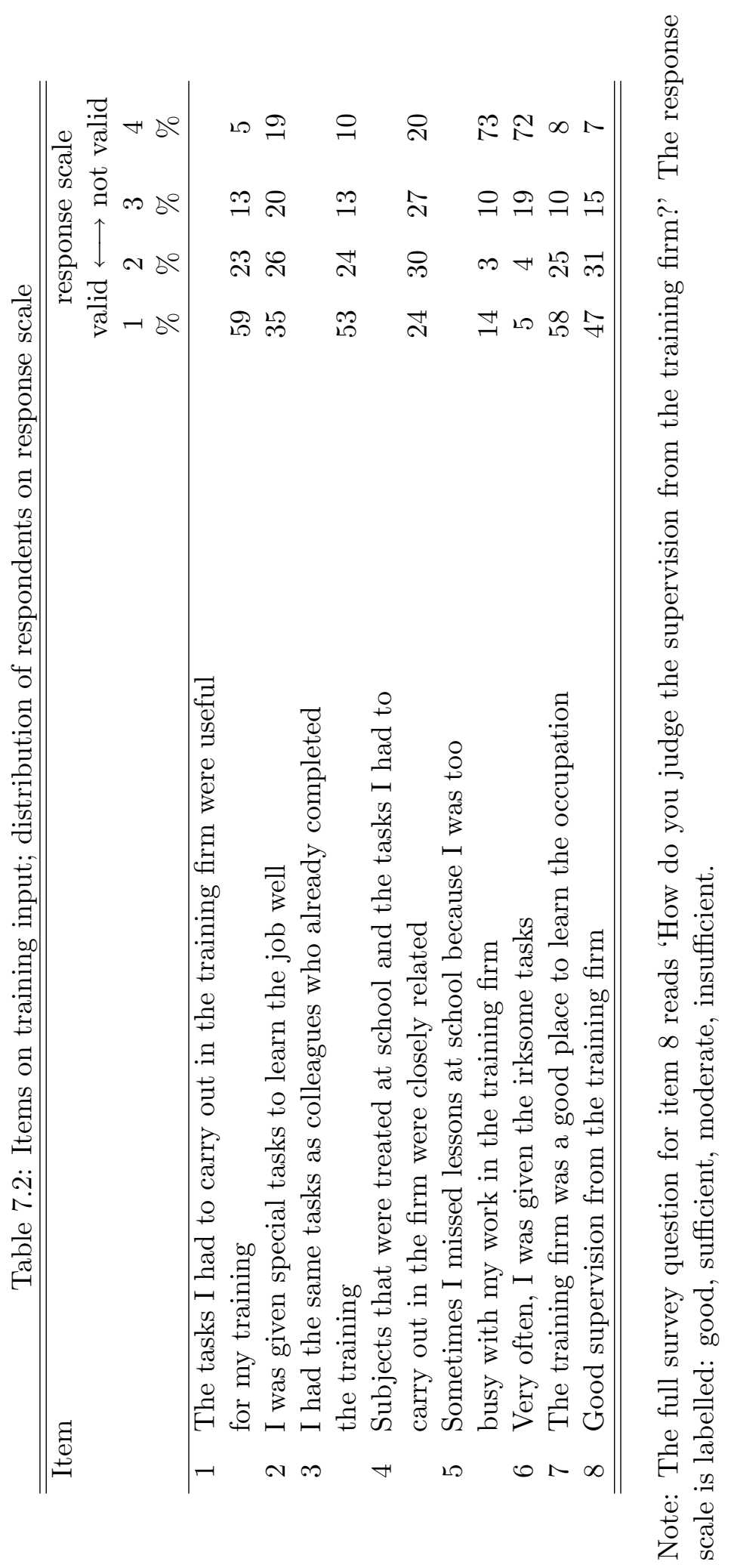




\section{CHAPTER 7. TRAINING INTENSITY AND TRAINING MOTIVES I}

To test the reliability of the scale, both the item total correlation and Cronbach's alpha were calculated. The item total correlation gives the relation between the score of a specific item and the total score. A high correlation indicates that the item concerned measures the same construct as the other items. Cronbach's alpha is a coefficient of reliability and gives the correlation between the sum of the variances of the scores for the individual items and the variance of the total score (Mueller, 1986). It measures how well a set of items measures an unidimensional underlying construct, in this case training input. Usually a coefficient of 0.7 or higher is considered acceptable (Nunnaly, 1978). If the value of Cronbach's alpha increases by leaving an item out, it can be concluded that this item does not measure the same as the total scale.

Table 7.3 shows for each item the average score $^{2}$, the standard deviation, the item total correlation and Cronbach's alpha if that item is deleted from the analysis. Both tests concluded that item 5 ('Sometimes I missed lessons at school because I was too busy with my tasks in he training firm') does not measure the same construct as the other items. The item total correlation is very low - only 0.01 - and Cronbach's $\alpha$ increases considerably if this item is deleted from the analysis. A possible explanation is that while it is difficult for third parties to judge the quality of on-the-job training, school attendance is easily observed. It is therefore much easier for training firms to save costs on on-the-job training without being perceived, than on off-the-job training. It was therefore decided to leave item 5 out of the input measure. Item 6 ('Very often I was given the irksome tasks') also has a low item total correlation, but Cronbach's $\alpha$ does not increase if we leave this item out.

As alpha gives the reliability of the scale under the assumption that the set of items is unidimensional (Cortina, 1993) additionally I conducted a principal component analysis on all items to test for the dimension of the scale. This analysis yields two components. The first component has a very low loading for item 5 and the second component has a high loading on item 5 but very low loadings on the other items. Furthermore the second component accounts for only $13 \%$ of the total variance (eigenvalue 1.049). It

\footnotetext{
${ }^{2}$ The scores of items that are negatively formulated are mirrored. A high average score indicates high training input.
} 


\subsection{ITEMS ON TRAINING INPUT}

can therefore be concluded that, apart from item 5, all items concerning the training in the firm indeed form a unidimensional reliable scale.

Table 7.3: Tests for reliability of the scale

\begin{tabular}{lcccc}
\hline \hline Item & $\begin{array}{c}\text { Average Score } \\
\text { (range 1-4) }\end{array}$ & $\begin{array}{c}\text { Standard } \\
\text { Deviation }\end{array}$ & $\begin{array}{c}\text { Item Total } \\
\text { Correlation }\end{array}$ & $\begin{array}{c}\text { Cronbach's } \alpha \\
\text { if item deleted }\end{array}$ \\
\hline 1 & 3.37 & 0.88 & 0.61 & 0.67 \\
2 & 2.76 & 1.12 & 0.51 & 0.68 \\
3 & 3.20 & 1.01 & 0.37 & 0.71 \\
4 & 2.57 & 1.05 & 0.45 & 0.70 \\
5 & 3.43 & 1.06 & 0.03 & 0.78 \\
6 & 3.57 & 0.81 & 0.32 & 0.72 \\
7 & 3.33 & 0.91 & 0.61 & 0.67 \\
8 & 3.17 & 0.94 & 0.57 & 0.67 \\
All items & & & & 0.73 \\
\hline \hline
\end{tabular}

Note: Items that are negatively formulated are first mirrored. A high average score thus means a high appreciation of the training input

An indicator for training input is then obtained by taking the average score on all items except item 5. Figure 7.1 gives the cumulative distribution of the training input indicator. If we define low training input by an average score of 2.5 (which is the median range of the response scale), then $16 \%$ of all respondents has had low training input.

In addition to the statements concerning the training place, the former apprentices were also asked about supervision at the school for vocational education. As the apprentices' progress at the training firm is supervised by the school and the school is also responsible for examinations of the practical component, the training input will to some extent also depend on the quality of the supervision by the school. Former apprentices were less satisfied with the supervision from the side of the school than with the supervision of the training firm. Only $29 \%$ said that supervision by the school was good (see Table 7.4). The item total correlation of the item concerning the supervision at school with the items concerning the training place, is 0.23 , suggesting that the supervision of the school indeed has some impact on the firm's training input. 
CHAPTER 7. TRAINING INTENSITY AND TRAINING MOTIVES I

Figure 7.1: Cumulative distribution of the training input measure

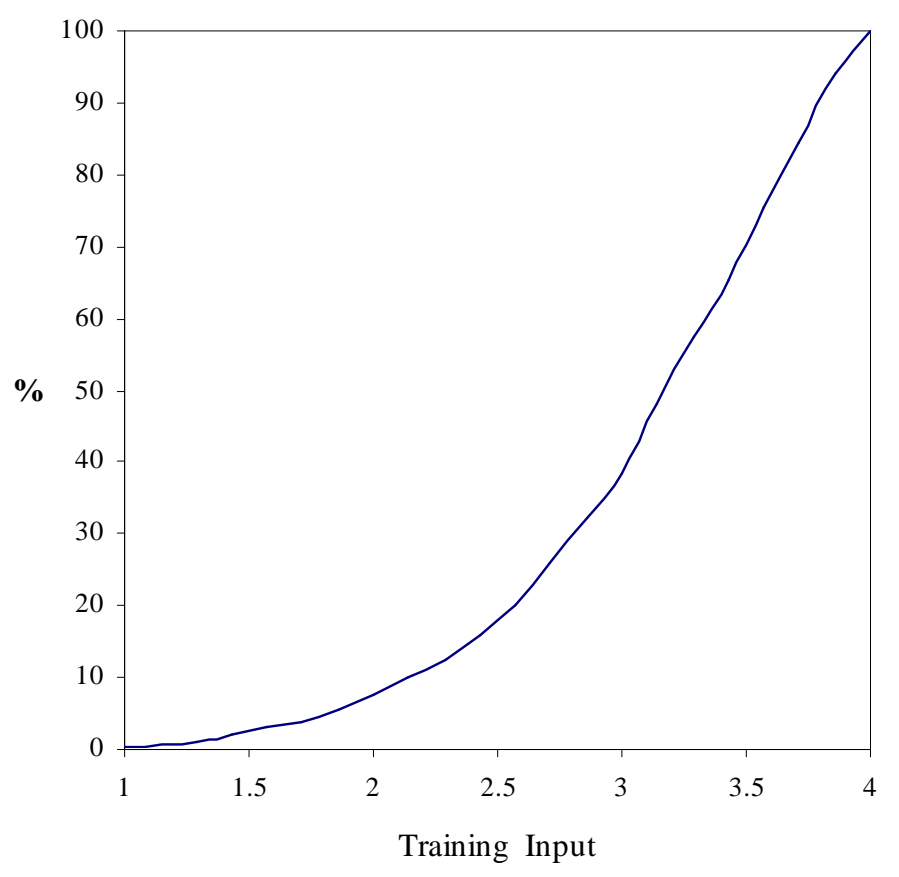

Table 7.4: Supervision from the school

\begin{tabular}{lr}
\hline \hline & $\%$ \\
\hline Good & 29 \\
Sufficient & 41 \\
Moderate & 22 \\
Insufficient & 8 \\
\hline $\mathrm{n}=858$ & \\
\hline \hline
\end{tabular}

Note: The survey question reads 'How do you judge the supervision from the school? 


\subsection{MEASURES FOR TRAINING MOTIVES}

\subsection{Measures for Training Motives}

I will use the characteristics of the apprenticeship place, the type of apprenticeship place and the type of appointment, as indicators for firms' training motives. As discussed in Chapter 5, there are two types of apprenticeship places in the Netherlands; traditional apprenticeship places and new-style apprenticeship places. Apprentices in traditional apprenticeship places have both a learning and an employment contract while apprentices in new-style places only have a learning contract. Borghans and Smits (1997) argue that firms which offer traditional apprenticeship places more often employ apprentices because of a future need for skilled workers than firms that offer new-style apprenticeship places, as they more often retain their workers. The type of appointment during the apprenticeship is an even better measure for a firm's motive for employing apprentices. It is plausible that firms which offer their apprentices permanent employment before the end of the training period, train them because of a future need for qualified labour. The same is true for firms that give apprentices a prospect of permanent employment, although it is not precluded that such firms simply want to keep the apprentice motivated to work hard. Firms that do not offer apprentices any prospect of renewal of their contract, are less likely to have investment motives.

Table 7.5: Type of apprenticeship place and type of appointment

\begin{tabular}{lc}
\hline \hline & $\%$ \\
\hline Type of apprenticeship place & \\
Traditional & 70 \\
New style; payment of expenses & 20 \\
New style; no payment of expenses & 10 \\
\hline $\mathrm{n}=896$ & \\
\hline Type of appointment during apprenticeship & 24 \\
Temporary; prospect of permanent appointment & 33 \\
Temporary; no prospect of permanent appointment & 43 \\
Permanent & \\
\hline $\mathrm{n}=845$
\end{tabular}

Note that the incidence of a permanent contract, may be correlated with apprentice ability. Apprentices who have a permanent appointment during 


\section{CHAPTER 7. TRAINING INTENSITY AND TRAINING MOTIVES I}

the training period were very often already employed in the training firm before they started the training. In that case the training firm knew the ability of the apprentice. The incidence of a temporary appointment with or without prospect on a permanent appointment is less likely to correlate with apprentice ability. If the apprentice starts working in the training firm, the firm has little information about the ability of the apprentice. ${ }^{3}$ In that case, a firm with investment motives will offer the apprentice the prospect to stay but whether it will actually retain the apprentice will of course depend on apprentice ability.

More than $40 \%$ of the respondents had already a permanent appointment during the training period (see Table 7.5). These all concerned apprentices in traditional apprenticeship places. Another $33 \%$ of the respondents were during their training period, given the prospect of obtaining permanent employment after completing their training. These also included apprentices from new-style apprenticeship places.

\subsection{Determinants of Training Input}

The training input measure has been regressed on the indicators for training motives. ${ }^{4}$ Control variables included in the analysis are; personal characteristics (age, gender and origin, previous education), training characteristics (training level and occupational group), characteristics of the training firm (firm size, sector of industry) and a dummy for good or sufficient supervision from the side of the school.

Table 7.6 shows the estimation results. The type of appointment indeed affects the training input in the way that was expected. Those who had a temporary appointment without any prospect of this becoming permanent

\footnotetext{
${ }^{3}$ Indeed, several economists suggest that it is only during the training period that the real capacities of apprentices are revealed. They argue that the main reason for firms to train apprentices is to select the best among them to stay after completing their training (Franz and Soskice, 1995; Acemoglu and Pischke, 1998).

${ }^{4}$ Strictly speaking the training input measure has no metrical scale. It can take on 22 values with a minimum of 1 and a maximum of 4 . For that reason it makes little sense to estimate a model in logarithms like the example in Chapter 6.
} 


\subsection{DETERMINANTS OF TRAINING INPUT}

after completing their training, received lower training input than those with a permanent appointment or a prospect of a permanent appointment, indicating that there is indeed a relation between training motives and training input.

Table 7.6: Determinants of training input (average score)

\begin{tabular}{|c|c|c|c|}
\hline & (1) & $(2)$ & $(3)^{a}$ \\
\hline Traditional apprenticeship & & $\begin{array}{c}0.104 \\
(0.094)\end{array}$ & $\begin{array}{c}-0.081 \\
(0.131)\end{array}$ \\
\hline New style (expenses) & & $\begin{array}{l}0.239 \\
(0.096) * *\end{array}$ & $\begin{array}{c}0.101 \\
(0.129)\end{array}$ \\
\hline New style (no expenses) & & -Reference- & \\
\hline Temporary appointment (prospect) & & $\begin{array}{c}0.025 \\
(0.062)\end{array}$ & $\begin{array}{c}-0.026 \\
(0.073)\end{array}$ \\
\hline Temp. appointment (no prospect) & & $\begin{array}{l}-0.189 \\
(0.068) * * *\end{array}$ & $\begin{array}{l}-0.205 \\
(0.087) * *\end{array}$ \\
\hline Permanent appointment & & -Reference- & \\
\hline Good supervision from school & $\begin{array}{c}0.174 \\
(0.05)\end{array}$ & $\begin{array}{l}0.158 \\
(0.050) * * *\end{array}$ & $\begin{array}{l}0.193 \\
(0.066) * * *\end{array}$ \\
\hline Firm size 1-9 workers & $\begin{array}{c}-0.115 \\
(0.061) *\end{array}$ & $\begin{array}{l}-0.106 \\
(0.061) *\end{array}$ & $\begin{array}{c}-0.072 \\
(0.074)\end{array}$ \\
\hline Firm size 10-99 workers & $\begin{array}{c}-0.010 \\
(0.054) *\end{array}$ & $\begin{array}{c}-0.081 \\
(0.054)\end{array}$ & $\begin{array}{c}-0.070 \\
(0.063)\end{array}$ \\
\hline Firm size $\geq 100$ workers & & -Reference- & \\
\hline Non-profit sector & $\begin{array}{l}0.363 \\
(0.098) * * *\end{array}$ & $\begin{array}{l}0.424 \\
(0.101) * * *\end{array}$ & $\begin{array}{l}0.323 \\
(0.120) * * *\end{array}$ \\
\hline Social service occupation & $\begin{array}{c}0.117 \\
(0.101)\end{array}$ & $\begin{array}{c}0.096 \\
(0.102)\end{array}$ & $\begin{array}{c}0.080 \\
(0.121)\end{array}$ \\
\hline Technical occupation & $\begin{array}{l}-0.134 \\
(0.065) * *\end{array}$ & $\begin{array}{l}-0.177 \\
(0.066) * * *\end{array}$ & $\begin{array}{c}-0.168 \\
(0.079) * *\end{array}$ \\
\hline Administrative occupation & & -Reference- & \\
\hline Apprenticeship level $1 / 2$ & $\begin{array}{c}0.016 \\
(0.048)\end{array}$ & $\begin{array}{c}0.014 \\
(0.048)\end{array}$ & $\begin{array}{c}0.014 \\
(0.057)\end{array}$ \\
\hline Previous years of schooling & $\begin{array}{c}-0.004 \\
(0.018)\end{array}$ & $\begin{array}{c}-0.002 \\
(0.018)\end{array}$ & $\begin{array}{c}-0.007 \\
(0.020)\end{array}$ \\
\hline Previous schooling: apprenticeship & $\begin{array}{c}0.102 \\
(0.099)\end{array}$ & $\begin{array}{c}0.090 \\
(0.099)\end{array}$ & $\begin{array}{c}0.140 \\
(0.107)\end{array}$ \\
\hline
\end{tabular}


CHAPTER 7. TRAINING INTENSITY AND TRAINING MOTIVES I

Table 7.6: continued

\begin{tabular}{lccc}
\hline \hline & $(1)$ & $(2)$ & $(3)^{a}$ \\
\hline Previous schooling: vocational & -0.024 & -0.016 & -0.086 \\
Age & $(0.055)$ & $(0.055)$ & $(0.067)$ \\
& -0.008 & -0.010 & -0.008 \\
Immigrant & $(0.004) * *$ & $(0.004) * *$ & $(0.005) *$ \\
& -0.133 & -0.144 & -0.028 \\
Woman & $(0.117)$ & $(0.116)$ & $(0.183)$ \\
& -0.057 & -0.036 & -0.000 \\
Constant & $(0.066)$ & $(0.066)$ & $(0.079)$ \\
& 3.356 & 3.330 & 3.603 \\
adjusted $R^{2}$ & $(0.212) * * *$ & $(0.239) * * *$ & 0.279 \\
F-test & 0.098 & 0.116 & 0.115 \\
$\mathrm{n}$ & $6.936 * * *$ & $6.486 * * *$ & $4.293 * * *$ \\
\hline \hline
\end{tabular}

Notes: ${ }^{a}$ sample restricted to former apprentices who would choose the same training again. ${ }^{*}=$ significant at $10 \%$ level, ${ }^{* *}=$ significant at $5 \%$ level, $* * *=$ significant at $1 \%$ level

The type of apprenticeship place also affects the training input. Those who had a new-style apprenticeship place but received some pecuniary reward had higher training input than those with a new-style apprenticeship place without any compensation for expenses. The quality of a traditional (paid) apprenticeship place is not significantly better, however. This result is due to the strong link between the type of appointment and the type of apprenticeship place. Only apprentices who have a traditional apprenticeship place can have a permanent employment contract with the training firm. When we correct for the type of appointment, the positive effect of the traditional apprenticeship found by Borghans and Smits (1997) disappears.

The quality of the supervision from the school indeed matters for the firm's training input. Former apprentices that report sufficient or good supervision from the school had a higher training input than apprentices for which the supervision from the school was moderate or insufficient.

One might worry that the effect of training motives is overestimated somewhat because the type of appointment is correlated with apprentice ability, this is especially the case for a permanent appointment during the apprenticeship. Note, however, that there is no significant difference in training in- 


\subsection{DETERMINANTS OF TRAINING INPUT}

put for those former apprentices who had a permanent appointment already during the training period and those who had a prospect of a permanent appointment after the training. This result suggests that the possible bias resulting from the correlation between apprentice ability and a permanent appointment is limited.

This conclusion is reinforced by the fact that observable characteristics that measure apprentice ability have no significant impact on training input. The number of years of education provides some information on the academic level of the candidate, while the fact that the candidate has completed vocational education and/or an earlier apprenticeship reveals something about his vocational qualities. Neither the number of years nor the type of education has any effect on training input. So there is no evidence that the best apprentices are selected for better apprenticeship places, although there may be some selection on apprentice characteristics unobservable for the researcher.

Nevertheless even if better apprentices were selected for the best training places this would not invalidate the conclusion that firms with investment motives provide higher training input, since in this case firms provide better training to better apprentices precisely because they have investment motives and expect the returns to training to be highest for the most able apprentices.

As the former apprentices were interviewed one and a half year after they finished the training their responses may be influenced by their situation at the moment of the survey. Those who were more successful after the training might unjustly give a more positive picture of their former training place than former apprentices who had less success. As current (labour market) success will partly depend on the type of appointment during the apprenticeship, those who had a permanent appointment have a much lower chance to become unemployed after the training, the positive relation between training input and training motives, as measured by the type of appointment, that is found, may be due to retrospective bias.

To test for this retrospective bias I will check whether the relation between training input and training motives still holds if we restrict the sample to former apprentices who would choose the same training again. This variable can be interpreted as an indication of the overall satisfaction with the training retrospectively. It is to be expected that this variable strongly cor- 


\section{CHAPTER 7. TRAINING INTENSITY AND TRAINING MOTIVES I}

relates with the former apprentice's (labour market) situation at the moment of the survey. If the relation between the type of appointment and the training intensity were only due to a retrospective bias, because those who are not satisfied with their current situation and for that reason report a lower training intensity, more often had a temporary contract during the training, than this effect would disappear if the sample were restricted to apprentices who are satisfied with the training retrospectively. ${ }^{5}$

Table 7.7: Type of appointment during apprenticeship and average training input for apprentices who would choose the same training again retrospectively and apprentices who would not

\begin{tabular}{lcc}
\hline \hline & \multicolumn{3}{c}{ Choose again? } \\
& yes & no \\
\hline Type of contract & $\%$ & $\%$ \\
Temporary; prospect of permanent appointment & 64 & 36 \\
Temporary; no prospect of permanent appointment & 52 & 48 \\
Permanent & 69 & 31 \\
Total & 62 & 38 \\
$\mathrm{~N}=975$ & & \\
\hline Training input & & \\
Mean & 3.24 & 2.97 \\
Std. Error Mean & 0.026 & 0.039 \\
& & \\
t-test for equality of means: $5.89^{* * *}$ & & \\
$\mathrm{n}=806$ & &
\end{tabular}

As can be seen from Table $7.762 \%$ of the former apprentices said that they would choose the same training again. This percentage is clearly related to the type of appointment during the apprenticeship. From those who had no prospect on a permanent appointment only $52 \%$ would choose the same training again. Furthermore average training input is significantly higher for former apprentices who would choose the same training again (see Table 7.7). When restricting the sample to apprentices who would choose the same

\footnotetext{
${ }^{5}$ Under the assumption that the retrospective error of the training input measure is perfectly correlated with the retrospective overall satisfaction of the training.
} 


\subsection{TRAINING INPUT AND TRAINING OUTPUT}

training again, I still found a positive relation between training motives and training input, however (see Table 7.6, third row). So it can be concluded that there is no evidence that the positive relation between training input and training motives is solely due to a retrospective bias.

\subsection{Training Input and Training Output}

It is to be expected that the training input has a considerable impact on the production of new skills. The consequences of low training input may be twofold. First, apprentices who receive low training input have a smaller chance of completing their training successfully. Secondly, low training input will lead to a lower skill level, even for those who acquire a certificate of qualification. This lower skill level will subsequently affect the labour market position of the former apprentice. In this section, both the chances of completing the apprenticeship successfully (acquire a certificate) and the wages of former apprentices will be explained by training input.

Table 7.8: Determinants of the chance to acquire a certificate of qualification (logit-estimation)

\begin{tabular}{|c|c|c|c|}
\hline & $(1)$ & $(2)$ & $(3)$ \\
\hline Training input & & $\begin{array}{l}0.587 \\
(0.155) * * *\end{array}$ & $\begin{array}{c}0.560 \\
(0.158) * * *\end{array}$ \\
\hline Good supervision from school & & $\begin{array}{l}0.580 \\
(0.207) * * *\end{array}$ & $\begin{array}{l}0.564 \\
(0.208) * * *\end{array}$ \\
\hline Traditional apprenticeship & & & $\begin{array}{c}0.586 \\
(0.410)\end{array}$ \\
\hline New style (expenses) & & & $\begin{array}{c}0.815 \\
(0.434) *\end{array}$ \\
\hline New style (no expenses) & & -Reference- & \\
\hline Temporary appointment (prospect) & & & $\begin{array}{c}0.338 \\
(0.273)\end{array}$ \\
\hline Temporary appointment (no prospect) & & & $\begin{array}{c}0.016 \\
(0.293)\end{array}$ \\
\hline Permanent appointment & & -Reference- & \\
\hline Firm size 1-9 workers & -0.803 & -0.724 & -0.674 \\
\hline
\end{tabular}


CHAPTER 7. TRAINING INTENSITY AND TRAINING MOTIVES I

Table 7.8: continued

\begin{tabular}{|c|c|c|c|}
\hline & $(1)$ & $(2)$ & $(3)$ \\
\hline & $(0.262) * * *$ & $(0.268) * * *$ & $(0.272) * *$ \\
\hline Firm size 10-99 workers & $\begin{array}{c}-0.366 \\
(0.242)\end{array}$ & $\begin{array}{c}-0.243 \\
(0.249)\end{array}$ & $\begin{array}{r}-0.182 \\
(0.256)\end{array}$ \\
\hline Firm size $\geq 100$ workers & & -Reference- & \\
\hline Non-profit sector & $\begin{array}{c}0.205 \\
(0.457)\end{array}$ & $\begin{array}{c}0.014 \\
(0.471)\end{array}$ & $\begin{array}{c}0.198 \\
(0.517)\end{array}$ \\
\hline Social service occupation & $\begin{array}{c}-0.391 \\
(0.439)\end{array}$ & $\begin{array}{c}-0.514 \\
(0.453)\end{array}$ & $\begin{array}{c}-0.481 \\
(0.470)\end{array}$ \\
\hline Technical occupation & $\begin{array}{c}-0.492 \\
(0.293) *\end{array}$ & $\begin{array}{c}-0.399 \\
(0.300)\end{array}$ & $\begin{array}{r}-0.439 \\
(0.307)\end{array}$ \\
\hline Administrative occupation & & -Reference- & \\
\hline Apprenticeship level $1 / 2$ & $\begin{array}{c}-0.271 \\
(0.210)\end{array}$ & $\begin{array}{c}-0.290 \\
(0.215)\end{array}$ & $\begin{array}{c}-0.310 \\
(0.216)\end{array}$ \\
\hline Previous years of schooling & $\begin{array}{c}0.047 \\
(0.086)\end{array}$ & $\begin{array}{c}0.057 \\
(0.089)\end{array}$ & $\begin{array}{c}0.060 \\
(0.091)\end{array}$ \\
\hline Previous schooling: apprenticeship & $\begin{array}{l}1.803 \\
(0.762) * *\end{array}$ & $\begin{array}{l}1.813 \\
(0.771) * *\end{array}$ & $\begin{array}{l}1.833 \\
(0.775) * *\end{array}$ \\
\hline Previous schooling: vocational & $\begin{array}{c}-0.243 \\
(0.246)\end{array}$ & $\begin{array}{c}-0.282 \\
(0.252)\end{array}$ & $\begin{array}{c}-0.236 \\
(0.255)\end{array}$ \\
\hline Age & $\begin{array}{c}0.050 \\
(0.020) * *\end{array}$ & $\begin{array}{l}0.053 \\
(0.020) * * *\end{array}$ & $\begin{array}{l}0.058 \\
(0.022) * * *\end{array}$ \\
\hline Immigrant & $\begin{array}{c}-0.358 \\
(0.499)\end{array}$ & $\begin{array}{c}-0.318 \\
(0.509)\end{array}$ & $\begin{array}{c}-0.348 \\
(0.515)\end{array}$ \\
\hline Woman & $\begin{array}{c}0.014 \\
(0.293)\end{array}$ & $\begin{array}{c}0.015 \\
(0.301)\end{array}$ & $\begin{array}{c}0.076 \\
(0.304)\end{array}$ \\
\hline Constant & $\begin{array}{c}0.650 \\
(0.991)\end{array}$ & $\begin{array}{c}-1.765 \\
(1.116)\end{array}$ & $\begin{array}{l}-2.550 \\
(1.296) * *\end{array}$ \\
\hline $\begin{array}{l}\text { LR-test } \\
\mathrm{n}=712\end{array}$ & $49.737 * * *$ & $74.992 * * *$ & $80.331 * * *$ \\
\hline
\end{tabular}

Table 7.8 gives the estimated coefficients of a logistic regression equation for the chances of obtaining a certificate of qualification. Both the training input measure and the dummy for sufficient or good supervision from the 


\subsection{TRAINING INPUT AND TRAINING OUTPUT}

school are included. ${ }^{6}$ Furthermore I have included several control variables for previous education, personal characteristics, training characteristics, and characteristics of the training firm and apprenticeship place.

The training input has indeed an impact on the chances of successfully completing one's training. The higher the value of the input measure, the greater the chances of success. The same is true for supervision. Apprentices who report good supervision from the side of the school, have a greater chance of success.

The type of appointment, an indicator for the firm's training motives has no effect on the chance of acquiring a certificate of qualification. As expected, previous training affects the chance of completing the apprenticeship successfully. Apprentices who did an apprenticeship before, have a higher chance of success than those who only had vocational education at school or general secondary education. Older apprentices also have a greater chance of success. This may be explained by the fact that older apprentices usually have some work experience before they start their training, which probably facilitates the acquisition of new skills.

Table 7.9 shows the estimated coefficients of a wage equation. Apart from the explanatory variables that were also included in the analysis of the chance of obtaining a qualification, there are now also dummy variables included for those who are still employed in their training firm and for current training activities. Furthermore, the variables of firm size and sector of industry now refer to the current employer and not to the training firm. The effect of training input on future wages is considerable. The estimated wage difference between those with the highest training input and those with the lowest training input, is about 17\%. Surprisingly, good supervision from the side of the school has a negative impact on future hourly wages. This result may be explained by a substitution effect of training input and supervision quality. Supervision from the side of the school may be less important if the training input is good. To test for this substitution effect, I have included the interaction of training input and supervision in the wage

\footnotetext{
${ }^{6}$ As the supervision from the school not only concerns the apprentice's progress at the training firms but also his progress at the school itself, it may both indirectly, through the firm's training input, and directly impact on training output.
} 


\section{CHAPTER 7. TRAINING INTENSITY AND TRAINING MOTIVES I}

equation. This substitution effect has the expected negative sign but is not significant. However, the negative effect of good supervision from the side of the school disappears in this case.

Table 7.9: Wage determinants (OLS, dependent variable is the natural logarithm of the hourly wages)

\begin{tabular}{|c|c|c|c|}
\hline & (1) & (2) & $(3)$ \\
\hline Training Input & & $\begin{array}{l}0.061 \\
(0.025) * *\end{array}$ & $\begin{array}{l}0.063 \\
(0.025) \text { *** }\end{array}$ \\
\hline Good supervision from school & & $\begin{array}{l}-0.063 \\
(0.032) * *\end{array}$ & $\begin{array}{l}-0.065 \\
(0.032) * *\end{array}$ \\
\hline Traditional apprenticeship & & & $\begin{array}{c}-0.028 \\
(0.063)\end{array}$ \\
\hline New style (expenses) & & & $\begin{array}{l}0.010 \\
(0.064)\end{array}$ \\
\hline New style (no expenses) & & -Reference- & \\
\hline Temporary appointment (prospect) & & & $\begin{array}{c}-0.040 \\
(0.041)\end{array}$ \\
\hline Temporary appointment (no prospect) & & & $\begin{array}{l}-0.145 \\
(0.048) * * *\end{array}$ \\
\hline Permanent appointment & & -Reference- & \\
\hline Still with training firm & $\begin{array}{c}0.025 \\
(0.031)\end{array}$ & $\begin{array}{c}0.018 \\
(0.031)\end{array}$ & $\begin{array}{c}-0.032 \\
(0.035)\end{array}$ \\
\hline Firm size 1-9 workers & $\begin{array}{l}-0.088 \\
(0.040) * *\end{array}$ & $\begin{array}{l}-0.082 \\
(0.040) * *\end{array}$ & $\begin{array}{l}-0.089 \\
(0.040) * *\end{array}$ \\
\hline Firm size 10-99 workers & $\begin{array}{l}-0.086 \\
(0.034) * * *\end{array}$ & $\begin{array}{l}-0.082 \\
(0.034) * *\end{array}$ & $\begin{array}{l}-0.078 \\
(0.033) * *\end{array}$ \\
\hline Firm size $\geq 100$ workers & & -Reference- & \\
\hline Non-profit sector & $\begin{array}{c}0.035 \\
(0.054)\end{array}$ & $\begin{array}{c}0.022 \\
(0.054)\end{array}$ & $\begin{array}{c}0.033 \\
(0.054)\end{array}$ \\
\hline Social service occupation & $\begin{array}{c}-0.110 \\
(0.060) *\end{array}$ & $\begin{array}{l}-0.118 \\
(0.060) * *\end{array}$ & $\begin{array}{l}-0.130 \\
(0.061) * *\end{array}$ \\
\hline Technical occupation & $\begin{array}{c}0.066 \\
(0.042)\end{array}$ & $\begin{array}{l}0.075 \\
(0.042) * *\end{array}$ & $\begin{array}{c}0.061 \\
(0.042)\end{array}$ \\
\hline Administrative occupation & & -Reference- & \\
\hline Apprenticeship level $1 / 2$ & $\begin{array}{l}-0.119 \\
(0.032) * * *\end{array}$ & $\begin{array}{l}-0.119 \\
(0.032) * * *\end{array}$ & $\begin{array}{l}-0.117 \\
(0.032) * * *\end{array}$ \\
\hline
\end{tabular}




\subsection{TRAINING INPUT AND TRAINING OUTPUT}

Table 7.9: continued

\begin{tabular}{|c|c|c|c|}
\hline & (1) & $(2)$ & (3) \\
\hline No diploma & $\begin{array}{c}-0.052 \\
(0.038)\end{array}$ & $\begin{array}{c}-0.047 \\
(0.039)\end{array}$ & $\begin{array}{c}-0.057 \\
(0.039)\end{array}$ \\
\hline Previous years of schooling & $\begin{array}{c}0.004 \\
(0.011)\end{array}$ & $\begin{array}{c}0.003 \\
(0.011)\end{array}$ & $\begin{array}{c}0.006 \\
(0.011)\end{array}$ \\
\hline Previous schooling: apprenticeship & $\begin{array}{c}0.010 \\
(0.058)\end{array}$ & $\begin{array}{c}0.006 \\
(0.058)\end{array}$ & $\begin{array}{c}-0.006 \\
(0.058)\end{array}$ \\
\hline Previous schooling: vocational & $\begin{array}{c}-0.054 \\
(0.036)\end{array}$ & $\begin{array}{c}-0.046 \\
(0.036)\end{array}$ & $\begin{array}{c}-0.046 \\
(0.037)\end{array}$ \\
\hline Currently apprenticeship & $\begin{array}{c}-0.022 \\
(0.049)\end{array}$ & $\begin{array}{c}-0.014 \\
(0.048)\end{array}$ & $\begin{array}{c}-0.028 \\
(0.048)\end{array}$ \\
\hline Currently training & $\begin{array}{c}-0.064 \\
(0.045)\end{array}$ & $\begin{array}{c}-0.060 \\
(0.044)\end{array}$ & $\begin{array}{c}-0.058 \\
(0.044)\end{array}$ \\
\hline Age & $\begin{array}{l}0.101 \\
(0.016) * * *\end{array}$ & $\begin{array}{c}0.109 \\
(0.016)\end{array}$ & $\begin{array}{l}0.101 \\
(0.017) * * *\end{array}$ \\
\hline Age squared/100 & $\begin{array}{l}-0.014 \\
(0.003) * * *\end{array}$ & $\begin{array}{l}-0.013 \\
(0.003) * * *\end{array}$ & $\begin{array}{l}-0.012 \\
(0.003) * * *\end{array}$ \\
\hline Immigrant & $\begin{array}{c}-0.075 \\
(0.068)\end{array}$ & $\begin{array}{r}-0.065 \\
(0.067)\end{array}$ & $\begin{array}{c}-0.068 \\
(0.067)\end{array}$ \\
\hline Woman & $\begin{array}{c}-0.074 \\
(0.042)\end{array}$ & $\begin{array}{c}-0.069 \\
(0.042)\end{array}$ & $\begin{array}{c}-0.063 \\
(0.042)\end{array}$ \\
\hline Constant & $\begin{array}{l}0.982 \\
(0.257) * * *\end{array}$ & $\begin{array}{c}0.837 \\
(0.265) * * *\end{array}$ & $\begin{array}{l}1.039 \\
(0.279) * * *\end{array}$ \\
\hline adjusted $R^{2}$ & 0.365 & 0.376 & 0.385 \\
\hline $\begin{array}{l}\text { F-test } \\
n=417\end{array}$ & $15.119 * * *$ & $14.233 * * *$ & $12.361 * * *$ \\
\hline
\end{tabular}

The type of appointment during the apprenticeship has the expected sign. Apprentices who had a permanent appointment or the prospect of a permanent appointment have higher earnings than those who had no prospect of continuing their employment relation with the training firm after completing the apprenticeship.

It is important to note that if actual training input were correlated with unobserved apprentice ability, because the best apprentices are selected for the best apprenticeship places, then the effects of ability and training input are difficult to unravel. Without correcting for the effect of unobserved ability 


\section{CHAPTER 7. TRAINING INTENSITY AND TRAINING MOTIVES I}

the effect of training input would then be overestimated (see also Chapter 6). To correct for omitted variable bias by IV-estimation I need an instrument that correlates with training input but not with apprentice ability. The only possible candidates in the data set are the region of the training firm and the sector of industry of the training firm. The idea is that the demand for and offer of apprenticeship places is fixed in each region since apprentice mobility between regions is very low. Also, most apprentices have a clear preference for a certain trade and will not easily switch between trades. However, it turns out that neither of these variables has a significant effect on training input. $^{7}$

Nevertheless it is not very likely that the estimated positive effect of training input is solely due to ability bias since variables indicating ability, like the level of the apprenticeship, do have a significant positive wage effect but do not affect training input. For example, if firms were only prepared to provide high training input to the best apprentices we would expect the training input on average to be higher for apprentices doing an apprenticeship at level $3 / 4$ than for apprentices at level $1 / 2$ since average ability will be higher at level 3/4. However, the level of the apprenticeship has no effect on training input (see Table 7.6)

\subsection{Conclusions}

In this chapter, I conducted a survey among former apprentices to study the relation between training input and training motives for apprenticeship training in the Netherlands. I measured input by looking at the extent in which firms let the learning interests of the apprentice prevail over productivity interests. Although training input is regulated and the training is certified, I have found that there is indeed a relation between training input and the motives of firms to hire apprentices. On average, firms that hire apprentices because of investment motives provide higher training input than firms that

\footnotetext{
${ }^{7}$ As a result the $\mathrm{F}$-statistic of the first stage regression is very low $(\mathrm{F}[24,563]=5.31)$ meaning that the instruments are weak (Stock, Wright, and Yogo, 2002; Staiger and Stock, 1997; Wooldridge, 2002) which leads to very large standard errors for estimates of the coefficient of interest, namely training input, in the second stage.
} 


\subsection{CONCLUSIONS}

hire apprentices for current production motives. Regulation in itself is not sufficient to guarantee good training to everyone if there are training firms that have no investment motives. I have also found some evidence that training input indeed matters for the production of new skills. First, the training input affects the chances of successful completion of the training. Second, higher training input leads to higher wages after the apprenticeship. 


\subsection{Appendix to Chapter 7}

Table 7.10: Descriptive statistics

\begin{tabular}{lrrc}
\hline \hline & mean & st. dev. & $\mathrm{n}$ \\
\hline Type of apprenticeship place & & & \\
Traditional & 0.70 & 0.447 & 886 \\
New style; payment of expenses & 0.20 & 0.386 & 886 \\
New style; no payment of expenses & 0.10 & 0.292 & 886 \\
Type of appointment during apprenticeship & & & \\
Temporary; prospect of permanent appointment & 0.24 & 0.428 & 845 \\
Temporary; no prospect of permanent appointment & 0.33 & 0.471 & 845 \\
Permanent & 0.43 & 0.495 & 845 \\
Training firm size & & & \\
1-9 workers & 0.24 & 0.428 & 839 \\
10-99 workers & 0.40 & 0.490 & 839 \\
100 workers & 0.35 & 0.478 & 839 \\
Training firm in non-profit sector & 0.17 & 0.380 & 840 \\
Occupational group & & & \\
Social service & 0.15 & 0.360 & 975 \\
Technical & 0.58 & 0.496 & 975 \\
Administration & 0.28 & 0.449 & 975 \\
Apprenticeship level 1/2 & 0.59 & 0.492 & 975 \\
Previous schooling & & & \\
Years of schooling & 10.60 & 1.486 & 883 \\
Apprenticeship & 0.06 & 0.238 & 929 \\
Vocational education & 0.70 & 0.460 & 929 \\
Current firm is training firm & 0.41 & 0.492 & 947 \\
Size current firm & & & \\
1-9 workers & 0.23 & 0.418 & 776 \\
10-99 workers & 0.36 & 0.479 & 776 \\
Z 100 workers & 0.42 & 0.494 & 776 \\
Current firm in non-profit sector & 0.17 & 0.374 & 785 \\
Gross hourly earnings guilders & 15.35 & 5.694 & 567 \\
Current training & & & \\
Apprenticeship & 0.12 & 0.321 & 954 \\
Other training & 0.15 & 0.352 & 954 \\
Personal characteristics & & & \\
Age & 25.35 & 7.239 & 960 \\
Immigrant & 0.06 & 0.241 & 969 \\
Woman & 0.38 & 0.486 & 974 \\
\hline \hline & & & \\
\hline
\end{tabular}




\section{Chapter 8}

\section{Training Intensity and Training Motives II: Evidence from Firms}

\subsection{Introduction}

An alternative approach to investigate the relation between training intensity and training motives is to use firm level data. The advantage of firm-level data compared to apprentice data is that firms can provide better information on training motives than apprentices. I conducted a survey among Dutch training firms in four sectors, the construction industry, the printing industry, the metal industry and the care sector (hospitals and nursing homes). The survey included a number of questions about the way in which training and work are organised in the firm. Based on these questions I have constructed training input measures for the aspects of the training programme discussed in Chapter 6, namely the complexity of production tasks, the learning content of production tasks, and the time for formal learning activities and instruction and supervision.

Not all aspects of the training are equally well observable by a third party. This difference in observability allows me to investigate whether the relation between training motives and training intensity also depends on the degree of information imperfection as predicted in Chapter 4. To check the 
observability of the different aspects of the training that I consider, I will test whether the training input measures affect the firm's training reputation. It is to be expected that mainly training efforts that are easily observable matter for the training reputation. An indicator of the firm's training reputation is the chance that the firm is nominated for the yearly elections for the best training firm in the sector.

To measure the firm's training motives, I included several questions referring to factors that determine the firm's expected future benefits from training, namely the degree of firm-specificity, the degree of monopsony power and the expected quit rate. I also included some questions to measure directly whether the firm has current and/or future benefits from apprenticeship training.

Firstly, I will regress the measures for training input on the measures for expected future benefits. Secondly, I will test whether the measures for training input matter in the sense that they impact on the output from training. The indicator for training output I will consider, is the chance that the apprentice completes the training with a certificate of qualification.

\subsection{The Survey}

The survey was addressed at recognised training firms in the construction industry, the printing industry, the metal industry and the care sector (hospitals and nursing homes) that employed apprentices or had recently employed apprentices. These are all sectors in which the apprenticeship system has a strong tradition. The intended respondent was the contact of the firm with the concerning body for vocational education and training. This could be the practical trainer, the co-ordinator of training activities but also the owner of the firm.

To make sure that the questions were sufficiently linked with the daily practice in training firms, I discussed a draft of the questionnaire with experts from the bodies of vocational education. The exact questions and their relation to the theoretical concepts from Chapter 6 are discussed in the next sessions. The complete questionnaire can be found in the appendix to this chapter. 


\subsection{THE SURVEY}

The bodies for vocational and training of the concerning sectors provided data files with addresses and contacts of recognised training firms in their sector. To obtain a relatively homogeneous group of firms for each sector, I selected only firms that train for certain qualifications. ${ }^{1}$ Table 8.34 in the appendix gives an overview of the selected qualifications for each sector.

The survey took place either by internet or by a telephone interview. All contacts in the sample received a letter with the invitation to participate in the survey and an instruction of how to fill in the questionnaire by internet. Those contacts that were not able or not willing to fill in the questionnaire by internet within two weeks were approached for a telephone interview. This was the case for most of the respondents, only $17 \%$ of the respondents filled in the questionnaire by internet. The internet questionnaire and the telephone questionnaire were identical. By telephone, the interview took on average about 20 minutes.

Table 8.1: Method of interview and no apprentices at the moment of the survey by economic sector

\begin{tabular}{lccc}
\hline \hline Sector & $\begin{array}{c}\text { Interview } \\
\text { by internet } \\
\%\end{array}$ & $\begin{array}{c}\text { No apprentices } \\
\text { at survey date } \\
\%\end{array}$ & Total \\
& 11 & 19 & 227 \\
\hline Construction industry & 10 & 38 & 191 \\
Printing industry & 22 & 10 & 250 \\
Metal industry & 23 & 2 & 251 \\
Hospitals and nursing homes & 17 & 16 & 919 \\
Total &
\end{tabular}

About 3,500 firms have been approached. The initial response rate was $40 \%$. However, not all responding firms were employing apprentices at the moments of the interview or had employed apprentices recently. ${ }^{2}$ If a firm had no apprentices at the moment of the survey and had no apprentices during any moment in the last two years either, the interview was broken off.

\footnotetext{
${ }^{1}$ Only in the printing industry, all firms were included in the sample because the number of firms that train apprentices in this sector is rather small.

${ }^{2}$ This is due to the fact that not all firms that have a recognition to train apprentices actually do train.
} 


\section{CHAPTER 8. TRAINING INTENSITY AND TRAINING MOTIVES II}

This was the case for $35 \%$ of the responding firms. The final sample consists of 919 training firms, $16 \%$ of which had no apprentices at the moment of the survey but had employed apprentices during the past two years (see Table 8.1) The respondent was in most cases either a practical trainer or the firm's co-ordinator of training activities (46\% and 35\% of the respondents) (see Table 8.2). Table 8.3 gives the distribution of firm size by economic sector.

Table 8.2: Position of the respondent in relation to the apprenticeship system by economic sector

\begin{tabular}{lccc}
\hline \hline Sector & \multicolumn{3}{c}{ Position respondent } \\
& Trainer & Co-ordinator & Other \\
& $\%$ & $\%$ & $\%$ \\
\hline Construction industry & 25 & 45 & 30 \\
Printing industry & 54 & 25 & 21 \\
Metal industry & 69 & 18 & 12 \\
Hospitals and nursing homes & 37 & 43 & 20 \\
Total & 46 & 33 & 21 \\
\hline $\mathrm{n}=919$ & & & \\
\hline \hline
\end{tabular}

Table 8.3: Firm size by economic sector

\begin{tabular}{lrrrr}
\hline \hline Sector & \multicolumn{5}{c}{ Number of employees } \\
& $<10$ & $10-99$ & $100-499$ & $\geq 500$ \\
\hline Construction industry & $\%$ & $\%$ & $\%$ & $\%$ \\
Printing industry & 23 & 62 & 15 & 0 \\
Metal industry & 35 & 53 & 9 & 2 \\
Hospitals and nursing homes & 12 & 65 & 19 & 4 \\
Total & 0 & 28 & 38 & 34 \\
$\mathrm{n}=906$ & 16 & 52 & 21 & 11 \\
\hline \hline
\end{tabular}




\subsection{ITEMS ON TRAINING INPUT}

\subsection{Items on Training Input}

The survey included 16 items on training input. These items try to capture the extent in which the firm gives priority either to training or to production. For each item respondents were asked to which extent it applied to apprentices in their firm on a 4-point scale. Some items give a positive indication of training input and others a negative indication of training input. The training input possibly is a delicate issue for many firms. It can be expected that respondents are not willing to declare that the training input in their firm falls short, even if they think that this is the case. Therefore I tried to formulate the questions meant to measure training input in a neutral way so that it is not directly clear to the respondent whether a certain item is a positive or a negative indication of training input. For example the item 'apprentices carry out the same tasks as qualified colleagues' is a positive indication for training input meant to measure the complexity of the apprentice's tasks. Table 8.4 gives an overview of the items and their distribution on the response scale. The respondent was asked to keep in mind an apprentice of level 2 (construction, printing and metal) or level 3 (hospitals and nursing homes) halfway his training programme. ${ }^{3}$

As discussed in Chapter 6, the weigh off between training and production may affect different aspects of the training program. In Chapter 7 my aim was to find one underlying construct for training input based on all aspects of the training. In this chapter, it is possible to measure the different aspects of the training input separately because I have more items for each aspect. The items all refer to the formal and informal aspects of the training programme I distinguished in Chapter 6.

\footnotetext{
${ }^{3}$ If the respondent had no experience with apprentices at this level than the reference was level 3 for the construction, printing and metal industries and level 4 for hospitals and nursing homes.
} 


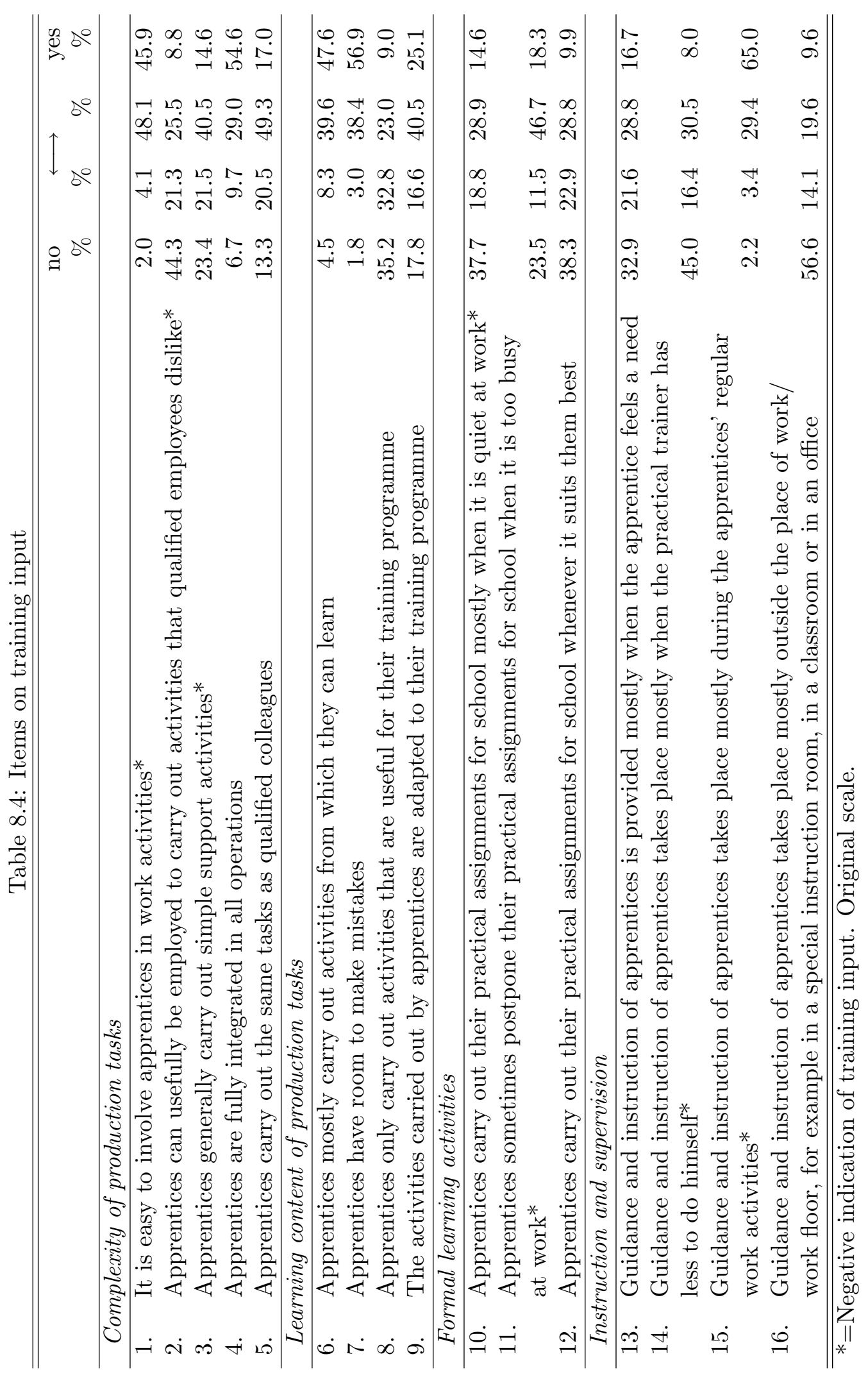




\subsection{ITEMS ON TRAINING INPUT}

The first aspect is the complexity of production tasks (productive work) the apprentice performs in the firm. Priority to production implies simple tasks in which the apprentice is directly productive while priority to learning implies more complex tasks in which the apprentice needs more supervision and is less productive. Items 1, 2 and 3 are a negative indicator for training input (simple tasks) and items 4 and 5 a positive indicator for training input (complex tasks).

The second aspect is the learning content of production tasks. Is the apprentice given special tasks to learn the occupation? All items concerning this aspect are a positive indicator of training input.

The third aspect is the time for formal learning activities. The practical assignments from the school are part of the training program and the apprentice has to complete these assignments before he can pass the final examination. Is the apprentice given enough room within the firm to perform these tasks? Items 10 and 11 are negative indicators of training input, they indicate that priority is given to productive work, while item 12 is a positive indicator.

Finally there is a group of items that refer to time for instruction and supervision of the apprentice in the training firm. Items 13 and 16 are positive indicators, there is time reserved for this activity and the apprentice is guided whenever he needs help. Items 14 and 15 are negative indicators, suggesting that productive work is given priority to guidance and instructions.

To check whether the items in a category indeed measure the same underlying construct, first of all I considered the item total correlation. ${ }^{4}$ This is the correlation of a specific item with the total score of all other items. To facilitate the interpretation of the results the scale is reversed for items that give an indication of low training input ${ }^{5}$ so that in what follows a high score indicates high training input for all items. Table 8.5 gives the item total correlation both for all items combined and for the four quality categories separately. The correlation between the items seems to be quite low and sometimes even negative. The item total correlations within the four

\footnotetext{
${ }^{4}$ As it is expected that, unlike in Chapter 7, the items do not form a unidimensional scale Cronbach's alpha is not reported here.

${ }^{5}$ This is the case for items $1,2,3,10,11,14$ and 15 .
} 
categories are much higher but still there seem to be some items that do not fit in the category they are assigned to.

For that reason I will next examine whether the four training input categories considered are supported by the data or whether there are other training input categories underlying the data. First, I will consider whether there are items that turn out not to measure training input and should therefore be deleted from the analysis. Secondly, I will check whether the remaining items in a category measure the same underlying construct or should be rearranged to form new more meaningful categories. To this end I will again consider the item total correlation. Additionally, I will perform a factor analysis for each (new) category. ${ }^{6}$

A closer look at the items that negatively correlate with the total score suggests some explanations. While items 12 and 13 were included to measure whether firms give priority to training whenever possible, they probably are an indication for something else, namely indifference to training. If the apprentice does not express any need for instruction there will be no instruction. Furthermore item 1 is probably too vague to be an indicator for training input because it doesn't tell anything about the complexity of the work apprentices can be employed at. ${ }^{7}$ Moreover, this item does not reveal whether apprentices perform really productive tasks, but only whether it is possible to employ them. As a consequence, this item seems to be true for nearly all firms, only $6 \%$ of the respondents reports that this item does not apply for apprentices in their firm. The same critique holds for item 15, less than $6 \%$ of the respondents reports that this item does not apply for their firm. So this item has little discriminative power with respect to training input.

\footnotetext{
${ }^{6}$ Although a factor analysis assumes that the items have a normal distribution, which is clearly not the case here, since the items have categorical scale, it can be used as an indication for the validity of the training input categories (Bartholomew and Knott, 1999).

${ }^{7}$ If it concerns complex tasks it is a positive indicator of training input; if it concerns simple tasks it is a negative indicator.
} 


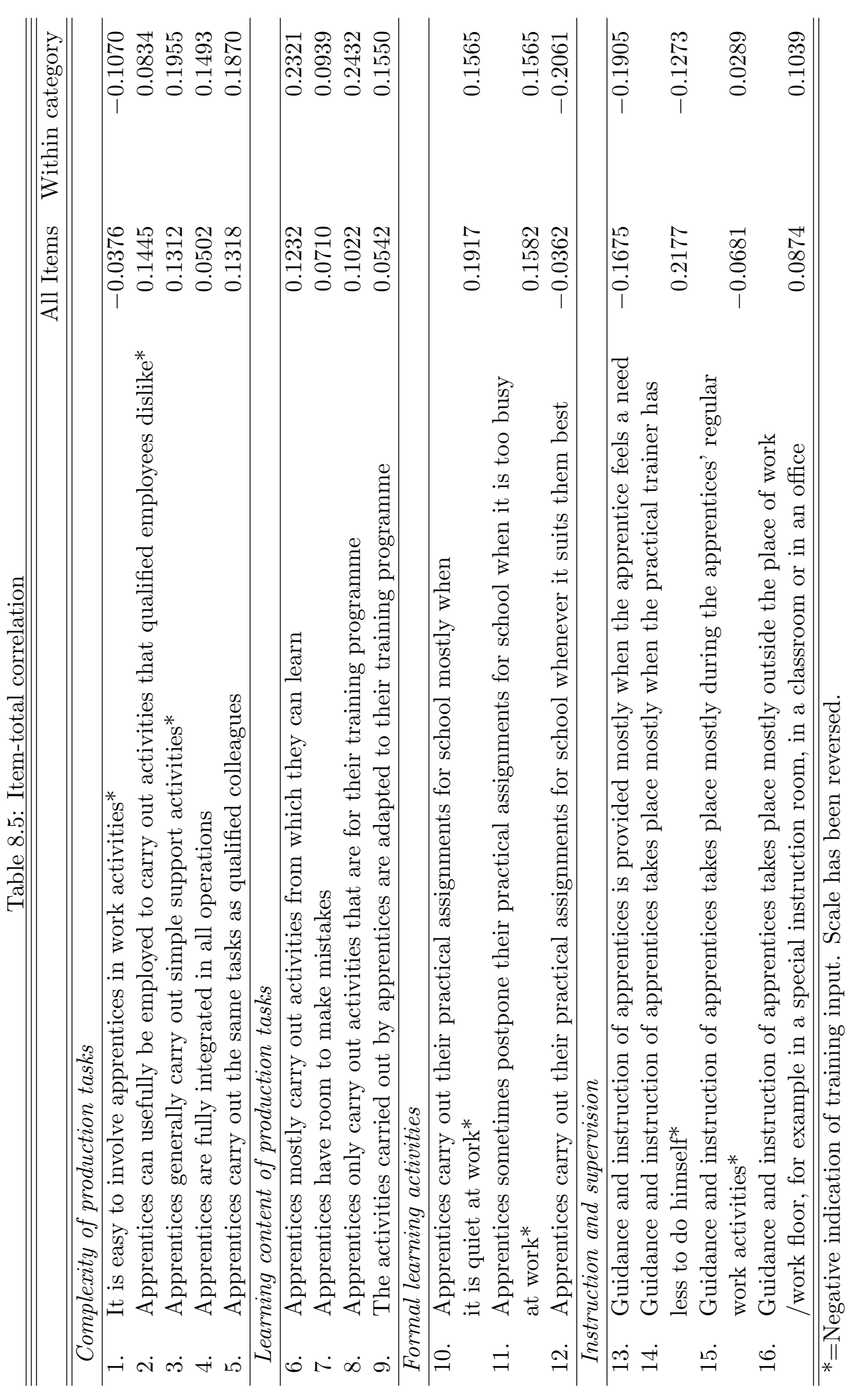


CHAPTER 8. TRAINING INTENSITY AND TRAINING MOTIVES II

If items 1, 12, 13 and 15 would be dropped, than the category supervision and instruction would only contain two items (14 and 16) which have a low correlation. In the category time for formal learning activities there would remain two items as well but these have a high correlation (items 10 and 11). As both items refer to time and occasion apprentices have to perform the practical assignments they may correlate with item 14 which refers to time and occasion the supervisor has for training the apprentice. We could thus drop item 16 and form a new category time for formal learning and instruction with items 10, 11, 14. A factor analysis shows that items 10, 11 and 14 indeed measure the same underlying construct while item 16 does not.

A factor analysis on the items in the category learning content of production tasks suggests that item 7 should be deleted as well, as this analysis turns up two factors the first with high loadings on item 6, 8 and 9 and a second with a high loading on item 7 .

Finally a factor analysis on the remaining items in the category complexity of production tasks suggests that there are two factors. The first factor has positive loadings on all items although items 4 and 5 have somewhat higher loadings than items 2 and 3. The second factor has positive loadings on items 2 and 3 and negative loadings on 4 and 5. A possible explanation for this is that these items not only explain the complexity of the tasks the apprentices has to fulfill ${ }^{8}$ (the first factor) but also whether apprentices perform any productive tasks at all, irrespective of the complexity of these tasks. The first factor is a measure for training input, the second is not. Therefore I will only consider the first factor.

To summarise we now have three categories namely complexity of production tasks with items 2, 3, 4 and 5, learning content of production tasks with items 6, 8 and 9 and time for formal learning and instruction with items 10, 11 and 14 (see Table 8.6). To obtain training input scores for each category, it will be assumed that each item and each score have equal weigh. ${ }^{9}$ So

\footnotetext{
${ }^{8}$ In which case the positive effect of complex tasks on training input is bigger than the negative effect of simple tasks.

${ }^{9}$ The factor scores are no reliable weights because the items do not have a normal distribution. Alternatively we could estimate a logit-probit latent variable model for poly-
} 


\subsection{ITEMS ON TRAINING INPUT}

the average item score within each category is taken as the training input measure for that category.

Table 8.6: New training input categories

Complexity of production tasks

2. Apprentices can usefully be employed to carry out activities that qualified employees dislike*

3. Apprentices generally carry out simple support activities*

4. Apprentices are fully integrated in all operations

5. Apprentices carry out the same tasks as qualified colleagues

Learning content of production tasks

6. Apprentices mostly carry out activities from which they can learn

8. Apprentices only carry out activities that are useful for their training programme

9. The activities carried out by apprentices are adapted to their training programme

Time for formal learning and instruction

10. Apprentices carry out their practical assignments for school mostly when it is quiet at work*

11. Apprentices sometimes postpone their practical assignments for school when it is too busy at work*

14. Guidance and instruction of apprentices takes place mostly when the practical trainer has less to do himself*

*=Negative indication of training input. Scale has been reversed.

tomous data and use the conditional mean of the component score (Bartholomew and Knott, 1999; Knott and Albanese, 1999). This method allows for different weights by item and score. For the items in the category complexity of production tasks I estimated a two factor model and for the items in the two other categories a one factor model. A measure for training input in each category is obtained by taking the estimated conditional means of the latent variables. However, due to the limited number of observations, the standard errors of the estimates are very large. Therefore the conditional mean is not expected to be a more accurate measure than the average item score. For that reason I decided to use the average item score instead. 


\subsubsection{Observability of the Training}

Not all aspects of the training program are equally well observed by the apprentice or a third party. These differences in the degree of observability allow me to test whether the relation between training motives and training intensity depends on the observability of the training as predicted in Chapter 4. If firms give priority to production only with regard to aspects of the training program that are difficult to observe, we would expect that the relation between training input and training motives will be strongest for those aspects that are the least observable.

The time for learning and instruction will, in general, be better observable than the complexity of production tasks. Also, because it is better observable this first aspect of the training is often regulated. ${ }^{10}$ As a result it will be easier for a training firm to save on training costs by lowering the complexity of production tasks than by devoting less (formal) time to learning and instruction. The observability of the learning content of production tasks will be somewhere in between the observability of the complexity of production tasks and the time for formal learning and instruction.

These expected differences in observability of the three training aspects are indeed supported by the data. It is to be expected that the measurement error will be higher if the training is less observable. The respondents have different positions with respect to training. Practical trainers are in a good position to observe all aspects of the training but this is often not true for training co-ordinators who are remoter of the daily training practise. Respondents who are less certain about a particular aspect of the training will tend to avoid the extremes of the response scale. Although the measurement error will increase, the variance of the input measure will thus decrease. As expected the variance of the complexity of production tasks is lower than the variance of the other two aspects of the training (see Table 8.7 and Figure $8.1)$.

Another indication of the observability of the different aspects of the training, is their effect on the firm's training reputation. It is very likely that

\footnotetext{
${ }^{10}$ Only those aspects of the training program that are verifiable can be successfully regulated.
} 


\subsection{ITEMS ON TRAINING INPUT}

Table 8.7: Mean and standard deviation of training input measures

\begin{tabular}{lccc}
\hline \hline Input measure & Mean & Standard deviation & $\mathrm{N}$ \\
\hline Complexity of production tasks & 2.89 & 0.56 & 896 \\
Learning content of production tasks & 2.70 & 0.62 & 906 \\
Time for formal learning and instruction & 2.73 & 0.79 & 892 \\
\hline \hline
\end{tabular}

especially those aspects of the training that are easily observable by a third party determine the training reputation. An indicator of the firm's training reputation is the probability to win the award of the best training firm within the sector. To stimulate good training practices in each sector of industry, the training bodies yearly elect the best training firm in the sector. In the survey it was asked whether the firm would make a chance to be nominated in these elections. Table 8.8 shows that $10 \%$ of the training firms estimates this chance to be great. Another $20 \%$ of the respondents does not know whether the firm makes any chance. The idea is that firms that have a good reputation for training will perceive this chance as higher than other firms.

I estimated a probit model to explain the probability that the chance to be nominated is perceived as great relative to the categories fair, small and don't know. In addition to the training input measures, I included a wide range of control variables. Table 8.9 gives the significance of the training input measures. ${ }^{11}$ The complexity of production tasks has no effect on the chance to be nominated but the other two input measures, the learning content of production tasks and time for formal learning and instruction, do affect this chance. This might either mean that, in the view of the firm and/or the board for vocational education, the complexity of production tasks does not really matter for overall training input or that this aspect of training input is not very well observable and therefore does not contribute to the training reputation. If the latter is indeed the case, firms may put too much accent on the observable aspects of the training and neglect the aspects of training that are less easily observed by a third party, especially if the firm has no investment motives for apprenticeship training.

\footnotetext{
${ }^{11}$ Table 8.29 in the appendix to this chapter gives the full estimation results.
} 
CHAPTER 8. TRAINING INTENSITY AND TRAINING MOTIVES II

Table 8.8: Subjective chance to become the best training firm in the sector

\begin{tabular}{lcccc}
\hline \hline Sector & \multicolumn{4}{c}{ Chance } \\
& great & fair & small & unknown \\
\hline & $\%$ & $\%$ & $\%$ & $\%$ \\
\hline Construction industry & 8 & 29 & 45 & 18 \\
Printing industry & 9 & 18 & 53 & 20 \\
Metal industry & 9 & 23 & 46 & 22 \\
Hospitals and nursing homes & 13 & 41 & 27 & 19 \\
Total & 10 & 28 & 42 & 20 \\
\hline $\mathrm{n}=919$, Chi2, $\mathrm{P}=0.000$ & & & & \\
\hline \hline
\end{tabular}

Note: The survey question reads 'Every year, one company in each sector is chosen as best apprenticeship company. What chance do you think your company has to be nominated?'.

Table 8.9: Chance to be nominated for the best training firm award explained: The effects of training input and expected future benefits

\begin{tabular}{ll}
\hline \hline Complexity of production tasks & Chi2(1) $=0.01$ \\
Learning content of production tasks & Chi2 $(1)=17.22^{* * *}$ \\
Time for formal learning and instruction & Chi2 $(1)=10.89^{* * *}$ \\
\hline \hline
\end{tabular}

Notes: The effects of training input are tested against a model where only background variables explain the chance to be nominated.

* significant at $10 \%$ level, ${ }^{* *}$ significant at $5 \%$ level, ${ }^{* *}$ significant at $1 \%$ level. 


\subsection{ITEMS ON TRAINING INPUT}

Figure 8.1: Densities of the training input measures
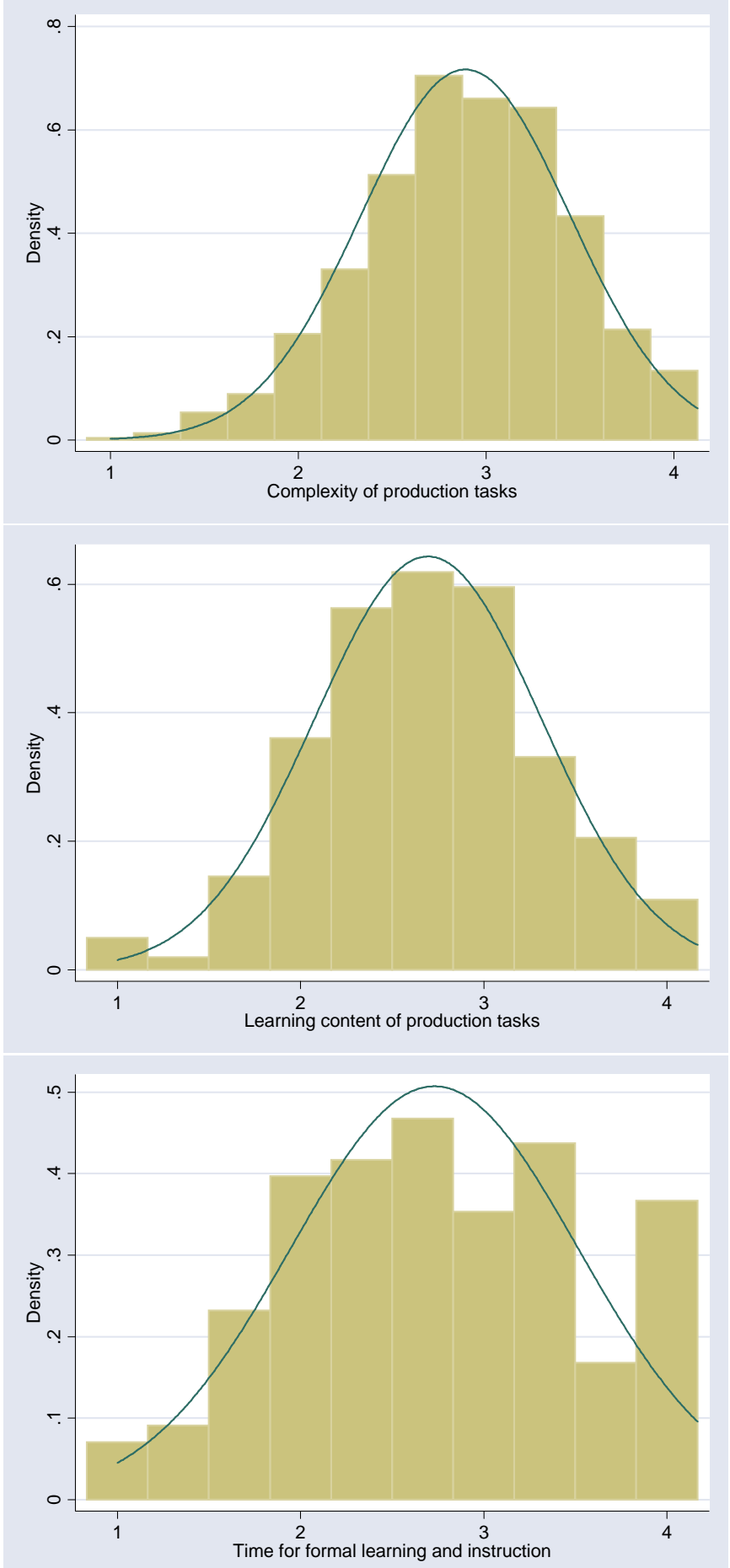


\subsection{Measures for Training Motives}

Measures for training motives that I will consider are the factors that determine the firm's expected future benefits from training, namely the degree of firm-specificity, the degree of monopsony power and the exogenous quit rate and a number of direct measures for current and/or future benefits from training.

\section{Degree of Firm-Specificity}

To measure the degree of firm-specificity I included two questions in the survey. First, the degree of firm-specificity was asked directly. Table 8.10 gives an overview of the results. The degree of firm-specificity of apprenticeship training is quite high in most firms. More than $40 \%$ of the respondents reports a firm-specificity of more than $30 \%$. Only $8 \%$ says that apprentices do not learn any firm-specific skills and knowledge. The degree of firmspecificity does not vary much between the sectors. Only the construction industry reports on average a lower degree of firm-specificity. The most important firm-specific knowledge the apprentice learns is the knowledge of specific operational processes and procedures (see Table 8.11).

Table 8.10: The degree of firm-specificity of apprenticeship training

\begin{tabular}{lrrccc}
\hline \hline Sector & \multicolumn{5}{c}{ Firm-specificity } \\
& 0 & $1-10 \%$ & $11-20 \%$ & $21-30 \%$ & $>30 \%$ \\
& $\%$ & $\%$ & $\%$ & $\%$ & $\%$ \\
\hline Construction & 12 & 15 & 19 & 19 & 35 \\
Printing & 9 & 12 & 20 & 15 & 44 \\
Metal & 5 & 12 & 20 & 19 & 44 \\
Hospitals/Nursing homes & 7 & 14 & 21 & 17 & 41 \\
Total & 8 & 13 & 20 & 18 & 41 \\
\hline $\mathrm{n}=869$, Chi2, $\mathrm{P}=0.427$ & & & & \\
\hline \hline
\end{tabular}

Note: The survey question reads 'Some knowledge and skills that employees have is specific for the company in which they work. Examples are the company culture, its client base, and specific equipment. Which part of the knowledge and skills that apprentices acquire in your company is specific for your company?'. 


\subsection{MEASURES FOR TRAINING MOTIVES}

Table 8.11: Most important type of firm-specific skills and knowledge learnt during the apprenticeship

\begin{tabular}{lr}
\hline \hline Skill type & $\%$ \\
\hline Knowledge of the company culture & 18 \\
Operation of specific machines and equipment & 21 \\
Knowledge of specific operational processes and procedures & 38 \\
Knowledge of the client base & 13 \\
Knowledge of specific company products & 10 \\
Knowledge of company computer programs & 1 \\
\hline $\mathrm{n}=820$ & \\
\hline \hline
\end{tabular}

Note: The survey question reads 'I will mention various types of company-specific knowledge and skills. Which of these is the most important one that apprentices learn in your company?'.

A second measure for firm-specificity is the number of weeks a worker who was trained for the same qualification in an external firm would need to become as productive as an internally trained worker. In $50 \%$ of the firms this is 8 weeks or less (Table 8.12). This result seems to contradict the high degree of firm-specificity reported through the direct question. Table 8.13 gives the median and the mean of the necessary number of weeks by the degree of firm-specificity from the direct question. The median and mean number of weeks increases with the degree of firm-specificity but the standard deviation is very high. This suggests that the question on the number of weeks is not answered very accurately. Also, note that the number of missing values is very high for this question (19\%) indicating that the question was difficult to answer. 
CHAPTER 8. TRAINING INTENSITY AND TRAINING MOTIVES II

Table 8.12: Time needed for an externally trained worker to reach the same productivity as an internally trained worker (in weeks)

\begin{tabular}{lccccc}
\hline \hline Sector & \multicolumn{5}{c}{ Percentile number of weeks } \\
& p10 & p25 & p50 & p75 & p90 \\
\hline Construction & 1 & 4 & 6 & 10 & 25 \\
Printing & 3 & 4 & 8 & 12 & 26 \\
Metal & 3 & 4 & 8 & 20 & 30 \\
Hospitals/Nursing homes & 2 & 4 & 6 & 10 & 16 \\
Total & 2 & 4 & 8 & 12 & 26 \\
\hline $\mathrm{n}=746$ & & & & \\
\hline \hline
\end{tabular}

Note: The survey question reads 'If your company were to employ qualified employees trained as apprentices by another company, how many weeks would it take for them to achieve the same productivity level as employees trained as apprentices in your company?'.

Table 8.13: Time needed for an externally trained worker to reach the same productivity as an internally trained worker (number of weeks) by level of firm-specificity of the training

\begin{tabular}{lcrr}
\hline \hline Firm-specificity & Weedian & Mean & St. dev. \\
& 4 & 6.59 & 8.50 \\
$0 \%$ & 6 & 7.94 & 8.75 \\
$1-10 \%$ & 8 & 11.46 & 14.45 \\
$11-20 \%$ & 8 & 13.14 & 15.97 \\
$21-30 \%$ & 8 & 12.01 & 13.47 \\
More than 30\% & 6 & 9.57 & 10.92 \\
Unknown & 8 & 11.07 & 13.35 \\
Total & & & \\
\hline $\mathrm{n}=746$ & & &
\end{tabular}




\subsection{MEASURES FOR TRAINING MOTIVES}

\section{Degree of Monopsony Power}

For the degree of monopsony power I will consider three measures. The first measure is the number of firms with similar economic activities as the training firm in a geographical area of $25 \mathrm{~km}$ around (see also Harhoff and Kane (1997)). These similar firms have the same skills needs as the training firm and therefore are the potential future employers of the training firm's apprentices who do not want to leave the region. Table 8.14 gives the percentiles of the number of firms by sector of industry. Note that this variable mainly gives an indication of differences in monopsony power within sectors. Differences in monopsony power between sectors depend not only on the number of competitors but also on the size of the competitors (number of employees). For example, for hospitals and nursing homes the median number of competitors is much smaller than in the other sectors but the average number of employees in hospitals and nursing homes is much higher.

Table 8.14: Number of similar firms in the region (25 km radius)

\begin{tabular}{lrrrrr}
\hline \hline Sector & \multicolumn{5}{c}{ Percentiles of the number of firms } \\
& p10 & p25 & p50 & p75 & p90 \\
\hline Construction & 10 & 20 & 40 & 80 & 100 \\
Printing & 3 & 10 & 30 & 70 & 150 \\
Metal & 4 & 10 & 20 & 50 & 100 \\
Hospitals/Nursing homes & 1 & 3 & 6 & 12 & 25 \\
\hline $\mathrm{n}=727$ & & & & \\
\hline \hline
\end{tabular}

Note: The survey question reads 'How many other construction companies/graphics firms/metal firms/similar care institutions are there in your region (roughly a $25-\mathrm{km}$ radius)?'.

Another measure for monopsony power I will consider is the urbanisation grade of the place of business (Table 8.15). The urbanisation grade is measured by the number of addresses in a surrounding of $1 \mathrm{~km}^{2}$ of the place of business. The higher the degree of urbanisation, the less monopsony power the training firm will have. The absolute number of competitors does not necessarily depend on the urbanisation grade, as there are differences in the total number of firms by sector. ${ }^{12}$ Therefore, when considering the relation

\footnotetext{
${ }^{12}$ For example, there are much more construction companies than nursing homes but
} 
between the two measures, the number of similar firms and the urbanisation grade, a correction has to be made for sector. When correcting for sector the number of similar firms increases with the urbanisation grade. Furthermore I considered the relation between urbanisation grade and a missing value for the number of similar firms. As expected, respondents of firms in an area with a low urbanisation grade have less difficulties to give the number of similar firms in the region than respondents of other areas. While in total the number of similar firms is missing for $21 \%$ of the responding firms, this is the case for only $12 \%$ of the responding firms in an area with a low or very low urbanisation grade.

Table 8.15: Urbanisation grade of place of business

\begin{tabular}{lccccc}
\hline \hline Sector & \multicolumn{5}{c}{ Urbanisation Grade } \\
& very high & high & moderate & low & very low \\
\hline & $\%$ & $\%$ & $\%$ & $\%$ & $\%$ \\
\hline Construction industry & 7 & 19 & 20 & 32 & 22 \\
Printing industry & 18 & 29 & 20 & 21 & 13 \\
Metal industry & 4 & 19 & 22 & 36 & 18 \\
Hospitals/ nursing homes & 17 & 34 & 22 & 15 & 12 \\
Total & 11 & 25 & 21 & 26 & 16 \\
\hline $\mathrm{n}=919$, Chi2, $\mathrm{P}=0.000$ & \multicolumn{7}{|c}{} \\
\hline \hline
\end{tabular}

Note: With more than 2,500 addresses in a surrounding of $1 \mathrm{~km}^{2}$ the urbanisation grade is classified as very high, between 2,500 and 1,500 addresses as high, between 1,500 and 1,000 addresses as moderate, between 1,000 and 500 addresses as low and with less than 500 addresses as very low (Source: CBS-Statline).

A final measure for the degree of competition is the ease with which the firm's apprentices will find a similar job in an external firm in the same region once they have completed their training. More than $30 \%$ of the respondents thinks that apprentices would face some difficulties to find a similar job in another firm (Table 8.16). There are, however, considerable differences between economic sectors. For workers trained in hospitals and nursing homes it is much easier to find a similar job in the region than for workers trained in the printing industry. Nevertheless when comparing this measure for monopsony power with the number of similar firms in the surrounding or the urbanisanursing homes are found more often in areas with a high urbanisation grade. 


\subsection{MEASURES FOR TRAINING MOTIVES}

tion grade we find (1) that it is easier to find a similar job when the mean number of firms in the region is higher and (2) the percentage of firms that reports that it is very easy to find a similar job increases with the urbanisation grade (Tables 8.17 and 8.18). So, the various measures for monopsony power, considered here, all point into the same direction.

Table 8.16: Possibility to find a similar job in the region (25 km radius)

\begin{tabular}{|c|c|c|c|c|}
\hline \multirow[t]{3}{*}{ Sector } & \multicolumn{4}{|c|}{ Easy to find a similar job? } \\
\hline & very & reasonably & fairly & very \\
\hline & easy & easy & difficult & difficult \\
\hline & $\%$ & $\%$ & $\%$ & $\%$ \\
\hline Construction industry & 33 & 45 & 16 & 6 \\
\hline Printing industry & 21 & 35 & 26 & 18 \\
\hline Metal industry & 30 & 48 & 17 & 6 \\
\hline Hospitals and nursing homes & 56 & 39 & 4 & 1 \\
\hline Total & 36 & 42 & 15 & 7 \\
\hline $\mathrm{n}=870$, Chi $2, \mathrm{P}=0.000$ & & & & \\
\hline
\end{tabular}

Note: The survey question reads 'Is it easy for employees who have been trained in your company through the apprenticeship system to find a similar job at another construction company/ graphics firm/ metal firm/ care institution in the same region (roughly a $25-\mathrm{km}$ radius)?'.

Table 8.17: Number of similar firms in the region by the ease to find a similar job in the region ( $25 \mathrm{~km}$ radius)

\begin{tabular}{lrr}
\hline \hline Similar job & \multicolumn{2}{c}{ Number of firms } \\
& mean & \multicolumn{1}{c}{ st. } \\
& 156.28 & 1075.77 \\
\hline Very easy & 69.16 & 589.98 \\
Reasonably easy & 34.90 & 40.06 \\
Fairly difficult & 48.63 & 72.36 \\
Very difficult & 58.33 & 180.18 \\
Unknown & 93.06 & 740.13 \\
Total & & \\
\hline $\mathrm{n}=727$ & \\
\hline \hline
\end{tabular}


CHAPTER 8. TRAINING INTENSITY AND TRAINING MOTIVES II

Table 8.18: Possibility to find a similar job by urbanisation grade of place of business

\begin{tabular}{lcrrrr}
\hline \hline Similar job & \multicolumn{5}{c}{ Urbanisation Grade } \\
& very high & high & moderate & low & very low \\
\hline Very easy & $\%$ & $\%$ & $\%$ & $\%$ & $\%$ \\
Reasonably easy & 42 & 37 & 34 & 32 & 28 \\
Fairly difficult & 36 & 37 & 39 & 42 & 46 \\
Very difficult & 12 & 13 & 12 & 16 & 16 \\
Unknown & 6 & 8 & 8 & 5 & 7 \\
\hline $\mathrm{n}=870$, Chi2, $\mathrm{P}=0.532$ & 4 & 5 & 7 & 6 & 3 \\
\hline \hline
\end{tabular}

\section{The Quit Rate}

To measure the exogenous quit rate, I included a question on the chance that an apprentice trained in the firm would want to keep working in the firm after completing the training. However, this question could not be asked in all cases. In many firms, apprentices are given a permanent contract already during the training period. During the try-out of the questionnaire it became clear that respondents assume that apprentices with a permanent contract always want to stay in the firm after completing the training. ${ }^{13}$ Therefore the question concerning the chance that an apprentice wants to keep working in the firm has been posed only to firms in which apprentices do not have a permanent contract.

Table 8.19 shows that in $29 \%$ of the responding firms apprentices have a permanent contract. Among hospitals and nursing homes the number of companies that offer apprentices a permanent contract is even higher (59\%). Only in the construction industry the number of firms that offer apprentices a permanent contract during the training period is very small (13\%). This is related to the fact that in this sector most apprentices do not have a learning contract with a single firm but with a training co-operation that places the apprentices at the affiliated firms.

\footnotetext{
${ }^{13}$ In fact, most respondents thought the same question was asked two times which lead to irritation.
} 


\subsection{MEASURES FOR TRAINING MOTIVES}

Table 8.19: Type of contract during the apprenticeship

\begin{tabular}{|c|c|c|c|c|c|}
\hline \multirow[t]{4}{*}{ Sector } & \multicolumn{5}{|c|}{ Type of contract } \\
\hline & \multicolumn{3}{|c|}{ Learning\&Employment } & \multirow[t]{2}{*}{ Learning } & \multirow{2}{*}{$\begin{array}{c}\text { Training } \\
\text { co-ope- } \\
\text { ration }\end{array}$} \\
\hline & Permanent & Temporary & Total & & \\
\hline & $\%$ & $\%$ & $\%$ & $\%$ & $\%$ \\
\hline Construction industry & 13 & 9 & 22 & 9 & 69 \\
\hline Printing industry & 31 & 34 & 65 & 24 & 10 \\
\hline Metal industry & 36 & 43 & 81 & 15 & 4 \\
\hline Hospitals/nursing homes & 59 & 30 & 79 & 7 & 3 \\
\hline Total & 35 & 29 & 66 & 13 & 21 \\
\hline$n=903$ & & & & & \\
\hline
\end{tabular}

Note: The survey question reads 'What type of contract do apprentices usually have in your company? [if both a learning contract and an employment contract] Is this usually a permanent employment contract or a temporary employment contract?'.

Most firms estimate the chance that an apprentice without a permanent contract wants to stay quite high. Nearly half of the respondents estimated this chance to be between $75 \%$ and $100 \%$ and only $25 \%$ of the respondents estimated this chance to be lower than $75 \%$ (see Table 8.20). In hospitals and nursing homes the chance that a worker will stay is estimated somewhat higher than in the other sectors considered here.

Not only the quit rate but also the total time the worker stays in the training firms after completing the training is an important determinant of the expected future benefits. I included a question about the average time an internally trained worker who has accepted a job offer in the training firm or had a permanent contract during the training period already, would stay with the training firm after completing the training. In about $60 \%$ of the responding firms the average duration is more than 5 years (Table 8.21). 
CHAPTER 8. TRAINING INTENSITY AND TRAINING MOTIVES II

Table 8.20: Chance the apprentice wants to keep working in the firm (apprentices without a permanent contract)

\begin{tabular}{lccc}
\hline Sector & \multicolumn{3}{c}{ Chance } \\
& $\leq 75 \%$ & $75-100 \%$ & $100 \%$ \\
\hline & $\%$ & $\%$ & $\%$ \\
\hline Construction industry & 24 & 46 & 29 \\
Printing industry & 34 & 39 & 28 \\
Metal industry & 26 & 52 & 22 \\
Hospitals and nursing homes & 12 & 59 & 29 \\
Total & 25 & 48 & 27 \\
\hline $\mathrm{n}=575$, Chi2, $\mathrm{P}=0.005$ & & & \\
\hline \hline
\end{tabular}

Note: The survey question reads 'How great is the chance that an apprentice who is trained in your company wants to keep working in your company after having completed the training programme?'.

Table 8.21: Average time an apprentice stays in the training firm after completing the training (conditional on staying)

\begin{tabular}{lcccc}
\hline \hline Sector & Number & or years & \\
& $0-2$ & $3-4$ & $>5$ & not applicable \\
\hline & $\%$ & $\%$ & $\%$ & $\%$ \\
\hline Construction industry & 11 & 18 & 66 & 5 \\
Printing industry & 13 & 19 & 54 & 14 \\
Metal industry & 7 & 24 & 55 & 14 \\
Hospitals and nursing homes & 6 & 27 & 61 & 6 \\
Total & 9 & 22 & 59 & 10 \\
\hline $\mathrm{n}=738$, Chi2, $\mathrm{P}=0.002$ & & & \\
\hline \hline
\end{tabular}

Note: The survey question reads 'The next question concerns apprentices who entered into employment with your company after having completed the training programme. On average, how many years do such former apprentices remain with your company?'. 


\subsection{MEASURES FOR TRAINING MOTIVES}

\section{Current or Future Benefits?}

The degree of firm-specificity, the degree of monopsony power and the expected quit rate all affect future training benefits. To measure whether firms indeed have future benefits from apprenticeship training it was also asked whether apprentices are financially attractive for the firm. It was asked how interesting apprentices are if costs are weight against the benefits in general and if all apprentices were to leave the training firm after completing the training. The idea is that if the apprenticeship system is financially attractive only if apprentices stay after the training, the firm must have future training benefits. Firms for which the apprenticeship system is attractive even if all apprentices leave must have some current benefits that compensate the training costs.

For more than $90 \%$ of the firms, the apprenticeship system is slightly or very interesting from a financial perspective (Table 8.22). If apprentices all were to leave after completing the training the apprenticeship system would be attractive for less than $30 \%$ of the training firms, meaning that future benefits are important for most firms.

Does this mean that firms always want to retain apprentices after the training? Table 8.19 showed that $35 \%$ of the firms offers apprentices a permanent contract during the apprenticeship period already. From Table 8.23 it becomes clear that among those firms that do not offer a permanent contract already during the apprenticeship, a quarter certainly offers a continuation of the appointment after the training. In $35 \%$ of the firms, the chance on a continuation of the contract is between $75 \%$ and $100 \%$ and in $40 \%$ of the firms it is less than $75 \%$. So although for most firms apprenticeship are only financially attractive if the apprentice is to stay in the training firms after completing the training, it is not certain at forehand, that all apprentices are offered a continuation of their contract. One reason might be that firms train apprentices to select the best workers and only offer the best apprentices a continuation (Franz and Soskice, 1995; Acemoglu and Pischke, 1999a). Table 8.24 shows that the probability that the apprentice is suitable to continue working in the firm is for most firms greater than the chance that the firm indeed offers employment. This means that the screening mechanism is not the 


\section{CHAPTER 8. TRAINING INTENSITY AND TRAINING MOTIVES II}

only explanation. Firms face uncertainty with respect to the future labour demand they have. Therefore they are not certain that they can keep all apprentices that they train. Nevertheless it can be expected that the higher the chance a firm wants to retain the apprentice after the training, the higher the expected future returns will be, all other things equal. Therefore the chance that the firm offers the apprentice a continuation of his appointment is also an indication for future benefits.

Table 8.22: How interesting are apprentices for the firm if costs are weight against the benefits in general and if the apprentice were to go after having completed the training

\begin{tabular}{|c|c|c|c|c|}
\hline \multicolumn{5}{|l|}{ Sector } \\
\hline & $\begin{array}{c}\text { very } \\
\text { interesting }\end{array}$ & $\begin{array}{c}\text { slightly } \\
\text { interesting }\end{array}$ & $\begin{array}{c}\text { slightly } \\
\text { uninteresting }\end{array}$ & $\begin{array}{c}\text { very } \\
\text { uninteresting }\end{array}$ \\
\hline In general & $\%$ & $\%$ & $\%$ & $\%$ \\
\hline Construction & 20 & 67 & 8 & 5 \\
\hline Printing & 33 & 58 & 8 & 2 \\
\hline Metal & 37 & 54 & 7 & 2 \\
\hline Hospitals & 48 & 46 & 3 & 2 \\
\hline Total & 35 & 56 & 6 & 3 \\
\hline \multicolumn{5}{|c|}{ Apprentice quits } \\
\hline Construction & 7 & 21 & 28 & 44 \\
\hline Printing & 9 & 22 & 22 & 47 \\
\hline Metal & 5 & 17 & 26 & 52 \\
\hline Hospitals & 11 & 24 & 31 & 33 \\
\hline Total & 8 & 21 & 27 & 44 \\
\hline $\mathrm{n}=883$, Chi2, & & & & \\
\hline
\end{tabular}

Note: The survey question reads 'How interesting are apprentices for your company if you weigh the costs against the benefits? and How interesting are apprentices for your company if they were to go and work for another company after having completed their training?'. 


\subsection{MEASURES FOR TRAINING MOTIVES}

Table 8.23: Chance the apprentice is offered an appointment at the firm (apprentices without a permanent contract)

\begin{tabular}{lccc}
\hline \hline Sector & \multicolumn{3}{c}{ Chance } \\
& $\leq 75 \%$ & $75-100 \%$ & $100 \%$ \\
\hline & $\%$ & $\%$ & $\%$ \\
\hline Construction industry & 44 & 31 & 26 \\
Printing industry & 58 & 23 & 20 \\
Metal industry & 29 & 49 & 22 \\
Hospitals and nursing homes & 24 & 35 & 40 \\
Total & 40 & 35 & 26 \\
\hline $\mathrm{n}=569$, Chi2, $\mathrm{P}=0.000$ & & & \\
\hline \hline
\end{tabular}

Note: The survey question reads 'How great is the chance that an apprentice who is trained in your company is offered an appointment at your company after having completed the training programme?'.

Table 8.24: Chance the apprentice is suitable to continue working in the firm (apprentices without a permanent contract)

\begin{tabular}{lccc}
\hline \hline Sector & \multicolumn{3}{c}{ Chance } \\
& $\leq 75 \%$ & $75-100 \%$ & $100 \%$ \\
\hline & $\%$ & $\%$ & $\%$ \\
\hline Construction industry & 33 & 35 & 32 \\
Printing industry & 29 & 35 & 35 \\
Metal industry & 24 & 46 & 30 \\
Hospitals and nursing homes & 7 & 35 & 59 \\
Total & 25 & 38 & 37 \\
\hline $\mathrm{n}=585$, Chi2, $\mathrm{P}=0.000$ & & & \\
\hline
\end{tabular}

Note: The survey question reads 'How great is the chance that an apprentice who is trained in your company is suitable to continue working in your company after having completed the training programme?'. 


\subsection{Determinants of Training Input}

The three measures for training input, discussed in section 8.3, have been regressed on the measures for training motives; the degree of firm-specificity, the degree of monopsony power, the quit rate and the incidence of current and/or future benefits from apprenticeship training. Table 8.25 gives an overview of all the measures for training motives included in the regression.

For firm-specificity I included a dummy variable for a firm-specificity of more than $10 \%^{14}$ and dummy variables for more or less than two months time needed for an external worker to reach the same productivity as an internally trained worker.

Monopsony power is represented by a dummy variable for less than 10 competitors in the region, ${ }^{15}$ a dummy variable for a high or very high urbanisation grade and a dummy variable indicating that it will be difficult to find a similar job in another firm in the region.

For the quit rate I included dummy's for the chance that the apprentice will stay and dummy variables for the average time the former apprentice will stay in the training firm after completing the training.

Finally I included a dummy variable indicating that the firm has only future benefits ${ }^{16}$ and dummy variables for the chance that the firm offers the apprentice a continuation of his appointment after completing the training. 1718

\footnotetext{
${ }^{14}$ Including separate dummy variables for all response categories separately does not change the results.

${ }^{15}$ I also included a dummy variable for less competitors than the first quartile in the sector but this variable has no explanatory power.

${ }^{16}$ This is the case if the apprenticeship system is only financially attractive for the firm if the apprentice is going to stay after completing the training.

${ }^{17}$ The chance that an apprentice is suitable to stay is not included in the regressions because it is too highly correlated with the chance that the apprentice is offered employment.

${ }^{18}$ For both the chance that the apprentice wants to stay and the chance that the apprentice is offered employment after completing the training, the $100 \%$ category includes permanent contracts. So the coefficient of the dummy variable for a permanent contract during the apprenticeship has to be interpreted relative to the $100 \%$ categories of these two variables.
} 


\subsection{DETERMINANTS OF TRAINING INPUT}

As discussed in section 8.4 some questions of the survey were not very well answered and so the variables based on these questions contain a lot of missing values. To save on observations the missing values for these variables are included in the regression as a separate dummy category. ${ }^{19}$

Table 8.25: Measures for training motives

\begin{tabular}{l}
\hline Degree of firm-specificity \\
Dummy for firm-specificity $10 \%$ or more \\
Dummy for $\leq 2$ months needed to reach productivity \\
Dummy for $>2$ months needed to reach productivity (reference) \\
Dummy for number of months needed to reach productivity unknown \\
Degree of monopsony power \\
Dummy for more than 10 competitors (reference) \\
Dummy for less than 10 competitors \\
Dummy for number of competitors is unknown \\
Dummy for difficult to find a job \\
Dummy for high urbanisation grade \\
Quit rate \\
Dummy for permanent contract \\
Dummy for chance the apprentice wants to stay $100 \%$ \\
Dummy for chance the apprentice wants to stay between $75 \%$ and $100 \%$ \\
Dummy for chance the apprentice wants to stay below $75 \%$ (reference) \\
Dummy for $0-2$ years in training firm after completing the training \\
Dummy for $3-4$ years in training firm after completing the training \\
Dummy for $\geq 5$ years in training firm after completing the training (reference) \\
Dummy for number of years unknown \\
Current or future benefits? \\
Dummy for only future training benefits \\
Dummy for chance the apprentice is offered employment $100 \%$ \\
Dummy for chance the apprentice is offered employment $75 \%$ and $100 \%$ \\
Dummy for chance the apprentice is offered employment below $75 \%$ (reference) \\
\hline \hline
\end{tabular}

\footnotetext{
${ }^{19}$ This is the case for the number of competitors in the region, the time needed for an externally trained worker to reach the same productivity as an internally trained worker and the average number of years a stayer remains with the training firm.
} 
Firm characteristics included in the regressions are economic sector, firm size, a dummy for no apprentices at the time of the survey, ${ }^{20}$ a dummy for firms with only one apprentice, a dummy for the function of the respondent, dummy's for the type of contract, dummy's for the qualification level of the training and a dummy indicating whether the interview took place by internet or not.

Table 8.26 gives the joint significance of the training motive measures. ${ }^{21}$ The first measure for training input, the complexity of production tasks, is clearly affected by training motives. The explained variance increases by more than $50 \%$. The most important factor is the degree of monopsony power. The degree of firm-specificity does not affect the complexity of production tasks. This suggests either that the degree of firm-specificity is not an important determinant of the expected future benefits or that the complexity of production tasks can only be high if the training is little firm-specific. The latter is not very plausible, however.

For the other training input measures, the learning content of production tasks and the time for formal learning and instruction, training motives seem to have little impact. For the learning content of production tasks only the firm-specificity of the training has a positive impact whereas for time for formal learning and instruction only the degree of monopsony power matters.

One reason why training motives matter mostly for the complexity of production tasks and not for the learning content or the time for formal learning and instruction is that this first aspect of the training is more difficult to observe. As explained in section 8.3, the training firm can more easily cheat on aspects of the training programme that are difficult to observe. For that reason, firms will only have an incentive to pay attention to these aspects of the training if there is a future benefit of doing so.

\footnotetext{
${ }^{20}$ This concerns firms that employed apprentices only during the past two years.

${ }^{21}$ Tables $8.30,8.31$ and 8.32 in the appendix to this chapter give the full estimation results for the three training input indicators.
} 


\subsection{TRAINING INPUT AND TRAINING OUTPUT}

Table 8.26: Training input explained: tests on the effect of training motives

\begin{tabular}{llll}
\hline \hline & $\begin{array}{c}\text { Complexity } \\
\text { production } \\
\text { tasks }\end{array}$ & $\begin{array}{c}\text { Learning } \\
\text { content } \\
\text { production } \\
\text { tasks }\end{array}$ & $\begin{array}{c}\text { Time for } \\
\text { learning and } \\
\text { instruction }\end{array}$ \\
\hline \hline Firm-specificity & $\mathrm{F}(3,685)=0.88$ & $\mathrm{~F}(3,684)=2.35^{*}$ & $\mathrm{~F}(3,676)=0.72$ \\
Monopsony power & $\mathrm{F}(4,685)=4.03^{* * *}$ & $\mathrm{~F}(4,684)=0.55$ & $\mathrm{~F}(4,676)=2.19^{*}$ \\
Quit rate & $\mathrm{F}(6,685)=2.71^{* *}$ & $\mathrm{~F}(6,684)=1.59$ & $\mathrm{~F}(6,676)=0.76$ \\
Current/future benefits & $\mathrm{F}(3,685)=2.53^{*}$ & $\mathrm{~F}(3,684)=0.89$ & $\mathrm{~F}(3,676)=0.59$ \\
\hline \hline
\end{tabular}

* significant at $10 \%$ level

$* *$ significant at $5 \%$ level

$* * *$ significant at $1 \%$ level

\subsection{Training Input and Training Output}

In this section, I will test whether training input matters for training outcomes. The subjective chance that an apprentice in the firm will obtain a diploma is used as an output indicator. In firms that have high training input this chance is expected to be higher than in firms that have low training input. Table 8.27 shows that less than $15 \%$ of the firms estimates this chance below $75 \%$. About half of the firms estimates this chance between $75 \%$ and $100 \%$ and nearly one third says that this chance is $100 \%$.

I estimated the relation between the chance on a diploma and the input quality measures by use of an interval regression. ${ }^{22}$ Table 8.28 shows that the subjective chance to obtain a diploma is strongly affected by the complexity of production tasks but not by the learning content of productions tasks or the time for learning and instruction. So although, as the results of this chapter show, it does not pay for the firm to pay attention to this first aspect if it has no investment motives, it is still an important aspect of training input.

One might worry that the relation between training input and training output is overestimated because the best training firms are able to attract the best apprentices. However, apprentices will choose their apprenticeship

${ }^{22}$ Table 8.27 gives the full estimation results. 
CHAPTER 8. TRAINING INTENSITY AND TRAINING MOTIVES II

place based on the observable aspects of the training programme, and the effect found here is based on aspects of the training that are unobservable for apprentices at the moment they start their training. Nevertheless to control for selection, I included the chance that the firm thinks an apprentice is suitable to stay in the training firm after completing the training as a proxy for apprentice ability. This does not alter the results.

Table 8.27: Subjective chance that an apprentice obtains a diploma

\begin{tabular}{lccc}
\hline \hline Sector & \multicolumn{3}{c}{ Chance } \\
& $\leq 75 \%$ & $75-100 \%$ & $100 \%$ \\
\hline Construction industry & $\%$ & $\%$ & $\%$ \\
Printing industry & 16 & 49 & 36 \\
Metal industry & 12 & 48 & 40 \\
Hospitals and nursing homes & 18 & 54 & 28 \\
Total & 16 & 61 & 22 \\
$\mathrm{n}=887$, Chi2, $\mathrm{P}=0.004$ & 16 & 54 & 31 \\
\hline \hline
\end{tabular}

Note: The survey question reads 'How great is the chance that an apprentice who is trained in your company obtains a diploma?'. 


\subsection{CONCLUSIONS}

Table 8.28: Chance to obtain a diploma explained: The effects of training input and expected future benefits

\begin{tabular}{ll}
\hline \hline Complexity of production tasks & Chi2 $(1)=6.50^{* * *}$ \\
Learning content of production tasks & Chi2 $(1)=2.31$ \\
Time for learning and instruction & Chi2 $2(1)=1.48$ \\
Firm-specificity & Chi2 $(3)=5.37$ \\
Monopsony power & Chi $2(4)=4.12$ \\
Quit rate & Chi2 $(6)=52.74^{* * *}$ \\
Current/future term benefits & Chi2 $2(3)=2.08$ \\
\hline \hline
\end{tabular}

Notes: The effects of training input are tested against a model where only background variables explain the chance to obtain a diploma and the effects of expected future benefits are tested against a model where both background characteristics and the training input indicators explain this chance. * significant at $10 \%$ level, ** significant at $5 \%$ level, ${ }^{* * *}$ significant at $1 \%$ level.

\subsection{Conclusions}

In this chapter, I tested whether there is a relation between a firm's training motives and training intensity. I conducted a survey among training firms in the construction industry, the printing industry, the metal industry and the care sector to obtain measures for both the training input and training motives. I constructed input measures for three aspects of the training place, namely the complexity of production tasks, the learning content of production tasks and the formal time for learning and instruction. For the firm's training motives I considered the degree of firm-specificity, the degree of monopsony power, the quit rate and a direct measure for the incidence of future benefits from apprenticeship training.

I found that the complexity of production tasks does not affect the firm's training reputation, measured by the chance to be nominated for the elections of the best training firm in the sector, while the two other aspects of training that are more easily to observe, the learning content of production tasks and the formal time for learning and instruction do matter for the firms' s training reputation.

Furthermore I found that training motives matter mostly for that aspect of the training input that is most difficult to observe by third parties, namely 
CHAPTER 8. TRAINING INTENSITY AND TRAINING MOTIVES II

the complexity of production tasks. For the learning content of production tasks and the time for learning and instruction there is less evidence that training motives matter for training input. I also found that the complexity of productions tasks, is the most effective training input, as it has the highest impact on the output from training, the chance to obtain a diploma.

So, the complexity of production tasks is the most effective part of training input, but firms only have an incentive to pay attention to this aspect if they have investment motives. Firms without investment motives tend to pay more attention to the aspects of the training that are easily observable, but less effective in terms of training output, because these aspects contribute to their reputation.

The results of this chapter again suggest that regulation of the training is not sufficient to guarantee good training if the firm does not have investment motives. Regulation will only be possible for the observable parts of the training while precisely the unobservable aspects of the training seem to be very important determinants of training output. It is therefore important that policies aimed at increasing the number of apprenticeship places do not stimulate firms without investment motives to participate in the apprenticeship system. 


\subsection{APPENDIX TO CHAPTER 8}

\subsection{Appendix to Chapter 8}

Table 8.29: Probit analysis for the probability that the chance to be nominated as the best training firm in the sector is perceived as great

\begin{tabular}{|c|c|c|}
\hline & $(1)$ & $(2)$ \\
\hline Complexity of production tasks & & $\begin{array}{c}-0.007 \\
(0.096)\end{array}$ \\
\hline Learning content of production tasks & & $\begin{array}{l}0.343 \\
(0.083) * * *\end{array}$ \\
\hline Time for learning and instruction & & $\begin{array}{l}0.229 \\
(0.070) * * *\end{array}$ \\
\hline Construction industry & $\begin{array}{c}-0.187 \\
(0.196)\end{array}$ & $\begin{array}{c}-0.266 \\
(0.201) *\end{array}$ \\
\hline Printing industry & $\begin{array}{c}-0.175 \\
(0.183)\end{array}$ & $\begin{array}{c}-0.159 \\
(0.187)\end{array}$ \\
\hline Metal industry & $\begin{array}{l}-0.453 \\
(0.222) * *\end{array}$ & $\begin{array}{l}-0.501 \\
(0.230) * *\end{array}$ \\
\hline Firm size $<10$ workers & $\begin{array}{c}-0.129 \\
(0.255)\end{array}$ & $\begin{array}{c}-0.014 \\
(0.261)\end{array}$ \\
\hline Firm size 10-99 workers & $\begin{array}{c}-0.051 \\
(0.196)\end{array}$ & $\begin{array}{c}-0.024 \\
(0.199)\end{array}$ \\
\hline Firm size 100-499 workers & $\begin{array}{c}0.214 \\
(0.195)\end{array}$ & $\begin{array}{c}0.209 \\
(0.197)\end{array}$ \\
\hline No apprentices & $\begin{array}{l}-0.518 \\
(0.175) * * *\end{array}$ & $\begin{array}{l}-0.536 \\
(0.179) * * *\end{array}$ \\
\hline 1 apprentice & $\begin{array}{l}-0.400 \\
(0.136) * * *\end{array}$ & $\begin{array}{l}-0.374 \\
(0.139) * * *\end{array}$ \\
\hline Employment and learning contract & $\begin{array}{c}-0.055 \\
(0.168)\end{array}$ & $\begin{array}{c}-0.021 \\
(0.172)\end{array}$ \\
\hline Learning contract & $\begin{array}{c}-0.231 \\
(0.207)\end{array}$ & $\begin{array}{c}-0.265 \\
(0.210)\end{array}$ \\
\hline Practical trainer & $\begin{array}{c}0.088 \\
(0.138)\end{array}$ & $\begin{array}{c}0.052 \\
(0.142)\end{array}$ \\
\hline Co-ordinator & $\begin{array}{c}0.136 \\
(0.138)\end{array}$ & $\begin{array}{c}0.086 \\
(0.141)\end{array}$ \\
\hline Surveyed by internet & $\begin{array}{c}0.153 \\
(0.134)\end{array}$ & $\begin{array}{c}0.160 \\
(0.136)\end{array}$ \\
\hline Q13 refers to level 2 & $\begin{array}{c}0.134 \\
(0.218) \\
\end{array}$ & $\begin{array}{c}0.093 \\
(0.225) \\
\end{array}$ \\
\hline
\end{tabular}


CHAPTER 8. TRAINING INTENSITY AND TRAINING MOTIVES II

Table 8.29: continued

\begin{tabular}{lcc}
\hline \hline & $(1)$ & $(2)$ \\
\hline Q13 refers to level 4 & -0.290 & -0.309 \\
& $(0.304)$ & $(0.306)$ \\
Constant & 0.011 & -1.522 \\
& $(0.248)$ & $(0.458) * * *$ \\
Observations & 700 & 700 \\
\hline \hline
\end{tabular}

Standard errors in parentheses

* significant at $10 \%$ level

** significant at $5 \%$ level

$* * *$ significant at $1 \%$ level 


\subsection{APPENDIX TO CHAPTER 8}

Table 8.30: Training input explained (OLS): Complexity of production tasks

\begin{tabular}{|c|c|c|}
\hline & $(1)$ & $(2)$ \\
\hline Firm-specificity $10 \%$ or more & & $\begin{array}{c}0.056 \\
(0.051)\end{array}$ \\
\hline$\leq 2$ months needed to reach productivity & & $\begin{array}{c}0.063 \\
(0.048)\end{array}$ \\
\hline Number of months unknown & & $\begin{array}{c}0.045 \\
(0.068)\end{array}$ \\
\hline Less than 10 competitors & & $\begin{array}{c}-0.042 \\
(0.055)\end{array}$ \\
\hline Number of competitors is unknown & & $\begin{array}{c}0.097 \\
(0.058) *\end{array}$ \\
\hline Difficult to find a job & & $\begin{array}{c}-0.012 \\
(0.052)\end{array}$ \\
\hline High urbanisation grade & & $\begin{array}{l}-0.161 \\
(0.046) * * *\end{array}$ \\
\hline Permanent contract & & $\begin{array}{l}0.256 \\
(0.078) * * *\end{array}$ \\
\hline Chance apprentice wants to stay $75 \%-100 \%$ & & $\begin{array}{c}0.060 \\
(0.071)\end{array}$ \\
\hline Chance the apprentice wants to stay $100 \%$ & & $\begin{array}{c}0.022 \\
(0.082)\end{array}$ \\
\hline $0-2$ years in training firm & & $\begin{array}{c}0.043 \\
(0.086)\end{array}$ \\
\hline $3-4$ years in training firm & & $\begin{array}{c}-0.063 \\
(0.056)\end{array}$ \\
\hline Number of years in training firm unknown & & $\begin{array}{c}-0.072 \\
(0.055)\end{array}$ \\
\hline Only future training benefits & & $\begin{array}{c}-0.003 \\
(0.044)\end{array}$ \\
\hline Chance employment offer $75 \%-100 \%$ & & $\begin{array}{c}0.099 \\
(0.066)\end{array}$ \\
\hline Chance employment offer $100 \%$ & & $\begin{array}{l}0.202 \\
(0.074) * * *\end{array}$ \\
\hline Construction industry & $\begin{array}{c}0.109 \\
(0.083)\end{array}$ & $\begin{array}{c}0.096 \\
(0.086)\end{array}$ \\
\hline Printing industry & $\begin{array}{c}0.038 \\
(0.077)\end{array}$ & $\begin{array}{c}0.082 \\
(0.082)\end{array}$ \\
\hline Metal industry & $\begin{array}{c}-0.140 \\
(0.090)\end{array}$ & $\begin{array}{c}-0.152 \\
(0.093)\end{array}$ \\
\hline
\end{tabular}


CHAPTER 8. TRAINING INTENSITY AND TRAINING MOTIVES II

Table 8.30: continued

\begin{tabular}{lcc}
\hline \hline & $(1)$ & $(2)$ \\
\hline Firm size $<10$ workers & -0.023 & -0.010 \\
Firm size 10-99 workers & $(0.106)$ & $(0.109)$ \\
Firm size 100-499 workers & -0.141 & -0.151 \\
& $(0.083) *$ & $(0.085) *$ \\
No apprentices & -0.046 & -0.037 \\
& $(0.082)$ & $(0.083)$ \\
1 apprentice & -0.196 & -0.202 \\
& $(0.071) * * *$ & $(0.072) * * *$ \\
Employment and learning contract & -0.011 & -0.016 \\
& $(0.056)$ & $(0.055)$ \\
Learning contract & 0.087 & 0.049 \\
& $(0.071)$ & $(0.076)$ \\
Practical trainer & -0.045 & -0.020 \\
& $(0.084)$ & $(0.084)$ \\
Co-ordinator & 0.104 & 0.083 \\
& $(0.057) *$ & $(0.057)$ \\
Surveyed by internet & 0.016 & 0.016 \\
& $(0.058)$ & $(0.058)$ \\
Q13 refers to level 2 & 0.165 & 0.155 \\
& $(0.057) * * *$ & $(0.059) * * *$ \\
Q13 refers to level 4 & -0.082 & -0.091 \\
Constant & $(0.087)$ & $(0.087)$ \\
& -0.024 & 0.015 \\
Observations & $(0.130)$ & $(0.130)$ \\
Adjusted R-squared & 2.900 & 2.756 \\
\hline \hline Stand & $(0.105) * * *$ & $(0.144) * * *$ \\
\hline
\end{tabular}

Standard errors in parentheses

* significant at $10 \%$ level

** significant at $5 \%$ level

$* * *$ significant at $1 \%$ level 


\subsection{APPENDIX TO CHAPTER 8}

Table 8.31: Training input explained (OLS): Learning content of production tasks

\begin{tabular}{|c|c|c|}
\hline & $(1)$ & $(2)$ \\
\hline Firm-specificity $10 \%$ or more & & $\begin{array}{l}0.145 \\
(0.059) * *\end{array}$ \\
\hline$\leq 2$ months needed to reach productivity & & $\begin{array}{c}0.070 \\
(0.055)\end{array}$ \\
\hline Number of months unknown & & $\begin{array}{c}0.029 \\
(0.079)\end{array}$ \\
\hline Less than 10 competitors & & $\begin{array}{c}0.037 \\
(0.064)\end{array}$ \\
\hline Number of competitors is unknown & & $\begin{array}{c}-0.014 \\
(0.066)\end{array}$ \\
\hline Difficult to find a job & & $\begin{array}{c}-0.079 \\
(0.060)\end{array}$ \\
\hline High urbanisation grade & & $\begin{array}{c}-0.014 \\
(0.053)\end{array}$ \\
\hline Permanent contract & & $\begin{array}{c}-0.095 \\
(0.090)\end{array}$ \\
\hline Chance apprentice wants to stay $75 \%-100 \%$ & & $\begin{array}{c}0.024 \\
(0.082)\end{array}$ \\
\hline Chance apprentice wants to stay $100 \%$ & & $\begin{array}{c}0.153 \\
(0.094)\end{array}$ \\
\hline 0-2 years in training firm & & $\begin{array}{c}0.049 \\
(0.100)\end{array}$ \\
\hline 3-4 years in training firm & & $\begin{array}{c}-0.079 \\
(0.064)\end{array}$ \\
\hline Number of years in training firm unknown & & $\begin{array}{c}-0.064 \\
(0.064)\end{array}$ \\
\hline Only future training benefits & & $\begin{array}{c}-0.016 \\
(0.051)\end{array}$ \\
\hline Chance employment offer $75 \%-100 \%$ & & $\begin{array}{c}-0.012 \\
(0.076)\end{array}$ \\
\hline Chance employment offer $100 \%$ & & $\begin{array}{c}-0.122 \\
(0.085)\end{array}$ \\
\hline Construction industry & $\begin{array}{c}-0.013 \\
(0.095)\end{array}$ & $\begin{array}{c}-0.002 \\
(0.099)\end{array}$ \\
\hline Printing industry & $\begin{array}{c}-0.040 \\
(0.088)\end{array}$ & $\begin{array}{c}-0.035 \\
(0.095)\end{array}$ \\
\hline Metal industry & $\begin{array}{c}-0.101 \\
(0.103)\end{array}$ & $\begin{array}{c}-0.094 \\
(0.107)\end{array}$ \\
\hline
\end{tabular}


CHAPTER 8. TRAINING INTENSITY AND TRAINING MOTIVES II

Table 8.31: continued

\begin{tabular}{lcc}
\hline \hline & $(1)$ & $(2)$ \\
\hline Firm size $<10$ workers & -0.248 & -0.242 \\
Firm size 10-99 workers & $(0.121) * *$ & $(0.127) *$ \\
& -0.082 & -0.080 \\
Firm size 100-499 workers & $(0.095)$ & $(0.098)$ \\
& -0.028 & -0.024 \\
No apprentices & $(0.094)$ & $(0.096)$ \\
& 0.079 & 0.094 \\
1 apprentice & $(0.081)$ & $(0.083)$ \\
& 0.030 & 0.041 \\
Employment and learning contract & $(0.064)$ & $(0.064)$ \\
& -0.070 & -0.008 \\
Learning contract & $(0.081)$ & $(0.088)$ \\
& 0.122 & 0.144 \\
Practical trainer & $(0.096)$ & $(0.097)$ \\
& 0.041 & 0.030 \\
Co-ordinator & $(0.065)$ & $(0.066)$ \\
& 0.064 & 0.054 \\
Surveyed by internet & $(0.066)$ & $(0.067)$ \\
& -0.001 & 0.010 \\
Q13 refers to level 2 & $(0.065)$ & $(0.068)$ \\
Q13 refers to level 4 & 0.147 & 0.146 \\
Constant & $(0.099)$ & $(0.100)$ \\
& -0.035 & -0.021 \\
Observations & $(0.146)$ & $(0.148)$ \\
Adjusted R-squared & 2.770 & 2.640 \\
\hline \hline Stand errors in par & $(0.120) * * *$ & $(0.167) * * *$ \\
\hline
\end{tabular}

Standard errors in parentheses

* significant at $10 \%$ level

** significant at $5 \%$ level

$* * *$ significant at $1 \%$ level 


\subsection{APPENDIX TO CHAPTER 8}

Table 8.32: Training input explained (OLS): Time for learning and instruction

\begin{tabular}{|c|c|c|}
\hline & $(1)$ & $(2)$ \\
\hline Firm-specificity $10 \%$ or more & & $\begin{array}{c}0.035 \\
(0.072)\end{array}$ \\
\hline$\leq 2$ months needed to reach productivity & & $\begin{array}{c}0.030 \\
(0.067)\end{array}$ \\
\hline Number of months unknown & & $\begin{array}{c}0.133 \\
(0.096)\end{array}$ \\
\hline Less than 10 competitors & & $\begin{array}{l}0.157 \\
(0.078) * *\end{array}$ \\
\hline Number of competitors is unknown & & $\begin{array}{c}-0.047 \\
(0.081)\end{array}$ \\
\hline Difficult to find a job & & $\begin{array}{c}-0.117 \\
(0.073)\end{array}$ \\
\hline High urbanisation grade & & $\begin{array}{c}0.082 \\
(0.065)\end{array}$ \\
\hline Permanent contract & & $\begin{array}{c}0.137 \\
(0.109)\end{array}$ \\
\hline Chance apprentice wants to stay $75 \%-100 \%$ & & $\begin{array}{c}0.069 \\
(0.100)\end{array}$ \\
\hline Chance apprentice wants to stay $100 \%$ & & $\begin{array}{c}0.096 \\
(0.115)\end{array}$ \\
\hline $0-2$ years in training firm & & $\begin{array}{c}0.045 \\
(0.121)\end{array}$ \\
\hline $3-4$ years in training firm & & $\begin{array}{c}-0.107 \\
(0.079)\end{array}$ \\
\hline Number of years in training firm unknown & & $\begin{array}{c}-0.076 \\
(0.078)\end{array}$ \\
\hline Only future training benefits & & $\begin{array}{c}0.053 \\
(0.063)\end{array}$ \\
\hline Chance employment offer $75 \%-100 \%$ & & $\begin{array}{c}0.089 \\
(0.093)\end{array}$ \\
\hline Chance employment offer $100 \%$ & & $\begin{array}{c}0.060 \\
(0.104)\end{array}$ \\
\hline Construction industry & $\begin{array}{l}0.364 \\
(0.115) * * *\end{array}$ & $\begin{array}{l}0.408 \\
(0.122) \text { *** }\end{array}$ \\
\hline Printing industry & $\begin{array}{c}-0.095 \\
(0.108)\end{array}$ & $\begin{array}{c}-0.051 \\
(0.116)\end{array}$ \\
\hline Metal industry & $\begin{array}{c}0.188 \\
(0.126) \\
\end{array}$ & $\begin{array}{c}0.237 \\
(0.132) *\end{array}$ \\
\hline
\end{tabular}


CHAPTER 8. TRAINING INTENSITY AND TRAINING MOTIVES II

Table 8.32: continued

\begin{tabular}{lcc}
\hline \hline & $(1)$ & $(2)$ \\
\hline Firm size $<10$ workers & -0.099 & 0.013 \\
Firm size 10-99 workers & $(0.148)$ & $(0.155)$ \\
& 0.004 & 0.079 \\
Firm size 100-499 workers & $(0.117)$ & $(0.121)$ \\
& 0.061 & 0.111 \\
No apprentices & $(0.116)$ & $(0.119)$ \\
& -0.106 & -0.088 \\
1 apprentice & $(0.098)$ & $(0.101)$ \\
& -0.237 & -0.250 \\
Employment and learning contract & $(0.078) * * *$ & $(0.078) * * *$ \\
& -0.040 & -0.066 \\
Learning contract & $(0.098)$ & $(0.107)$ \\
& -0.041 & -0.031 \\
Practical trainer & $(0.117)$ & $(0.119)$ \\
& 0.151 & 0.138 \\
Co-ordinator & $(0.079) *$ & $(0.080) *$ \\
& 0.188 & 0.174 \\
Surveyed by internet & $(0.081) * *$ & $(0.082) * *$ \\
& 0.003 & -0.019 \\
Q13 refers to level 2 & $(0.079)$ & $(0.083)$ \\
Q13 refers to level 4 & 0.059 & 0.067 \\
Constant & $(0.120)$ & $(0.122)$ \\
& 0.067 & 0.063 \\
Observations & $(0.181)$ & $(0.184)$ \\
Adjusted R-squared & 2.566 & 2.281 \\
\hline \hline Stand errors & $(0.147) * * *$ & $(0.203) * * *$ \\
\hline & 708 & 708 \\
& 0.07 & 0.07 \\
\hline
\end{tabular}

Standard errors in parentheses

* significant at $10 \%$ level

** significant at $5 \%$ level

$* * *$ significant at $1 \%$ level 


\subsection{APPENDIX TO CHAPTER 8}

Table 8.33: Chance to obtain a diploma (interval regression)

\begin{tabular}{|c|c|c|c|}
\hline & $(1)$ & $(2)$ & $(3)$ \\
\hline Complexity of production tasks & & $\begin{array}{l}2.865 \\
(1.124) * * *\end{array}$ & $\begin{array}{l}1.935 \\
(1.102) * *\end{array}$ \\
\hline Learning content of production tasks & & $\begin{array}{l}1.446 \\
(0.953) *\end{array}$ & $\begin{array}{l}1.335 \\
(0.924) *\end{array}$ \\
\hline Time for learning and instruction & & $\begin{array}{c}0.994 \\
(0.812)\end{array}$ & $\begin{array}{c}0.864 \\
(0.783)\end{array}$ \\
\hline Firm-specificity $10 \%$ or more & & & $\begin{array}{c}-1.364 \\
(1.414)\end{array}$ \\
\hline$\leq 2$ months to reach productivity & & & $\begin{array}{c}0.213 \\
(1.335)\end{array}$ \\
\hline Number of months unknown & & & $\begin{array}{l}-3.396 \\
(1.902) * *\end{array}$ \\
\hline Less than 10 competitors & & & $\begin{array}{c}-0.534 \\
(1.549)\end{array}$ \\
\hline Number of competitors unknown & & & $\begin{array}{c}-1.989 \\
(1.615)\end{array}$ \\
\hline Difficult to find a job & & & $\begin{array}{c}-0.669 \\
(1.444)\end{array}$ \\
\hline High urbanisation grade & & & $\begin{array}{c}-1.958 \\
(1.296) *\end{array}$ \\
\hline Permanent contract & & & $\begin{array}{l}13.812 \\
(2.327) * * *\end{array}$ \\
\hline Apprentice wants to stay $75 \%-100 \%$ & & & $\begin{array}{l}5.942 \\
(2.150)_{* * *}\end{array}$ \\
\hline Apprentice wants to stay $100 \%$ & & & $\begin{array}{l}11.934 \\
(2.451) * * *\end{array}$ \\
\hline $0-2$ years in training firm & & & $\begin{array}{c}0.348 \\
(2.385)\end{array}$ \\
\hline 3-4 years in training firm & & & $\begin{array}{c}-1.926 \\
(1.565)\end{array}$ \\
\hline Number of years unknown & & & $\begin{array}{c}-1.814 \\
(1.545)\end{array}$ \\
\hline Only future training benefits & & & $\begin{array}{c}-1.446 \\
(1.247)\end{array}$ \\
\hline Chance employment offer $75 \%-100 \%$ & & & $\begin{array}{l}1.504 \\
(2.085)\end{array}$ \\
\hline Chance employment offer $100 \%$ & & & $\begin{array}{c}-0.157 \\
(2.291)\end{array}$ \\
\hline Apprentice suitable to stay $75 \%-100 \%$ & 1.727 & 1.825 & 4.202 \\
\hline
\end{tabular}


CHAPTER 8. TRAINING INTENSITY AND TRAINING MOTIVES II

Table 8.33: continued

\begin{tabular}{|c|c|c|c|}
\hline & $(1)$ & $(2)$ & $(3)$ \\
\hline \multirow{3}{*}{ Apprentice suitable to stay $100 \%$} & $(1.543)$ & $(1.531)$ & $(2.472) * *$ \\
\hline & 5.756 & 5.465 & 6.440 \\
\hline & $(1.587) * * *$ & $(1.577) * * *$ & $(2.537) * * *$ \\
\hline \multirow[t]{2}{*}{ Construction industry } & -0.782 & -1.493 & 0.100 \\
\hline & $(2.396)$ & $(2.395)$ & $(2.434)$ \\
\hline \multirow[t]{2}{*}{ Printing industry } & -0.228 & -0.207 & 1.093 \\
\hline & $(2.233)$ & $(2.219)$ & $(2.279)$ \\
\hline \multirow[t]{2}{*}{ Metal industry } & -6.630 & -6.326 & -5.633 \\
\hline & $(2.652) * * *$ & $(2.640) * * *$ & $(2.640) * *$ \\
\hline \multirow[t]{2}{*}{ Firm size $<10$ workers } & 10.425 & 11.104 & 10.413 \\
\hline & $(3.081) * * *$ & $(3.069) * * *$ & $(3.080) * * *$ \\
\hline \multirow[t]{2}{*}{ Firm size 10-99 workers } & 8.579 & 9.157 & 8.451 \\
\hline & $(2.452) * * *$ & $(2.440) * * *$ & $(2.429) * * *$ \\
\hline \multirow[t]{2}{*}{ Firm size 100-499 workers } & 7.393 & 7.609 & 7.655 \\
\hline & $(2.452) * * *$ & $(2.434) * * *$ & $(2.390) * * *$ \\
\hline \multirow{2}{*}{ No apprentices } & -4.758 & -4.293 & -1.499 \\
\hline & $(2.037) * * *$ & $(2.031) * *$ & $(2.016)$ \\
\hline \multirow[t]{2}{*}{1 apprentice } & 1.748 & 1.935 & 1.873 \\
\hline & $(1.612)$ & $(1.611)$ & $(1.553)$ \\
\hline \multirow[t]{2}{*}{ Employment and learning contract } & 1.757 & 1.619 & -0.749 \\
\hline & $(2.109)$ & $(2.096)$ & $(2.098)$ \\
\hline \multirow[t]{2}{*}{ Learning contract } & 1.111 & 1.200 & 2.707 \\
\hline & $(2.449)$ & $(2.432)$ & $(2.357)$ \\
\hline \multirow{2}{*}{ Practical trainer } & 1.448 & 0.866 & 0.321 \\
\hline & $(1.648)$ & $(1.644)$ & $(1.590)$ \\
\hline \multirow[t]{2}{*}{ Co-ordinator } & 0.507 & 0.109 & -0.134 \\
\hline & $(1.685)$ & $(1.680)$ & $(1.626)$ \\
\hline \multirow[t]{2}{*}{ Surveyed by internet } & -0.442 & -0.887 & 0.020 \\
\hline & $(1.653)$ & $(1.647)$ & $(1.649)$ \\
\hline \multirow[t]{2}{*}{ Q13 refers to level 2} & 5.428 & 5.394 & 6.375 \\
\hline & $(2.545) * *$ & $(2.529) * *$ & $(2.450) * * *$ \\
\hline \multirow[t]{2}{*}{ Q13 refers to level 4} & -4.550 & -4.565 & -3.319 \\
\hline & $(3.867)$ & $(3.837)$ & $(3.729)$ \\
\hline \multirow[t]{2}{*}{ Constant } & 76.066 & 61.292 & 59.469 \\
\hline & $(3.243) * * *$ & $(5.413) * * *$ & $(5.750) * * *$ \\
\hline Observations & 690 & 690 & 690 \\
\hline
\end{tabular}

Standard errors in parentheses

* significant at $10 \%$ level, ${ }^{* *}$ significant at $5 \%$ level, ${ }^{* * *}$ significant at $1 \%$ level 
Table 8.34: Selected qualifications (Crebo codes between brackets)

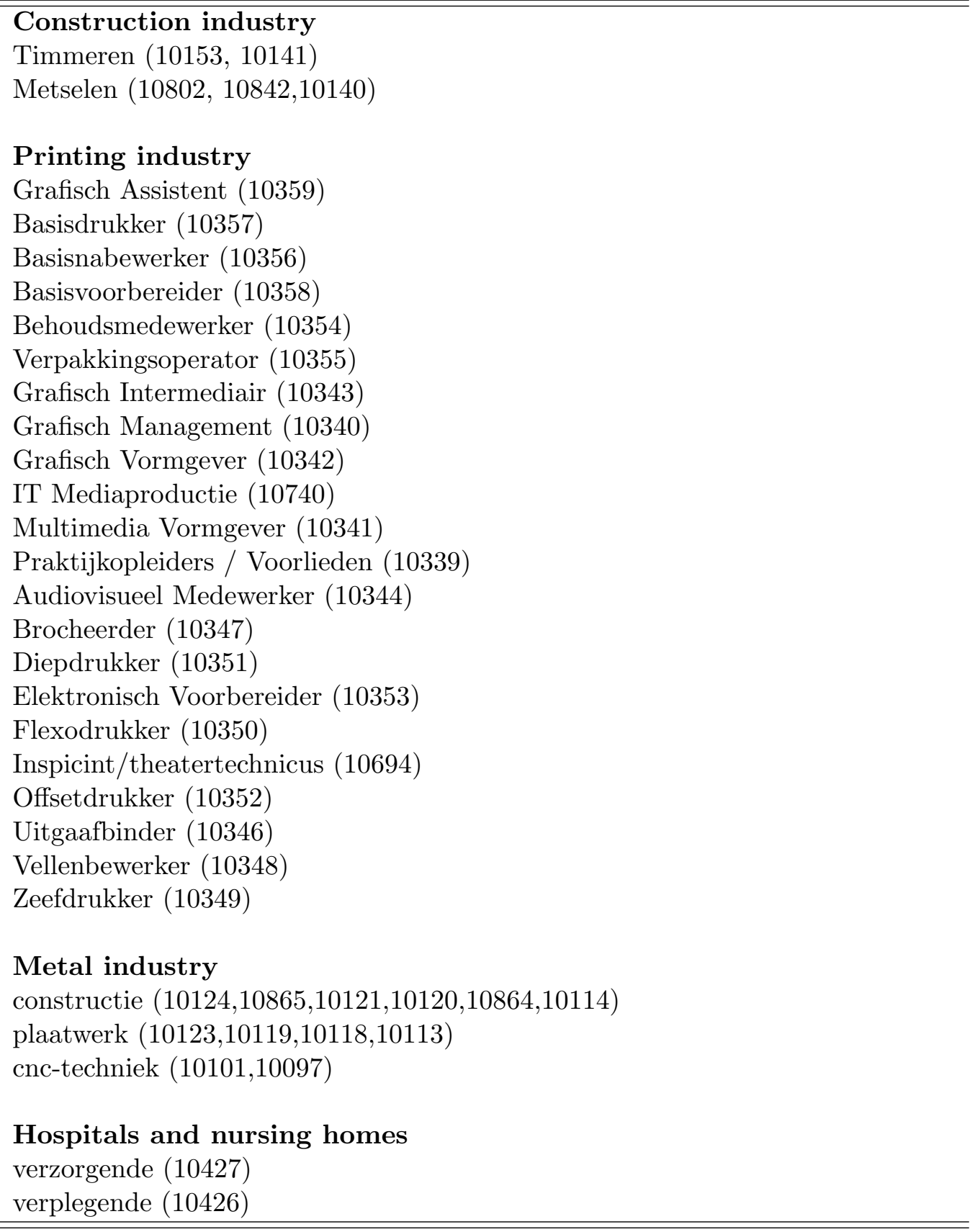




\section{Questionnaire for Companies Offering Apprenticeships}

\section{Introduction on the phone:}

Good morning/afternoon. I am <interviewer $>$ from Intomart in Hilversum. On behalf of the Research Centre for Education and the Labour Market, we are conducting a study of apprenticeships places in your company or institution. You should have received a letter explaining this project. For this study, we would like to speak with $<$ name $>$. Is that you? This questionnaire will take about 15 minutes. Would that be possible now? Interviewer: If the person concerned no longer works there or will be unavailable for a longer period of time, ask the practical trainer or co-ordinator

\section{Both versions:}

The following questions concern the pupils in working-and-learning tracts, formerly called < construction, printing, metal: apprenticeship system/ care: in-service education $>$. This refers to those pupils who spend several days a week working, while going to school for the remaining days. They will be called apprentices in this questionnaire. We will not ask any questions about so-called occupational education pupils, who spend an uninterrupted period of time in a traineeship setup. This study is not concerned with trainees.

2a. What is your position in relation to the apprenticeship system in your company? Is it - read the list below - (multiple answers possible)

- Practical trainer/construction: master

- Co-ordinator

- Other

- (do not read this aloud) Unknown

2b. How many apprentices does your company have at the moment?

- . apprentices

- unknown

If 0 apprentices or unknown:

2c. Were there any apprentices in your company during the past two years?

- Yes

- No > end of questionnaire

- Unknown > end of questionnaire

If practical trainer:

2d. How many apprentices are you personally supervising at this moment? 


\subsection{APPENDIX TO CHAPTER 8}

- . apprentices

- unknown

2e. For which qualification levels does your company train apprentices? (multiple answers possible)

- level 1

- level 2

- level 3

- level 4

- unknown

3. What type of contract do apprentices usually have in your company? Is it:

- both a learning contract and an employment contract

- only a learning contract

- a contract through training co-operation

- (do not read out loud) unknown

if both a learning contract and an employment contract:

4. Is this usually a permanent employment contract or a temporary employment contract?

- permanent employment contract

- temporary employment contract

- unknown

5. How great is the chance that an apprentice who is trained in your company obtains a diploma?

- $0 \%$

- between $0 \%$ and $25 \%$

- between $25 \%$ and $50 \%$

- $50 \%$

- between $50 \%$ and $75 \%$

- between $75 \%$ and $100 \%$

- $100 \%$

- unknown 
If no permanent contract (Q4 must be code 2 or 3, or Q3 must be code 2 through 4):

6. How great is the chance that an apprentice who is trained in your company wants to keep working in your company after having completed the training programme?

- $0 \%$

- between $0 \%$ and $25 \%$

- between $25 \%$ and $50 \%$

- $50 \%$

- between $50 \%$ and $75 \%$

- between $75 \%$ and $100 \%$

- $100 \%$

- unknown

If no permanent contract (Q4 must be code 2 or 3, or Q3 must be code 2 through 4):

7. How great is the chance that an apprentice who is trained in your company is suitable to continue working in your company after having completed the training programme?

- $0 \%$

- between $0 \%$ and $25 \%$

- between $25 \%$ and $50 \%$

- $50 \%$

- between $50 \%$ and $75 \%$

- between $75 \%$ and $100 \%$

- $100 \%$

- unknown

If no permanent contract (Q4 must be code 2 or 3, or Q3 must be code 2 through 4):

8. How great is the chance that an apprentice who is trained in your company is offered an appointment at your company after having completed the training programme?

- $0 \%$

- between $0 \%$ and $25 \%$

- between $25 \%$ and $50 \%$ 


\subsection{APPENDIX TO CHAPTER 8}

- $50 \%$

- between $50 \%$ and $75 \%$

- between $75 \%$ and $100 \%$

- $100 \%$

- unknown

9. The next question concerns apprentices who entered into employment with your company after having completed the training programme. On average, how many years do such former apprentices remain with your company?

- 0-2 years / 3-4 years / 5 years or more

- not applicable

- unknown

10. How interesting are apprentices for your company if you weigh the costs against the benefits?

- Very interesting

- Slightly interesting

- Slightly uninteresting

- Very uninteresting

- Unknown

11. How interesting are apprentices for your company if they were to go and work for another company after having completed their training?

- Very interesting

- Slightly interesting

- Slightly uninteresting

- Very uninteresting

- Unknown

12. I will now list a number of possible reasons for training apprentices, instead of recruiting qualified employees from the labour market. Can you please indicate to what extent these reasons are important for your company? You may choose from the following options to indicate how important it is for your company to train apprentices

- Very important

- Slightly important

- Slightly unimportant 
CHAPTER 8. TRAINING INTENSITY AND TRAINING MOTIVES II

- Very unimportant

- (do not read out loud) unknown

a. The knowledge and skills of employees who have been trained in this company match the needs of this company better than the knowledge and skills of employees trained elsewhere.

b. In the case of employees trained in this company, we know better what their capabilities are than in the case of employees trained elsewhere.

c. Employees who have been trained in this company need less introduction than employees trained elsewhere.

d. In the case of employees who have been trained in this company, we know better what they have learned during their studies than in the case of employees trained elsewhere.

e. Qualified employees are hard to find.

13. I will now list a number of statements with regard to the training, supervision and activities of apprentices in your company. Can you indicate to what extent these statements apply. Think of an apprentice at ${ }^{* *}$ level who is halfway through the training programme?

Indicate for each statement whether for your company it

- does not apply at all

- does not apply to some extent

- applies to some extent

- applies completely

- unknown

** determining the level: for construction/printing/metal, if question 2e has code 2: 2 if no code 2: 3 for care, if question 2 e has code $3: 3$ if no code $3: 4$

a. It is easy to involve apprentices in work activities

b. Apprentices can usefully be employed to carry out activities that qualified employees dislike.

c. Apprentices generally carry out simple support activities.

d. Apprentices carry out their practical assignments for school mostly when it is quiet at work. 


\subsection{APPENDIX TO CHAPTER 8}

e. Guidance and instruction of apprentices is provided mostly when the apprentice feels a need.

f. Apprentices mostly carry out activities from which they can learn.

g. Apprentices sometimes postpone their practical assignments for school when it is too busy at work.

h. Apprentices have room to make mistakes.

i. Guidance and instruction of apprentices takes place mostly when the practical trainer has less to do himself.

j. Apprentices only carry out activities that are useful for their training programme.

k. Apprentices carry out their practical assignments for school whenever it suits them best.

1. Apprentices are fully integrated in all operations.

m. Guidance and instruction of apprentices takes place mostly during the apprentices' regular work activities.

n. The activities carried out by apprentices are adapted to their learning programme.

o. Guidance and instruction of apprentices takes place mostly outside the place of work/work floor, for example in a special instruction room, in a classroom or in an office.

p. Apprentices carry out the same tasks as qualified colleagues.

14. < if practical trainer (Q2a):> Have you < if other (Q2a):> Has a practical trainer (for construction: master) of apprentices in your company completed a special course to supervise apprentices?

- Yes

- No

- Unknown

15. How much working time, on average, <if practical trainer $(\mathrm{Q} 2 \mathrm{a}):>$ do you <if other $(\mathrm{Q} 2 \mathrm{a}):>$ does a practical trainer (for construction: master) of apprentices in your company spend on guidance and instruction of apprentices? Is this: 
- Up to a quarter of the time

- Between a quarter and a third of the time

- Half to three quarters of the time

- More than three quarters of the time

- (do not read out loud) unknown

If 1 or more pupils at this time (Question 2b):

16. How many pupils, on average, <if practical trainer (Q2a): $>$ do you $<$ if other (Q2a): > does a practical trainer (for construction: master) of apprentices in your company have at the same time? In this case, the number of pupils includes both apprentices (BBL) and trainees (BOL).

- pupils

- unknown

17. How much of the working time of the apprentices in your company is spent on learning and instruction? Is this:

- Up to a quarter of the time

- Between a quarter and a third of the time

- Half to three quarters of the time

- More than three quarters of the time

- (do not read out loud) unknown

18. Every year, one company in each sector is chosen as best apprenticeship company. What chance do you think your company has to be nominated?

- A great chance

- A fair chance

- A small chance

- Unknown

19. Some knowledge and skills that employees have is specific for the company in which they work. Examples are the company culture, its client base, and specific equipment. Which part of the knowledge and skills that apprentices acquire in your company is specific for your company?

- $0 \%$ (nothing)

- $1-10 \%$

- $10-20 \%$

- $20-30 \%$ 


\subsection{APPENDIX TO CHAPTER 8}

- more than $30 \%$

- unknown

If at least some knowledge is company-specific (Q19 code 2-6):

20. I will mention various types of company-specific knowledge and skills. Which of these is the most important one that apprentices learn in your company? And which the second most important one? And the third? (up to 3 )

a. knowledge of the company culture

b. operation of specific machines and equipment

c. knowledge of specific operational processes and procedures

d. knowledge of the client base

e. knowledge of specific company products

f. knowledge of company computer programs

21. If your company were to employ qualified employees trained as apprentices by another company, how many weeks would it take for them to achieve the same productivity level as employees trained as apprentices in your company?

- . weeks

- unknown

22. How many other < construction companies/graphics firms/metal firms/ similar care institutions $>$ are there in your region (roughly a $25-\mathrm{km}$ radius)?

- . companies/institutions

- unknown

23. Is it easy for employees who have been trained in your company through the apprenticeship system to find a similar job at $<$ another construction company/graphics firm/metal firm/ care institution $>$ in the same region (roughly a $25-\mathrm{km}$ radius)?

- Very easy

- Reasonably easy

- Fairly difficult

- Very difficult 
CHAPTER 8. TRAINING INTENSITY AND TRAINING MOTIVES II

- Unknown

24. How many people are currently employed in your company? (INTERVIEWER: you may help, an approximate figure is also allowed)

- . people

- unknown 


\section{Chapter 9}

\section{Conclusion}

\subsection{Main Findings and Policy Implications}

The apprenticeship system is attributed many pedagogical advantages compared to school-based education. An important question is, however, whether these potential advantages indeed materialise. The training firm's main activity is producing goods or services. Training is not a goal in itself but has to be seen in the light of this main activity. The production interest of the firm may therefore conflict with the learning interest of the apprentice. This conflict of interests will have consequences for the quality of training. Two aspects of training will be affected, the training intensity and the content of the training programme. In this study I have analysed the consequences of conflicting interests for both aspects.

As most of the training takes place at the workplace, learning and working are closely interwoven. It will often be unclear whether an activity is aimed at learning or production. The training intensity is therefore difficult to verify by the apprentice or a third party. This means that the training firm can decrease the training intensity without this being perceived immediately. For this reason, it is expected that the firm's training motives have an impact on training intensity.

Firms may have several motives to offer apprenticeships. They may train apprentices because of a future need for qualified labour, in which case they have an investment motive. They may also employ apprentices because ap- 


\section{CHAPTER 9. CONCLUSION}

prentices are relative cheap labour; in that case they have a current production motive. If a firm employs apprentices because of a current production motive, it does not benefit from the training itself and therefore the firm may be tempted to save on training costs by lowering the training intensity.

In this study, I have found that firms with investment motives indeed provide better training than firms with current production motives. Especially those aspects of the training that are not easily observable by a third party are neglected if the firm has no investment motives. Unfortunately it turns out that these are also the aspects that are most effective in terms of training output. Furthermore, I found that neglecting these aspects has no negative impact on the firm's training reputation. The firm's training reputation depends on those aspects of the training that are easily observable but at the same time not very effective for training output.

If a firm trains because of investment motives, it has an interest in providing good training but there may still be a conflict of interest between the firm and the apprentice. This conflict stems from the fact that the apprentice often has a different skill need than the firm. Firms have a preference for skills that can be used in the training firm, the occupation or the industry for which the apprentice is being trained. The apprentice, on the other hand, also wants to acquire skills that have a wider applicability, so-called generic skills. On the basis of a theoretical model for the choice between generic and industry- or occupation-specific skills, I have shown that firms have an incentive to avoid generic training. If the apprentice has no say in the training decision, firms will not provide any generic training at all.

The policy implication of the latter finding is that regulation of the curriculum of the training programme, is very important for the apprenticeship system to function well. Representatives of both firms and workers should be involved in decisions concerning the curriculum of the training programme. Otherwise the training will tend to be too industry- or occupation-specific.

However, regulation is not sufficient to prevent firms from saving on training costs by lowering the training intensity. Regulation of the training intensity will induce firms to pay attention to those aspects of the training that are easily observable by training authorities but, as I have shown, may have little impact on training output. Those aspects of the training that are not 


\subsection{FUTURE RESEARCH}

observed, but more effective, will still be neglected if a firm has no investment motives. Therefore, it is important that training firms have future benefits from training apprentices. One way to achieve this is to allow firms to make a fixed part of the training firm-specific.

The findings of this study have important consequences for government policies aimed at increasing the number of apprenticeships. If such policies mainly stimulate firms without investment motives to hire apprentices, average training intensity will fall. This will be the case with, for example, wage cost subsidies for firms that employ apprentices. Wage cost subsidies increase current training profits, but do not affect future profits. Therefore, there is a risk that most of the extra apprenticeship places generated by the subsidy are in firms that employ apprentices because of current benefits.

\section{$9.2 \quad$ Future Research}

To analyse the effects of conflicting interests of firms and Apprentices, I developed two theoretical models. First I modelled the choice between generic and industry- or occupation-specific training. This model predicts that firms want the generic component of the training to be as small as possible. This prediction has not been tested empirically yet. To develop an empirical test will be particularly difficult. This remains an issue for future research.

The prediction of the second theoretical model in this study - the higher the expected (marginal) future benefits of training for the training firm, the higher the training intensity - has been tested empirically for the Netherlands. I used mostly indirect measures for future benefits from training. Empirical evidence on the actual return of investment is still lacking. Therefore, a promising direction for future research is to look at firms' actual returns to apprenticeship training. An important related question that remains to be answered is what are the sources of future benefits for firms? Economic theory provides several reasons as to why firms will have future benefits from apprenticeship training, but the empirical evidence for these theories is weak. It is most likely that several factors, such as firm-specificity of the training, imperfect information on the apprentice's ability and imperfect competition on the market for occupational skills, play a role simultaneously, although 


\section{CHAPTER 9. CONCLUSION}

their importance may differ between firms. Therefore, it is not very useful to oppose these theories, a better strategy is to assess their relative importance. Research in this area needs measures of actual productivity of internally and externally trained workers.

Another promising direction for future research is to integrate more educational insights in the training input measures. The educational literature provides little in terms of concrete guidelines as to how training and work should be organised to reach an optimal learning effect. Input measures for the type of productive work (complexity of production tasks) and the learning content of production tasks could gain from new educational insights. On the other hand, my methodology offers fruitful directions for educational research as well. For example, my methodology could be used to test the educational effectiveness of different configurations of training and work by relating input measures to output measures.

Lastly, a fertile line of further research would be to survey current and former apprentices and their training firms simultaneously. The advantage of such an approach is that for each aspect of the training programme the most appropriate respondent can be interviewed. For example, apprentices can probably give better information on training input while representatives of the firm have a better knowledge of the training motives. Also, firms can provide direct information on apprentice ability and motivation, which makes it easier to control for possible selection. 


\section{Bibliography}

Acemoglu, D., and J. Pischke (1998): "Why Do Firms Train? Theory and Evidence," Quarterly Journal of Economics, 113(1), 79-119.

(1999a): "Beyond Becker: Training in Imperfect Markets," Economic Journal, 109(453), 112-42.

Acemoglu, D., and J. Pischke (1999b): "Minimum Wages and On-theJob Training," Discussion Paper 2177, Centre for Economic Policy Research.

Acemoglu, D., And J. Pischke (1999c): "The Structure of Wages and Investment in General Training," Journal of Political Economy, 107(3), $539-72$.

Askildsen, A., and N. Ireland (1993): "Human Capital, Property Rights and Labour Managed Firms," Oxford Economic Papers, 45, 229-42.

Autor, D. (2001): "Why Do Temporary Help Firms Provide Free General Skills Training?," Quarterly Journal of Economics, 116(4), 1409-1448.

Bailey, T., and K. Hughes (1999): "Employer Involvement in WorkBased Learning Programs," Discussion Paper MDS-1311, National Center for Research in Vocational Education, University of California, Berkeley.

Bailey, T., K. Hughes, and T. BarR (1998): "Achieving Scale and Quality in School-to-Work Internships: Findings from an Employer Survey," Discussion Paper MDS-902, National Center for Research in Vocational Education, University of California, Berkeley. 


\section{BIBLIOGRAPHY}

Bardenleben, R. V. (1997): "Kosten und Nützen der Betrieblichen Berufsausbildung," in Die Zukunft der Dualen Berufsausbildung, ed. by K. u. T. M. Liesering, S. und Schober, pp. 283-289. Institut für Arbeitsmarkt und Berufsforschung der Bundesanstalt für Arbeit.

Barron, J., M. Berger, and D. Black (1997a): On the Job Training. W.E. Upjohn Institute for Employment Research, Michigan.

Barron, J. M., M. C. Berger, and D. A. Black (1997b): "How Well Do We Measure Training?," Journal of Labor Economics, 15(3), 505-528.

Bartholomew, D. J., And M. Knott (1999): Latent Variable Models and Factor Analysis, Kendall's Library of Statistics. Arnold, London, second edn.

Becker, G. (1962): "Investment in Human Capital: A Theoretical Analysis," Journal of Political Economy, 70(supplement), 9-49.

(1964): Human Capital, A Theoretical and Empirical Analysis with Special Reference to Education. The University of Chicago Press, Chicago.

Bishop, J. (1995): "Expertise and Excellence," Working Paper 95-13, Center for Advanced Human Resource Studies, Ithaca, New York.

Black, D., And M. Loewenstein (1997): "Dismissals and Match-Specific Rents," Labour Economics, 4, 325-40.

Blokhuis, F., M. Jellema, and W. J. NiJhof (2002): "De Kwaliteit van de Beroepspraktijkvorming. Een Onderzoek naar Praktijken en Ervaringen met de Beroepspraktijkvorming bij ROC Eindhoven," Discussion paper, Universiteit Twente.

Blokhuis, F. T. L. (2003): "Using the Learning Possibilities at the Workplace Effectively," Paper presented at the earli-conference, august 27, padova, Twente University.

Boom, A. (2001): "Firms' Investment in General Training and the Market for Skilled Labour," Working Paper 13, Freie Univerität Berlin, Berlin. 
Booth, A., And M. Chatteru (1998): "Unions and Efficient Training," The Economic Journal, 108, 328-43.

Booth, A., And S. Satchell (1994): "Apprenticeship and Job Tenure," Oxford Economic Papers, 46, 676-95.

Booth, A. L., and G. Zoega (2000): "Why Do Firms Invest in General Training? "Good" Firms and "Bad" Firms as a Source of Monopsony Power," ILR Working Paper 058, Institute for Labour Research.

Booth, Alison, L., M. Francesconi, and G. Zoega (2002): "Oliopsony, Institutions and the Effciency of General Training," Discussion Paper 618, IZA, Bonn.

Borghans, L., And W. Smits (1996): "Ontwikkelingen in het Leerlingwezen tot 2000," Report ROA-R-1996/6, ROA.

Borghans, L., And W. Smits (1997): "Succesfactoren in het Leerlingwezen," Tijdschrift voor arbeidsvraagstukken, 13(4), 321-33.

Borghans, L., W. Smits, J. Vlasblom, and A. Jacobs (2000): "Leren en Werken in het Nederlandse Beroepsonderwijs, Ontwikkelingen in de BBL 1999-2004," Report ROA-R-2000/2, Research Centre for Education and the Labour Market, Maastricht.

Bougheas, S., And Y. Georgellis (2001): "German Apprenticeship Training, Earning Profiles and Labour Turnover: Theory and Evidence," Paper presented at the 2001 eale conference.

Card, D., And A. B. Krueger (1992): "Does School Quality Matter? Returns to Education and the Characteristics of Public School in the United States," Journal of Political Economy, 100(1), 1-40.

Carrington, W. J. (1993): "Wage Losses for Displaced Workers: Is It Really the Firm That Matters?," Journal of Human Resources, 28, 435462. 


\section{BIBLIOGRAPHY}

Casey, B. (1986): "The Dual Apprenticeship System and the Recruitment and Retention of Young Persons in West Germany," British Journal of Industrial Relations, 24(1), 63-81.

- (1991): "Recent Developments in the German Apprenticeship System," British Journal of Industrial Relations, 29(2), 205-22.

Centre for Labour Market Research (1997): Evaluation of the Impact of Financial Incentives on the Recruitment of Entry Level Training, Evaluation and Monitoring Branch. Department of Employment, Education, Training and Youth Affairs, Canberra.

Chang, C., And Y. Wang (1996): "Human Capital Investments under Asymmetric Information: The Pigovian Conjecture Revisited," Journal of Labour Economics, 14(3), 505-19.

Clark, D. (2001): "Why Do German Firms Subsidize Apprenticeship Training? Tests of the Asymetric Information and Mobility Cost Explanations," Vierteljahrshefte zur Wirtschaftsforschung, 70(2001/1), 102-06.

(2002): "Matching, Screening and Firm Investment in General Training: Theory and Evidence," Working paper, Nuffield College, Oxford.

Clark, D., and R. Fahr (2001): "The Promise of Workplace Training for Non-College-Bound Youth: Theory and Evidence from German Apprenticeship," Discussion Paper 378, IZA.

Cortina, J. M. (1993): "What is Coefficient Alpha? An Examination of Theory and Applications," Journal of Applied Psychology, 78(1), 98-104.

DAmm-RüGer, S., U. Degen, And U. Grünewald (1988): Zur Struktur der Betrieblichen Ausbildungsgestaltung. Ergebnisse Einer Schriftliche Befragung in Ausbildingsbetrieben Von Industrie und Handwerk. Bericht zur Beruflichen Bildung Heft 101, Berlin und Bonn.

De Vries, I., And F. Heere (1993): Kosten en Baten van het Leerlingwezen bij Bedrijven. Organisatie voor Strategisch Arbeidmarktonderzoek, Den Haag. 
Den Boer, P., J. Frietman, And B. Hövels (2001): "Verantwoordelijkheden voor de Kwaliteit van de BPV," in De WEB Tussen Vraag en Aanbod, ed. by H. Heijke, pp. 117-143. Stuurgroep Evaluatie WEB.

Den Broeder, C. (1995): "The Match Between Education and Work: What Can We Learn from the German Apprenticeship System?," Research Memorandum 118, Central Planbureau, Den Haag.

Dockery, A., P. Koshy, T. Stromback, and W. Ying (1997): "The Cost of Training Apprentices in Australian Firms," Australian Bulletin of Labour, 23(3), 255-74.

Elbaum, B., And N. Singh (1995): "The Economic Rationale of Apprenticeship Training: Some Lessons from British and U.S. Experience," Industrial Relations, 34(4), 593-622.

Euwals, R., and R. Winkelmann (2001): "Why Do Firms Train? Empirical Evidence on the First Labour Market Outcomes of Graduated Apprentices," Discussion Paper 319, IZA.

Finegold, D., K. Wagner, and G. Mason (2000): "National SkillCreation Systems and Career Paths for Service Workers: Hotels in the United States, Germany and the United Kingdom," International Journal of Human Resource Management, 1(3), 497-516.

Franz, W., And D. Soskice (1995): "The German Apprenticeship System," in Institutional Frameworks and Labor Market Performance, ed. by F. Buttler, W. Franz, R. Shettkat, and D. Soskice, pp. 208-34, London and New York. Routledge.

Frietman, J. (1999): Het Matchen van Vraag en Aanbod in de BBL. Max Goote, Amsterdam.

Frietman, J. E. M. (1990): "De Kwaliteit van de Praktijkcomponent in het Leerlingwezen," Ph.D. thesis, Katholieke Universiteit Nijmegen.

Gospel, H. F. (1994): "The Survival of Apprenticeship Training: A British, American, Australian Comparison," British Journal of Industrial Relations, 32(4), 505-22. 


\section{BIBLIOGRAPHY}

- (1998): "The Revival of Apprenticeship Training," British Journal of Industrial Relations, 36(3), 435-57.

Hanushek, Eric, A. (2003): "The Failure of Input-Based Schooling Policies," The Economic Journal, 113, 64-98.

Harhoff, D., And T. J. Kane (1997): "Is the German Apprenticeship System a Panacea for the U.S. Labor Market?," Journal of Population Economics, 10(2), 171-96.

Hashimoto, M. (1981): "Firm-Specific Human Capital as a Shared Investment," American Economic Review, 71(3), 475-82.

Heijke, H., L. Borghans, and W. Smits (2001): "De WEB tussen vraag en aanbod," Report, Stuurgroep Evaluatie WEB.

Jacobs, R. L., And M. Jones (1995): Structured On-The-Job Training. Unleashing Employee Expertise in the Workplace. Berret-Koehler Publishers, San Fransisco.

Jones, I. S. (1986): "Apprentice Training Costs in British Manufacturing Establishments: Some New Evidence," British Journal of Industrial Relations, 24(3), 333-62.

Jonker, N. (2001): Job Performance and Career Prospects of Auditors, vol. 253 of Tinbergen Insitute Research Series. Thela Thesis, Amsterdam.

Katz, E., And A. Ziderman (1990): "'Investment in General Training: The Role of Information and Labour Mobility', Economic Journal, 100(403), 1147-58.

Kessler, A. S., and C. Lülfesmann (2000): "The Theory of Human Capital Revisited: On the Interaction of General and Specific Investments," Discussion Paper 2533, Centre for Economic Policy Research.

Knott, M., And M. T. Albanese (1999): Polymiss: A Computer Program for Fitting a One- or Two-Factor Logit-Probit Latent Variable Model to Polytomous Data When Observations May Be Missing. 
Kok, L., I. Groot, J. Hop, and L. Janssens (2002): "Kosten en Baten van Stage- en Leerlingplaatsen voor Zorginstellingen," Report ZW 28, OSA.

KraAyvanger, G. (1998): "De Wet Educatie en Beroepsonderwijs: Achtergronden en Kanttekeningen," in De WEB van Regelgeving naar Pedagogische Praktijk, ed. by G. Kraayvanger, B. Hövels, and F. Meijers, pp. 7-22, Amsterdam. Max Goote Kenniscentrum voor Beroepsonderwijs \& Volwasseneneducatie.

LANG, K. (1994): "Does the Human Capital/Educational Sorting Debate Matter for Development Policy?," American Economic Review, 84(1), 3538.

Lazear, Edward, P. (2003): "Firm-Specific Human Capital: A SkillWeights Approach," Working Paper 9679, National Bureau of Economic Research, Cambridge.

Leenknegt, G. J. (2001): Bestuurlijke en Juridische Aspecten van de WEB. Stuurgroep Evaluatie WEB.

Lieshout, H. V. (1996): Beroepsonderwijs in Duitsland. Max Goote Kenniscentrum voor Beroepsonderwijs en Volwasseneneducatie, Amsterdam.

Lindley, R. M. (1975): "The Demand for Apprentice Recruits by the Engineering Industry, 1951-71," Scottish Journal of Political Economy, 22(1), $1-24$.

Loeb, S., And J. Bound (1996): "The Effect of Measured School Inputs on Academic Achievement: Evidence from the 1920s, 1930s and 1940s Birth Cohorts," The Review of Economics and Satistics, 78(4), 653-664.

Loewenstein, M., And J. Spletzer (1998): "Dividing the Costs and Returns to General Training," Journal of Labor Economics, 16(1), 142-71.

LYNCH, L. M. (1993): "The Economics of Youth Training in the United States," The Economic Journal, 103, 1292-1302. 


\section{BIBLIOGRAPHY}

Malcomson, J., J. Maw, and B. McCormick (1997): "General Training by Firms, Contract Enforceability and Public Policy," Discussion Paper 21, University of Southampton.

Merrilees, W. J. (1983): "Alternative Models of Apprentice Recruitment: With Special Reference to the British Engineering Industry," Applied Economics, 15(1), 1-21.

Ministerie van Onderwijs, Cultuur en Wetenschappen (1996): Wet Educatie en Beroepsonderwijs, De Wettekst. Zoetermeer.

Ministry of Education, Culture And Science (2003): Key Figures 1998-2002. Education, Culture and Science in the Netherlands.

Mueller, D. J. (1986): Measuring Social Attitudes: A Handbook for Researchers and Practioners. Teachers College Press, New York/London.

NeAL, D. (1995): "Industry-Specific Human Capital: Evidence from Displaced Workers," Journal of Labor Economics, 13(4), 653-677.

Neubäumer, R. (1999): Der Ausbildungsstellenmarkt der Bundesrepublik Deutschland. Eine Theoretische und Empirische Analyse, vol. 77 of Sozialpolitischen Schriften. Duncker \& Humblot, Berlin.

Nieuwenhuis, L. (2001): Kwaliteit Getoetst in de BVE. Kwaliteit en Niveau van Aanbod en Examens in het Beroepsonderwijs en de Volwasseneneducatie. Stuurgroep Evaluatie WEB.

Nieuwenhuis, L., And J. Onstenk (1994): "Werkend Leren in Opleiding en Beroep: De Werkplek als Krachtige Leeromgeving," Comenius, 14, 198219.

Nunnaly, J. (1978): Psychometric Theory. McGrawhill, New York.

OECD (1994): Apprenticeship: Which Way Forward? OECD, Paris.

Onstenk, J. (1994): Leren en Opleiden op de Werkplek: Een Verkenning in Zes Landen. Max Goote Kenniscentrum voor beroepsonderwijs en volwasseneneducatie, Amsterdam. 
Onstenk, J. (1997): Lerend Leren Werken. Brede Vakbekwaamheid en de Integratie van Leren, Werken en Innoveren. Uitgeverij Eburon, Delft.

Oulton, N., And H. Steedman (1994): "The British System of Youth Training: A Comparison with Germany," in Training and the Private Sector: International Comparisons, ed. by L. M. Lynch, pp. 61-76, Chicago and London. National Bureau of Economic Research, University of Chicago Press, Comparative Labor Markets Series.

Poortman, C. L., W. J. Nijhof, and L. F. M. Nieuwenhuis (2003): "Competence Development Through Workplace Learning. In Secondary Vocational Education and Training," Presented at the human capital workshop, 15-16 december, maastricht, University of Twente.

Resnick, L. B. (1987): "Learning in School and Out," Educational Researcher, $16,13-20$.

Rivkin, S. G., E. A. Hanushek, and J. F. Kain (2002): "Teachers, Schools, and Academic Achievement," Working Paper 6691, National Bureau of Economic Research.

Rothwell, W. J., And H. Kazanas (1994): Improving on-the-Job Training. How to Establish and Operate a Comprehensive OJT Program. Jossey Bass, San Francisco.

Ryan, P. (1994): "Training Quality and Trainee Exploitation," in Britain's Training Decifit: The Centre for Economic Performance Report, ed. by R. Layard, K. Mayhew, and G. Owen, pp. 92-124, Aldershot. Avebury.

Schimmel, U. (1998): "The Educational Choice: Universal or Specific?," Discussion Paper 558-98, Universitat Mannheim. Institut fur Volkswirtschaftslehre und Statistik.

Schlicht, E. (1996): "Endogenous on-the-Job Training with Moral Hazard," Labour Economics, 3, 81-91.

Schuman, H., and S. Presser (1996): Questions 83 Answers in Attitude Surveys. Experiments on Question Form, Wording and Context. Sage Publications, Thousands Oaks. 


\section{BIBLIOGRAPHY}

Schwerdt, W. (2001): "Comparaison des Systèmes d'Apprentisage en France et en Allemagne: Une Analyse Économétrique," Ph.D. thesis, Université de Paris 1- Panthéon Sorbonne U.F.R. de Sciences Economiques.

Smits, W. (1999): "Schoolverlaters van de BBL 1997," Report ROA-R1999/6, Research Centre for Education and the Labour Market.

Smits, W., and T. Stromback (2001): The Economics of the Apprenticeship System. Edward Elgar, Cheltenham.

Soskice, D. (1994): "Reconciling Markets and Institutions: The German Apprenticeship System," in Training and the Private Sector: International Comparisons, ed. by L. M. Lynch, pp. 25-60, Chicago and London. National Bureau of Economic Research, University of Chicago Press, Comparative Labor Markets Series.

Staiger, D., And J. H. Stock (1997): "Instrumental Variables Regression with Weak Instruments," Econometrica, 65(3), 557-586.

Steedman, H. (1993): "The Economics of Youth Training in Germany," Economic Journal, 103, 1279-91.

Stevens, M. (1994a): "An Investment Model for the Supply of Training by Employers," Economic Journal, 104(424), 556-70.

(1994b): "A Theoretical Model of on-the-Job Training with Imperfect Competition," Oxford Economic Papers, 46(4), 537-62.

- (1996): "Transferable Training and Poaching Externalities," in Acquiring Skills: Market Failures, their Symptoms and Policy Responses, ed. by A. Booth, and D. Snower, pp. 19-40, Cambridge. Cambridge University Press.

Stock, J. H., J. H. Wright, and M. Yogo (2002): "A Survey of Weak Instruments and Weak Identification in Generalized Methods of Moments," Journal of Business \&J Economic Statistics, 20(4), 518-529. 
Todd, Petra, E., and I. Wolpin, Kenneth (2003): "On the Specification and Estimation of the Production Function for Cognitive Achievement," The Economic Journal, 113, 3-33.

VAN DER KLINK, M. R. (1999): "Effectiviteit van Werkplekopleidingen," Ph.D. thesis, Universiteit Twente, Enschede.

Vialla, A. (1997): "Apprentisage: Ruptures, Anchaînements de Contracts et Accès à l 'emploi," note d'information 97.22, Ministère de l'éducation nationale, de l'enseignement supérieur et de la recherche.

Von Bardeleben, R. (1994): "Kosten und Nützen der Betrieblichen Berufsausbilding," in Die Zukunft der Dualen Berufsausbildung, ed. by S. Liersering, K. Schober, and M. Tessaring, pp. 283-9. Insitut für Arbeitsmarkt und Berufsforschung der Bundesanstalt für Arbeit.

Wagner, K. (1998): "The German Apprenticeship After Unification," Discussion Paper FS I 98-301, Wissenschaftszentrum Berlin für Sozialforschung.

Weinberg, B. A. (2001): "Long-Term Wage Fluctuations with IndustrySpecific Human Capital," Journal of Labor Economics, 19(1), 231-264.

Werwatz, A. (1996): "How Firm-Specific is German Apprenticeship Training?," Discussion Paper 12-96, Humboldt-Universität zu Berlin.

Westergard-Nielsen, N., and A. R. Rasmussen (1997): "Apprenticeship Training in Denmark - the Impacts of Subsidies," Working Paper 97-07, Centre for Labour Market and Social Research, Århus.

Willems, E., And R. Welters (1999): "Methodiek Schoolverlatersinformatiesysteem 1997," Working Paper ROA-W-1999/1, ROA, Maastricht.

Wooldridge, J. M. (2002): Econometric Analysis of Cross Section and Panel Data. The MIT Press, Massachusetts. 
BIBLIOGRAPHY 


\section{Summary}

To investigate the effects of conflicting interests on training quality, I have made both theoretical and empirical analyses. Chapter 2 gives a review of the literature and presents the theoretical and empirical evidence for current production and investment motives for training apprentices. It is shown that although on average apprentices are a net cost for firms, there is great variation between firms. There are also many firms that have negative net costs. These firms may train apprentices because of current benefits. In Germany, this concerns in particular small firms in the craft sector. Evidence on future benefits is more scarce, but there is some evidence that large firms in the industry have future benefits more often than small firms in the craft sector, which is in line with empirical evidence on current benefits.

Chapter 3 models the choice between generic and industry- or occupationspecific skills. Firms train because of expected future benefits, but have a different skill interest than apprentices. Both types of skills - generic ones and specific ones - are transferable in the sense that they can be used outside the training firm but specific sills can only be used in a specific industry or occupation while generic skills have a larger market. The market for specific skills is imperfectly competitive. For that reason, firms in the industry (the training firm or any other firm in the industry), can appropriate part of the returns to industry or occupation-specific training. The expected share decreases, however, with the level of generic training. The reason is that the level of generic training determines the apprentice market wages outside the industry and thus sets a minimum limit on the wages that have to be paid within the industry. Therefore, firms have a preference for specific skills and want the level of generic skills to be as low as possible. Apprentices, on the 


\section{SUMMARY}

other hand, want a high level of generic skills.

If the training firm and the apprentice were to decide jointly on the curriculum of the training programme, the level of generic skills would be too high and the level of specific skills too low. Although the training firm wants the generic component to be as small as possible, it does not allow for the loss of the other firms within the industry. The expected benefits of the industry can be increased if firms in the industry decided jointly on the curriculum of the training. However, if the apprentice is not involved in the training decision, the level of generic training will be too low.

Chapter 4 presents a theoretical model for the training intensity under imperfect information. Apprentices do not perfectly observe the training intensity. If firms have no future benefits from training, they may be tempted to lower the training intensity to save on training costs, especially if the training wages do not depend on actual training intensity. The apprentice, knowing this, will not accept training wages that are sufficiently low to achieve the socially optimal level of training. It is shown that the underinvestment problem will be less severe as the firm's (marginal) expected future benefits from training are higher. If the firm has future benefits from training, it will harm itself if it lowers the training intensity. Apprentices are then prepared to accept lower training wages. For that reason, it can be opportune to allow firms to make a fixed part of the training firm-specific. The optimal degree of firm-specificity depends on the degree of observability of the training and the expected (exogenous) quit rate.

The relation between the firm's training motives (current production or investment motives) and the training intensity are tested empirically for the Netherlands in Chapter 7 and 8. To clarify the setting of these empirical analyses, Chapter 5 first gives an overview of the Dutch apprenticeship system. In the Netherlands, apprenticeship training is organised at the industry or occupational level. For each sector, the relevant body for vocational education and training is responsible for the quantity and quality of apprenticeship places in that sector. Although the training is highly regulated, there is still considerable variation in training intensity between firms.

Chapter 6 discusses the measures for training intensity that will be used for the empirical analysis. As training intensity itself is not observed, I 
consider both input and output from training. Training input is difficult to measure as working and learning at the workplace are often interwoven. To measure training input, I therefore consider the effort of the training firm to give priority to training relative to production. I considered different aspects of the training programme, the complexity of productions tasks, the learning content of production tasks, the time for formal learning activities at the workplace and the time for supervision and instruction. Output measures that I considered include the chance to complete the training successfully with a diploma and the wages after the apprenticeship.

In Chapters 7 and 8 I considered the relation between training input and training motives, and the relation between training input and training output. Chapter 7 is based on a written survey among former apprentices, while Chapter 8 is based on a telephone and Internet survey among training firms. Both surveys included items on the different aspects of the training programme. On the basis of these items, I constructed training input measures. In Chapter 7, I used a single input measure, while in Chapter 8 I used measures for each aspect of the training separately.

In Chapter 7, training motives are measured by characteristics of the apprenticeship place. It is assumed that firms who train apprentices because of investment motives offer their apprentices a permanent contract or the prospect of a permanent contract after the training. I have found that training input was higher for those apprentices who had a permanent contract or the prospect of a permanent contract, than for apprentices with a temporary contract, which indicates that there is indeed a relation between training intensity and training motives. I also found that training input matters for training output, as both the chance of obtaining a diploma and post-training wages were positively affected by the training input measure.

In Chapter 8, I considered three training input measures, namely the complexity of productions tasks, the learning content of production tasks, and the time for formal learning and instruction. Not all aspects are equally well observable by a third party. It is argued that the complexity of production tasks is more difficult to observe than the other aspects of the training. This difference in observability allows me to investigate whether the relation between training motives and training intensity also depends on the degree 


\section{SUMMARY}

of information imperfection, as predicted in Chapter 4.

Firstly, I considered the relation between the training input measure and the firm's training reputation (measured by the chance of being nominated for the elections of the best training firm in the sector). I found that only the better observable aspects of the training, the learning content of production tasks and the time for formal learning and instruction matter, while the complexity of production tasks has no effect. This result suggests that firms can save on the latter aspect of training without any damage to their reputation.

To measure training motives, I constructed several measures for factors that affect future profits (the degree of firm-specificity, the degree of monopsony power, and the exogenous quit rate) and measures for the incidence of current and future benefits. I have found that training motives mainly matter for the complexity of production tasks and not for the other aspects of the training that I considered. So firms without investment motives indeed save on those aspects of the training that are more difficult to observe.

Lastly, I considered the relation between training output, measured by the chance of an apprentice in a firm obtaining a certificate of qualification, and the training input measures. For this chance, only the complexity of productions tasks matters. So, although the complexity of production tasks is the most effective part of the training, this aspect of the training will be neglected if the training firm has no investment motives, because it is difficult to observe by third parties and therefore does not contribute to the firm's training reputation.

It can be concluded that the results of the empirical analyses in Chapter 7 and 8 confirm the theoretical prediction that training intensity is higher in firms with investment motives than in firms with current production motives. Firms without investment motives will economise especially on those aspects of the training that are not easily observable by a third party. 


\section{Summary in Dutch}

In veel West-Europese landen, zoals Duitsland, Oostenrijk, Zwitserland en Nederland, maar bijvoorbeeld ook in Australië neemt het leerlingwezen een belangrijke plaats in binnen het onderwijssysteem. De essentie van het leerlingwezen is dat een leerling een vak leert in een praktijkomgeving. De potentiële voordelen van het leerlingwezen zijn velerlei. Ten eerste zijn er didactische voordelen. Veel leerlingen leren makkelijker in de praktijk dan op school. Bovendien doen ze kennis en vaardigheden op die direct toepasbaar zijn in de praktijk zodat de transfer van het geleerde op school naar de dagelijkse beroepspraktijk voor een groot deel kan worden vermeden. Daarnaast kan het leerlingwezen de aansluiting tussen onderwijs en arbeidsmarkt verbeteren. Bedrijven weten immers vaak beter dan scholen welke vaardigheden nodig zijn voor bepaalde beroepen. Ook hebben ze meer inzicht in technologische ontwikkelingen in de bedrijfstak die vragen om nieuwe kennis en vaardigheden.

Of deze potentiële voordelen van het leerlingwezen ook daadwerkelijk tot uitdrukking komen is echter de vraag. De primaire activiteit van een bedrijf is het produceren van goederen en diensten. Andere activiteiten zoals het

opleiden en trainen van werknemers zijn hier een afgeleide van. Het gevaar bestaat daarom dat het opleidingsbelang in een bedrijf conflicteert met andere bedrijfsbelangen. Dat betekent dat training in bedrijven nooit los kan worden gezien van het totale productieproces. Voor een duidelijk beeld van de merites van het leerlingwezen is het daarom niet alleen van belang om inzicht te hebben in de didactische voor- en nadelen van deze leerweg maar ook in de economische overwegingen van het leerbedrijf.

Economisch onderzoek naar het leerlingwezen richt zich over het algemeen 


\section{SUMMARY IN DUTCH}

voornamelijk op de vraag waarom bedrijven bereid zijn leerplaatsen aan te bieden. In dit onderzoek wordt deze vraag vanuit een ander perspectief benaderd. Gegeven dat bedrijven leerplaatsen beschikbaar stellen, wat zijn dan de consequenties van hun opleidingsmotieven voor de kwaliteit van de training. Twee aspecten van trainingskwaliteit worden onderzocht, namelijk de trainingsintensiteit en het curriculum van de opleiding.

Bedrijven kunnen verschillende opleidingsmotieven hebben. Ze kunnen leerlingen opleiden vanwege een toekomstige behoefte aan gekwalificeerd personeel, in dat geval is er sprake van een investeringsmotief, of vanwege de directe productiviteit van de leerling, in dat geval is er sprake van een productiemotief. In het eerste geval verwacht het leerbedrijf de leerling in dienst te nemen na afloop van de opleiding in het tweede geval niet.

Als een bedrijf enkel leerlingen in dienst heeft vanwege hun bijdrage aan de productie, dan bestaat het gevaar dat het bedrijf meer geïnteresseerd in hun directe productiviteit dan in hun training. Het leerbedrijf kan dan in de verleiding komen om op de opleidingskosten te bezuinigen door de trainingsintensiteit te verlagen. Daarbij komt dat het voor leerlingen en ook voor derden moeilijk is om de trainingsintensiteit waar te nemen omdat werken en leren gedeeltelijk zijn geïntegreerd. Het zal bijvoorbeeld vaak moeilijk zijn om te beoordelen of de organisatie van het werk optimaal is in termen van het te behalen leereffect.

Als een bedrijf leerlingen opleidt vanuit een investeringsmotief heeft het zelf baat bij een hoge trainingsintensiteit. Toch kunnen ook in dat geval de belangen van het leerbedrijf conflicteren met de belangen van de leerling. Leerlingen hebben er baat bij om zoveel mogelijk vaardigheden te leren die breed toepasbaar zijn. Vaardigheden die niet alleen van belang zijn binnen het leerbedrijf en de bedrijfssector maar ook in andere bedrijven in andere bedrijfssectoren, zogenoemde generieke vaardigheden. Generieke vaardigheden vergroten de toekomstige flexibiliteit van de leerling. Het leerbedrijf heeft echter veel minder baat bij deze flexibiliteit dan de leerling en heeft een voorkeur voor bedrijfs- of bedrijfssectorspecifieke vaardigheden. Het risico bestaat daarom dat het leerbedrijf het curriculum van de opleiding te specifiek maakt.

Om de effecten van opleidingsmotieven op de kwaliteit van de training 
te onderzoeken heb ik zowel theoretische als empirische analyses gemaakt. Hoofdstuk 2 geeft een overzicht van de literatuur en presenteert de theoretische en empirische aanwijzingen voor productie- en investeringsmotieven. Ik laat zien dat, hoewel uit de meeste studies naar voren komt dat leerlingen gedurende de leerperiode gemiddeld genomen een netto kostenpost vormen, de variatie tussen bedrijven groot is. Er zijn ook vrij veel bedrijven voor wie de opbrengsten tijdens de leerperiode de trainingskosten ruimschoots overstijgen. Het is goed mogelijk dat juist deze bedrijven voornamelijk leerlingen in dienst hebben vanwege een productiemotief. In Duitsland betreft dit vooral kleine bedrijven in de ambachtelijke sector. Aanwijzingen voor toekomstige baten van het leerlingwezen zijn veel beperkter maar er zijn aanwijzingen dat in Duitsland voornamelijk grote bedrijven in de industrie toekomstige baten hebben.

In hoofdstuk 3 modelleer ik de keuze tussen generieke en industrie- of beroepsspecifieke vaardigheden. Bedrijven leiden leerlingen op vanwege de toekomstige baten maar hebben een voorkeur voor andere vaardigheden dan leerlingen. Zowel generieke als specifieke vaardigheden zijn overdraagbaar naar andere bedrijven maar specifieke vaardigheden kunnen enkel in een bepaalde bedrijfstak of beroepsgroep worden gebruikt terwijl generieke vaardigheden een veel grotere markt hebben. De markt voor specifieke vaardigheden is niet volledig concurrerend. Daarom kunnen bedrijven in de industrie, zowel het trainingsbedrijf als elk ander bedrijf in de industrie, zich een deel van de opbrengsten van specifieke training toe-eigenen. Het verwachte aandeel van bedrijven neemt echter af met de hoeveelheid generieke training. De reden hiervoor is dat de hoeveelheid generieke training het toekomstige marktloon buiten de industrie bepaalt en dus een ondergrens zet aan het loon dat in de bedrijfssector moet worden betaald. Bedrijven hebben daarom een voorkeur voor specifieke vaardigheden en willen de hoeveelheid generieke vaardigheden zo laag mogelijk houden. Leerlingen willen daarentegen juist een grote hoeveelheid generieke vaardigheden aanleren.

Als de leerling en het leerbedrijf samen over het curriculum zouden beslissen zou de hoeveelheid generieke vaardigheden te groot en de hoeveelheid specifieke vaardigheden te klein zijn vergeleken met het sociale optimum. Het leerbedrijf wil de generieke component weliswaar zo laag mogelijk hou- 


\section{SUMMARY IN DUTCH}

den maar houdt alleen rekening met het eigen verlies en niet met het verlies van ander bedrijven in de sector. De verwachte opbrengsten voor de bedrijfstak kunnen worden vergroot als alle bedrijven in de bedrijfstak gezamenlijk over het curriculum beslissen. Als de leerling niet in de beslissing betrokken is, zal de generieke component in dat geval echter te laag zijn.

In hoofdstuk 4 wordt een theoretisch model gepresenteerd voor de trainingsintensiteit onder onvolledige informatie. Leerlingen kunnen de trainingsintensiteit niet volledig waarnemen. Als bedrijven geen toekomstige opbrengsten van training hebben kunnen ze in de verleiding komen om op de trainingskosten te besparen door de trainingsintensiteit te verlagen. Leerlingen, zich bewust van dit risico, zullen op hun beurt niet akkoord gaan met een leerlingenloon dat laag genoeg is om de sociaal optimale trainingsintensiteit te realiseren. Dit onderinvesteringsprobleem is minder ernstig naarmate de verwachte marginale opbrengsten van training voor het leerbedrijf hoger zijn. Om deze reden kan het gunstig zijn om het leerbedrijf een vast gedeelte van het trainingsprogramma bedrijfsspecifiek te laten invullen. De optimale mate van bedrijfsspecificiteit van de training zal afhangen van de mate waarin de trainingsintensiteit waarneembaar is door leerlingen en derden en het verwachte (exogene) vertrekpercentage na afloop van de training.

De relatie tussen opleidingsmotieven en de trainingsintensiteit wordt empirisch getoetst voor het Nederlandse leerlingwezen in hoofdstukken 7 en 8 . Om de achtergrond van de analyses te verduidelijken wordt in hoofdstuk 5 eerst een overzicht gegeven van het Nederlandse leerlingwezen. In Nederland is het leerlingwezen, ofwel de Beroepsbegeleidende Leerweg (BBL) zoals het tegenwoordig wordt genoemd, georganiseerd op het niveau van bedrijfstak of beroepsgroep. Voor elke sector is een kenniscentrum beroepsonderwijs bedrijfsleven verantwoordelijk voor de kwantiteit en kwaliteit van leer(arbeid)plaatsen. Hoewel de training sterk gereguleerd is, is er toch een aanzienlijke variatie in trainingsintensiteit tussen leerbedrijven.

Hoofdstuk 6 bespreekt hoe trainingsintensiteit zal worden gemeten in de empirische analyses. Daar trainingsintensiteit een theoretisch begrip is dat in de praktijk niet waarneembaar is, beschouw ik zowel de input en output van training. Trainingsinput is moeilijk waarneembaar omdat werk en leren op de leerarbeidsplaats vaak door elkaar lopen. Ik kijk daarom naar de inspan- 
ning van het leerbedrijf om voorrang te geven aan taken die nuttig zijn voor de training en niet zozeer aan taken waarin de leerling zo productief mogelijk is. Daarbij beschouw ik verschillende aspecten van het trainingsprogramma, namelijk de complexiteit van productietaken, de leerinhoud van productietaken, de beschikbare tijd voor formele leeractiviteiten op de leerarbeidsplaats en de beschikbare tijd voor begeleiding en instructie. Output maten die ik bekijk zijn de kans de training succesvol af te sluiten met een diploma en de lonen na afloop van de training.

In hoofdstukken 7 en 8 onderzoek ik de relatie tussen trainingsinput en opleidingsmotieven en de relatie tussen trainingsinput en trainingsoutput. Hoofdstuk 7 is gebaseerd op een schriftelijke enquête onder ex-leerlingen en hoofdstuk 8 op een enquête via internet en per telefoon onder leerbedrijven. Beide enquêtes bevatten vragen over verschillende aspecten van het trainingsprogramma. Op basis van deze vragen heb ik trainingsinputmaten geconstrueerd. In hoofdstuk 7 betreft dit een enkele maat voor alle aspecten van het training programma samen, terwijl in hoofdstuk 8 voor elk aspect van het trainingsprogramma een afzonderlijke maat is geconstrueerd.

In hoofdstuk 7 worden opleidingsmotieven gemeten aan de hand van kenmerken van de leerarbeidsplaats. Er wordt aangenomen dat bedrijven die leerlingen opleiden vanwege investeringsmotieven hun leerlingen al tijdens de opleiding een vast arbeidscontract of uitzicht op een vast arbeidscontract aanbieden. Ik laat zien dat trainingsinput hoger is bij leerlingen die een vast contract of een uitzicht op een vast contract hadden dan bij leerlingen met een tijdelijk contract. Dit suggereert dat er inderdaad een relatie is tussen trainingsintensiteit en opleidingsmotieven. Verder blijkt ook dat de trainingsinputmaat die ik heb gebruikt van belang is voor trainingsoutput, zowel de kans op een diploma als de lonen na afloop van de opleiding worden positief beïnvloed door de trainingsinputmaat.

In hoofdstuk 8 bekijk ik drie verschillende trainingsinputmaten, namelijk een maat voor de complexiteit van productietaken, een maat voor de leerinhoud van productietaken en een maat voor de tijd beschikbaar voor formele leeractiviteiten en begeleiding. Niet alle aspecten van de training zijn even goed waarneembaar door derden. De complexiteit van productietaken is moeilijker waarneembaar dan de ander aspecten van de training die 


\section{SUMMARY IN DUTCH}

in dit onderzoek worden bekeken. Het verschil in observeerbaarheid maakt het mogelijk om te onderzoeken of de relatie tussen opleidingsmotieven en trainingsintensiteit ook afhankelijk is van de mate van waarneembaarheid van de training zoals voorspeld in het model van hoofdstuk 4 .

Allereerst heb ik de relatie tussen de trainingsinputmaten en de trainingsreputatie van het bedrijf bekeken. De trainingsreputatie wordt gemeten door de kans dat het leerbedrijf wordt genomineerd voor de bedrijfstakverkiezingen voor het beste leerbedrijf. Het zijn met name de beter observeerbare aspecten van de training, de leerinhoud van productietaken en de beschikbare tijd voor formele leeractiviteiten en begeleiding die van belang zijn. De complexiteit van productietaken heeft geen invloed op de trainingsreputatie. Dit resultaat suggereert dat bedrijven op dit laatste aspect van de training kunnen bezuinigen zonder negatieve gevolgen voor hun reputatie.

De opleidingsmotieven worden in hoofdstuk 8 gemeten door factoren die van invloed zijn op de verwachte toekomstige opbrengsten van training, zoals de mate van bedrijfsspecificiteit van de training, de mate van concurrentie voor ex-leerlingen, en de exogene vertrekkans na afloop van de opleiding, en enkele directe maten voor huidige en toekomstige baten van training. Het blijkt dat opleidingsmotieven vooral van belang zijn voor de complexiteit van productietaken en niet voor de andere aspecten van de training die ik bekijk. Bedrijven die geen investeringsmotieven hebben besparen inderdaad op die aspecten van de training die moeilijk waarneembaar zijn door derden.

Tenslotte heb ik nog de relatie bekeken tussen trainingsoutput, gemeten als de kans dat een leerling in een bedrijf een diploma behaalt, en de trainingsinputmaten. Alleen de complexiteit van productietaken heeft een positief effect op de trainingsoutput. De andere aspecten van de training hebben geen significant effect. Dus, hoewel de complexiteit van productietaken het meeste effectieve aspect van de training is, zal dit aspect worden verwaarloosd als het leerbedrijf geen investeringsmotief heeft omdat het niet waarneembaar is door derden en daardoor niet bijdraagt aan de trainingsreputatie van het bedrijf.

Op basis van de empirische analyses kan worden geconcludeerd dat de trainingsintensiteit inderdaad hoger is in bedrijven met investeringsmotieven dan in bedrijven die enkel leerlingen in dienst hebben vanwege hun direc- 
te bijdrage aan de productie. Bedrijven zonder investeringsmotieven zullen voornamelijk bezuinigen op die aspecten van het trainingsprogramma die moeilijk waarneembaar zijn. 
SUMMARY IN DUTCH 


\section{Curriculum Vitae}

Wendy Smits was born in Amsterdam, The Netherlands, on April 9, 1970. She attended secondary education at the Rijksscholengemeenschap in Schagen, where she finished VWO in 1988. In 1988 she started to study Econometrics at the University of Amsterdam where she obtained her Master's degree in 1994. During her study she worked as a Research Assistant at the Foundation for Economic Research of the University of Amsterdam (SEO) and at the department of Macro-Economics. In 1992-1993 she studied at the University of Toulouse, France, via the Erasmus exchange programme and she obtained a 'Maitrise des Sciences Economique'. Since 1994 she has worked as a Research Fellow at the Research Centre for Education and the Labour Market (ROA), Maastricht University. From Oktober till December 1997 she worked as a Visiting Fellow at the Centre for Labour Market Research, Curtin University of Technology, Perth, Australia. 


\section{CURRICULUM VITAE}




\section{ROA Dissertation Series}

1 Lex Borghans (1993), Educational Choice and Labour Market Information, Maastricht: Research Centre for Education and the Labour Market (ROA).

2 Frank Cörvers (1999), The Impact of Human Capital on International Competitiveness and Trade Performance of Manufacturing Sectors, Maastricht: Research Centre for Education and the Labour Market (ROA).

3 Ben Kriechel (2003), Heterogeneity among Displaced Workers, Maastricht: Research Centre for Education and the Labour Market (ROA).

4 Arnaud Dupuy (2004), Assignment and Substitution in the Labour Market, Maastricht: Research Centre for Education and the Labour Market (ROA).

5 Wendy Smits (2005), The Quality of Apprenticeship Training. Conflicting Interests of Firms and Apprentices, Maastricht: Research Centre for Education and the Labour Market (ROA). 